\title{
The potential for adverse effects in fish exposed to antidepressants in the
}

\section{aquatic environment}

Sophie L. Gould ${ }^{a}$, Matthew J. Winter ${ }^{a}$, William H. J. Norton ${ }^{b}$ and Charles R. Tyler ${ }^{a *}$

aBiosciences, College of Life and Environmental Sciences, University of Exeter, Exeter, Devon, EX4 4QD, UK.

bDepartment of Genetics and Genome Biology, College of Life Sciences, University of Leicester, University Rd, Leicester, LE1 7RH, UK.

Table S1: Global prescription statistics (pages S2 - S3)

Table S2: Comparative distribution of human and zebrafish serotonergic, adrenergic and dopaminergic receptors in neuronal and peripheral tissues (pages S4 - S10)

Table S3: Occurrence of antidepressants in the aquatic environment (pages S11 - S25)

Table S4: Bioaccumulation of antidepressants in fish tissues and biofluids (pages S26 - S38)

Table S5: Summary of in vivo data on sub-lethal effects reported in fish with aqueous antidepressant exposure (pages S39 - S56)

Table S6: Risk quotient calculations for assessing potential risk of antidepressant exposure in fish (pages S57 - S63)

References: (pages S64 - S87) 
Table S1. Summary of the total number of prescriptions dispensed and estimated annual mass usage of the most popular antidepressants including TCAs, SSRIs and SNRIs in the USA, England, Brazil, Australia and Sweden.

\begin{tabular}{|c|c|c|c|c|c|}
\hline $\begin{array}{l}\text { Antidepressant } \\
\text { (class) }\end{array}$ & Country & $\begin{array}{l}\text { Number of prescriptions } \\
\text { dispensed in } 2018\end{array}$ & $\begin{array}{l}\text { Daily defined dose } \\
\text { (mg/day) }\end{array}$ & $\begin{array}{l}\text { Estimated annual } \\
\text { mass usage }(g)\end{array}$ & Reference \\
\hline \multirow[t]{5}{*}{ Amitriptyline (TCA) } & USA & 10265000 & \multirow[t]{5}{*}{75} & 23096250 & (1) \\
\hline & England & 13532567 & & 10149425 & (2) \\
\hline & Brazil & 8265629 & & 6199222 & (3) \\
\hline & Australia & 2366938 & & 1775204 & (4) \\
\hline & Sweden & 419437 & & 314578 & (4) \\
\hline \multirow[t]{5}{*}{ Citalopram (SSRI) } & USA & 22224000 & \multirow[t]{5}{*}{20} & 13334400 & (1) \\
\hline & England & 14136645 & & 2827329 & (2) \\
\hline & Brazil & 5051155 & & 1010231 & (3) \\
\hline & Australia & 1762614 & & 352523 & (4) \\
\hline & Sweden & 1135550 & & 227110 & (4) \\
\hline Clomipramine (TCA) & England & 282652 & 100 & 282652 & (2) \\
\hline $\begin{array}{l}\text { Desvenlafaxine } \\
\text { (SNRI) }\end{array}$ & Australia & 2266218 & 50 & 1133109 & (4) \\
\hline Dosulepin (TCA) & England & 703879 & 150 & 1055819 & (2) \\
\hline \multirow[t]{4}{*}{ Duloxetine (SNRI) } & USA & 21035000 & \multirow[t]{4}{*}{60} & 37863000 & (1) \\
\hline & England & 1812334 & & 1087400 & (2) \\
\hline & Brazil & 4460523 & & 2676314 & (3) \\
\hline & Sweden & 327365 & & 196420 & (4) \\
\hline \multirow[t]{5}{*}{ Escitalopram (SSRI) } & USA & 25979000 & \multirow[t]{5}{*}{10} & 7793700 & (1) \\
\hline & England & 1100349 & & 110035 & (2) \\
\hline & Brazil & 10852868 & & 1085287 & (3) \\
\hline & Australia & 4406535 & & 440654 & (4) \\
\hline & Sweden & 603580 & & 60358 & (4) \\
\hline \multirow[t]{4}{*}{ Fluoxetine (SSRI) } & USA & 25578000 & \multirow[t]{4}{*}{20} & 15346800 & (1) \\
\hline & England & 6713763 & & 1342753 & (2) \\
\hline & Brazil & 8054380 & & 1610876 & (3) \\
\hline & Australia & 2039596 & & 407919 & (4) \\
\hline
\end{tabular}




\begin{tabular}{|c|c|c|c|c|c|}
\hline & Sweden & 276214 & & 55243 & (4) \\
\hline Imipramine (TCA) & England & 150526 & 100 & 150526 & (2) \\
\hline Lofepramine (TCA) & England & 197325 & 105 & 207191 & (2) \\
\hline \multirow[t]{3}{*}{ Nortriptyline (TCA) } & USA & 4347000 & \multirow[t]{3}{*}{75} & 9780750 & (1) \\
\hline & England & 609775 & & 457331 & (2) \\
\hline & Brazil & 1793719 & & 1345289 & (3) \\
\hline \multirow[t]{3}{*}{ Paroxetine (SSRI) } & USA & 11229000 & \multirow[t]{3}{*}{20} & 6737400 & (1) \\
\hline & England & 1351979 & & 270396 & (2) \\
\hline & Brazil & 5320964 & & 1064193 & (3) \\
\hline \multirow[t]{5}{*}{ Sertraline (SSRI) } & USA & 38383000 & \multirow[t]{5}{*}{50} & 57574500 & (1) \\
\hline & England & 14815719 & & 7407860 & (2) \\
\hline & Brazil & 9636908 & & 4818454 & (3) \\
\hline & Australia & 4255453 & & 2127727 & (4) \\
\hline & Sweden & 1340154 & & 670077 & (4) \\
\hline \multirow[t]{5}{*}{ Venlafaxine (SNRI) } & USA & 16121000 & \multirow[t]{5}{*}{100} & 48363000 & (1) \\
\hline & England & 4401567 & & 4401567 & (2) \\
\hline & Brazil & 5361432 & & 8042148 & (3) \\
\hline & Australia & 3097164 & & 4645747 & (4) \\
\hline & Sweden & 542199 & & 813300 & (4) \\
\hline
\end{tabular}


Table S2. Comparative distribution of human and zebrafish serotonergic, adrenergic and dopaminergic receptors in neuronal and peripheral tissues.

\begin{tabular}{|c|c|c|c|c|}
\hline $\begin{array}{l}\text { Receptor } \\
\text { family }\end{array}$ & $\begin{array}{l}\text { Receptor subtypes } \\
\text { in humans }\end{array}$ & Distribution in humans & $\begin{array}{l}\text { Receptor subtypes } \\
\text { in zebrafish }\end{array}$ & Distribution in zebrafish \\
\hline \multicolumn{5}{|c|}{ Serotonergic system } \\
\hline \multirow[t]{8}{*}{$5-\mathbf{H T}_{1}$} & 5-HTR1A & $\begin{array}{l}\text { Neuronal: hippocampus (high), raphe nuclei } \\
\text { (high), neocortex (high), amygdala, septum, } \\
\text { claustrum, basal ganglia, cerebellum (5) }\end{array}$ & 5-htr1aa & $\begin{array}{l}\text { Neuronal: preoptic area, optic tectum, } \\
\text { anterior hindbrain, medulla oblongata, } \\
\text { superior/intermediate reticular formations, } \\
\text { retina, pretectal diencephalic cluster, } \\
\text { dorsal/ventral thalamus, superior raphe } \\
\text { nucleus, cerebellar plate (6) }\end{array}$ \\
\hline & & & $5-h \operatorname{trlab}$ & $\begin{array}{l}\text { Neuronal: preoptic region, rhombomere } 1 \text {, } \\
\text { caudal hypothalamus (6) }\end{array}$ \\
\hline & 5-HTR1B & $\begin{array}{l}\text { Neuronal: cortical regions, striatum, } \\
\text { thalamus, raphe nuclei, hippocampal } \\
\text { formation ( } 7 \text { ) } \\
\text { Peripheral: cerebral arteries ( } 8 \text { ) }\end{array}$ & 5- htrlbd & $\begin{array}{l}\text { Neuronal: nearly ubiquitous but expression } \\
\text { levels strongest in the optic tectum, } \\
\text { tegmentum, intermediate hypothalamus, } \\
\text { posterior tuberculum, medulla oblongata, } \\
\text { superior raphe nucleus (6) }\end{array}$ \\
\hline & 5-HTR1D & $\begin{array}{l}\text { Neuronal: basal ganglia (globus pallidus } \\
\text { and substantia nigra) and specific areas of } \\
\text { the midbrain (periqueductal grey) and } \\
\text { spinal cord (9) }\end{array}$ & & \\
\hline & & Peripheral: heart $(10)$ & & \\
\hline & 5-HTR1E & $\begin{array}{l}\text { Neuronal: cortical areas, caudate, putamen, } \\
\text { amygdala, hypothalamus (9) }\end{array}$ & & \\
\hline & 5-HTR1F & $\begin{array}{l}\text { Neuronal: dorsal raphe, hippocampus } \\
\text { cortex, striatum, thalamus, hypothalamus } \\
\text { (10) }\end{array}$ & & \\
\hline & & Peripheral: mesentery, uterus (10) & & \\
\hline $5-\mathrm{HT}_{2}$ & 5-HTR2A & $\begin{array}{l}\text { Neuronal: cerebral cortex, claustrum, } \\
\text { endopiriform nucleus, olfactory }\end{array}$ & 5-htr2a & Unknown \\
\hline
\end{tabular}


bulb/anterior olfactory nucleus, brainstem

nuclei (pontine, motor trigeminal, facial and

hypoglossal nuclei), limbic system, basal

ganglia (caudate nucleus and accumbens),

hippocampus (9)

Peripheral: blood, gastrointestinal tract (9)

5-HTR2B Peripheral: small intestine (10)

5-HTR2C Neuronal: neocortical areas (layer V), 5-htr2c

caudate nuclei, substantia nigra,

hypothalamus, choroid plexus (11)
Neuronal: Preoptic, ventral thalamus, posterior tuberculum, dorsal thalamus, pretectum, dorsal tegmentum, ventral tegmentum, anterior medulla, posterior medulla (12)

Peripheral: Skin, axial muscle and ovaries (12)

\begin{tabular}{|c|c|c|}
\hline \multirow[t]{2}{*}{$5-\mathrm{HT}_{3}$} & $\begin{array}{l}\text { 5-HTR3 (A, B, C, } \\
\text { D, E) }\end{array}$ & $\begin{array}{l}\text { Neuronal: dorsal vagal complex, caudate } \\
\text { nuclei, putamen nuclei, cortical regions, } \\
\text { hippocampus (13) }\end{array}$ \\
\hline & & $\begin{array}{l}\text { Peripheral: dorsal root ganglion, } \\
\text { gastrointestinal tract, kidney, liver, lung, } \\
\text { testis, lymph nodes, tonsils (14) }\end{array}$ \\
\hline \multirow[t]{2}{*}{$5-\mathrm{HT}_{4}$} & 5-HTR4 & $\begin{array}{l}\text { Neuronal: caudate putamen, dentate gyru } \\
\text { CA1/3 field in hippocampus, frontoparie } \\
\text { cortex, entorhinal cortex, substantia nigra } \\
\text { (15) }\end{array}$ \\
\hline & & $\begin{array}{l}\text { Peripheral: atrium, intestine, bladder, } \\
\text { kidney, (16) }\end{array}$ \\
\hline $5-\mathrm{HT}_{5}$ & 5-HTR5A & $\begin{array}{l}\text { Neuronal: cortical areas, hippocampus, } \\
\text { amygdala, basal ganglia, substantia } \\
\text { innominata, cerebellum (17) }\end{array}$ \\
\hline
\end{tabular}




\begin{tabular}{|c|c|c|c|c|}
\hline & 5-HTR5B & $\begin{array}{l}\text { Does not encode a functional protein in } \\
\text { humans as the code sequence is interrupted } \\
\text { by stop codons (18) }\end{array}$ & & \\
\hline $5-\mathrm{HT}_{6}$ & 5-HTR6 & $\begin{array}{l}\text { Neuronal: caudate putamen (high), } \\
\text { hippocampus, amygdala, thalamus, } \\
\text { subthalamic nucleus, substantia nigra (19) }\end{array}$ & & \\
\hline \multirow[t]{2}{*}{$5-\mathrm{HT}_{7}$} & 5-HTR7 & $\begin{array}{l}\text { Neuronal: basal ganglia, internal capsule, } \\
\text { hippocampus, septum, thalamus, midbrain } \\
\text { structures }(20)\end{array}$ & 5-htr7 & Unknown \\
\hline & & $\begin{array}{l}\text { Peripheral: descending colon (high), ileum } \\
\text { (high), coronary artery (high), stomach, } \\
\text { kidney, liver, pancreas, spleen (21) }\end{array}$ & & \\
\hline \multicolumn{5}{|c|}{ Adrenergic system } \\
\hline \multirow[t]{6}{*}{$\alpha_{1}$} & $\mathrm{ADR} \alpha 1 \mathrm{~A}$ & Neuronal: hippocampus (22) & adralaa & Unknown \\
\hline & & $\begin{array}{l}\text { Peripheral: heart, aorta, spleen, liver, lung } \\
\text { (22) }\end{array}$ & adrolab & Unknown \\
\hline & $\mathrm{ADR} \alpha 1 \mathrm{~B}$ & Neuronal: hippocampus (22) & adralba & Unknown \\
\hline & & $\begin{array}{l}\text { Peripheral: heart, aorta, spleen, liver, lung } \\
\text { (22) }\end{array}$ & adralbb & Unknown \\
\hline & $\mathrm{ADR} \alpha 1 \mathrm{D}$ & Neuronal: hippocampus (22) & adrald & Unknown \\
\hline & & Peripheral: heart, aorta, spleen, lung (22) & & \\
\hline \multirow[t]{2}{*}{$\alpha_{2}$} & $\mathrm{ADR} \alpha 2 \mathrm{~A}$ & $\begin{array}{l}\text { Neuronal: frontal cortex, medulla } \\
\text { oblongata, hippocampus, cerebellum, } \\
\text { amygdala, thalamus, substantia nigra, pons, } \\
\text { putamen, nucleus accumbens, nucleus } \\
\text { caudatas, globus pallidus (23) }\end{array}$ & adr $\alpha 2 \mathrm{a}$ & $\begin{array}{l}\text { Neuronal: whole brain, telencephalon, optic } \\
\text { tectum (27) } \\
\text { Peripheral: eye, gills, gut/intestine, heart, } \\
\text { kidney, muscle, ovary, skin, swim bladder } \\
\text { (27) }\end{array}$ \\
\hline & & $\begin{array}{l}\text { Peripheral: spinal cord ( } 24) \text {, lymphocytes } \\
(25) \text {, eye (26) }\end{array}$ & & \\
\hline
\end{tabular}




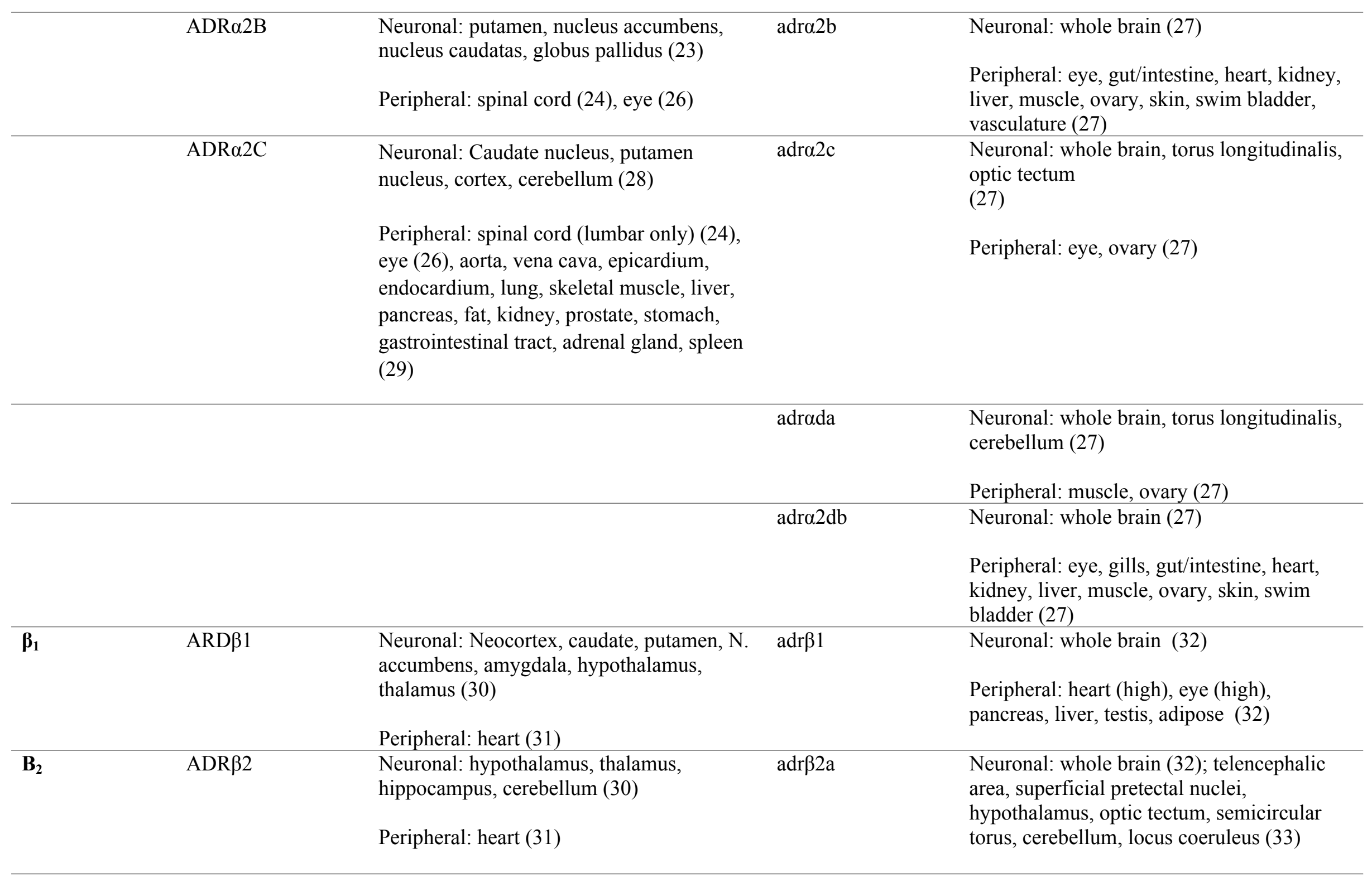


Peripheral: skin (high), muscle (high), eye

(high), gill, blood, adipose, pancreas, spleen, testis, liver, heart, kidney (32)

\begin{tabular}{|c|c|c|c|}
\hline & & & 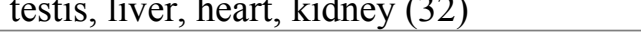 \\
\hline & & $\operatorname{adr} \beta 2 b$ & $\begin{array}{l}\text { Peripheral: muscle (high), liver (high), } \\
\text { pancreas (high) (32) }\end{array}$ \\
\hline $\mathbf{B}_{3}$ & ARD $\beta 3$ & $\begin{array}{l}\text { Peripheral: gall bladder, stomach, small } \\
\text { intestine, adipose, left atrium, prostate ( } 34)\end{array}$ & Peripheral: blood (32) \\
\hline & & $\operatorname{adr} \beta 3 b$ & Peripheral: blood (32) \\
\hline & & Dopaminergic system & \\
\hline D1 & DRD1 & $\begin{array}{l}\text { Neuronal: frontal, temporal and entorhinal } \\
\text { cortex, corpus callosum, cingula } \\
\text { anterior/posterior, hippocampus, } \\
\text { parahippocampus, amygdala, putamen } \\
\text { nuclei, caudate nuclei, accumbens, globus } \\
\text { pallidus, thalamus, substantia nigra, } \\
\text { cerebellum (35) }\end{array}$ & $\begin{array}{l}\text { Neuronal: diencephalon, rhombomeres, } \\
\text { hypothalamus (38) } \\
\text { Peripheral: retina (38) }\end{array}$ \\
\hline & & Peripheral: kidney (36), heart (37) & \\
\hline D2 & DRD2 & $\begin{array}{l}\text { Neuronal: frontal, temporal and entorhinal } \\
\text { cortex, corpus callosum, cingula } \\
\text { anterior/posterior, hippocampus, } \\
\text { parahippocampus, amygdala, putamen } \\
\text { nuclei, caudate nuclei, accumbens, globus } \\
\text { pallidus, thalamus, substantia nigra, } \\
\text { cerebellum (35) }\end{array}$ & $\begin{array}{l}\text { Neuronal: ephiphysis, tegmentum, } \\
\text { rhombomeres, diencephalon, tectum (41) } \\
\text { Peripheral: spinal cord (41) }\end{array}$ \\
\hline & & $\begin{array}{l}\text { Peripheral: lymphocytes (39), kidney (36), } \\
\text { heart (37), retina (40) }\end{array}$ & \\
\hline & & $\operatorname{drd} 2 b$ & $\begin{array}{l}\text { Neuronal: diencephalon, tegmentum, } \\
\text { rhombomeres, ephiphysis, tectum (41) }\end{array}$ \\
\hline & & & Peripheral: spinal cord (41) \\
\hline & & $\operatorname{drd} 2 \mathrm{c}$ & $\begin{array}{l}\text { Neuronal: telencephalon, diencephalon, } \\
\text { tegmentum, rhombomeres (41) }\end{array}$ \\
\hline
\end{tabular}




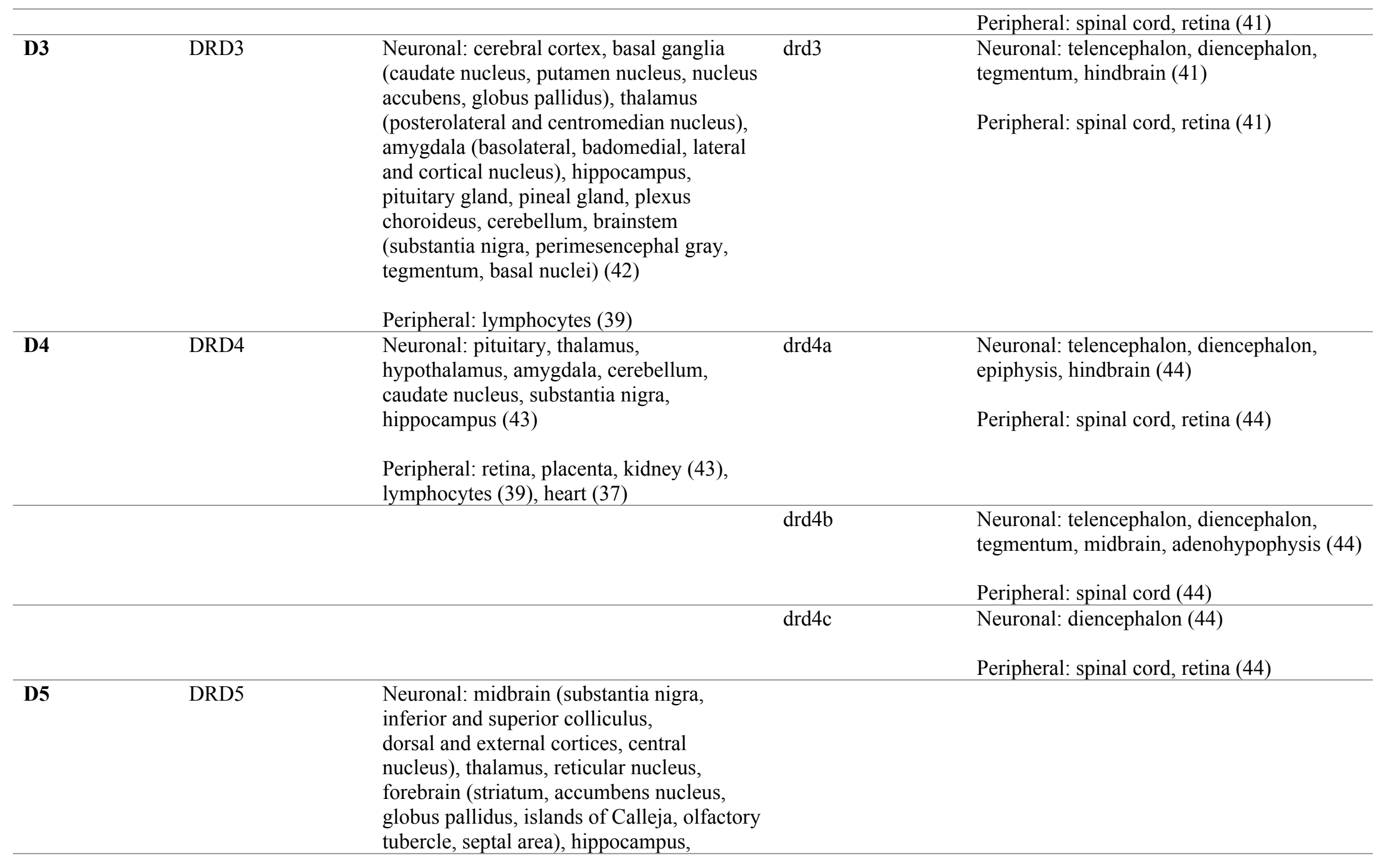


cerebral cortex, cerebellum, olfactory bulb 
Table S3. Occurrence of antidepressants in the aquatic environment (including parent compounds from the TCA, SSRI and SNRI classes, alongside the major metabolites where they themselves are prescribed). Surface waters sampling sites include: rivers, creeks, streams, tributaries, ponds, lakes, estuaries, wells and coastal waters. The mean, median and/or range is reported as data was variable across studies and where values are separate by a ',' several values were reported for this measurement e.g. different sampling sites.

\begin{tabular}{|c|c|c|c|c|c|c|c|c|}
\hline \multirow[t]{2}{*}{ Antidepressant } & \multicolumn{3}{|c|}{ WWTP effluent (ng L $\left.{ }^{-1}\right)$} & \multicolumn{3}{|c|}{ Surface water $\left(n g L^{-1}\right)$} & \multirow[t]{2}{*}{ Country } & \multirow[t]{2}{*}{ Reference } \\
\hline & Mean & Median & Range & Mean & Median & Range & & \\
\hline \multirow[t]{10}{*}{ Amitriptyline } & & & nd -80 & & & $157-196$ & Brazil & (3) \\
\hline & & & & 39.28 & & $0.156-54.8$ & Canada & (46) \\
\hline & & & & & 0.19 & $0.12-0.64$ & China & (47) \\
\hline & $0.8,<\mathrm{LOQ}$ & & $\begin{array}{l}\text { nd - } 4.8, \text { nd - } \\
0.2\end{array}$ & & & & China & $(48)$ \\
\hline & & & & & & nd -3.3 & $\begin{array}{l}\text { Czech } \\
\text { Republic }\end{array}$ & (49) \\
\hline & 0.3 & 0 & $14.6(\max )$ & & & & $\begin{array}{l}\text { EU-wide (17 } \\
\text { countries) }\end{array}$ & $(50)$ \\
\hline & & & nd -6.0 & & & nd & France & (51) \\
\hline & & & & & & 1 to 2 & Portugal & $(52)$ \\
\hline & & & $13-20$ & & & nd -0.4 & Spain & (53) \\
\hline & & & $65-122$ & & & & Spain & (54) \\
\hline
\end{tabular}




\begin{tabular}{|c|c|c|c|c|c|c|c|c|}
\hline & & & & & & $<1$ & Spain & $(55)$ \\
\hline & & & $<\mathrm{LOQ}-28$ & & & $<$ LOQ & Sweden & (56) \\
\hline & & & & 0.32 & & $<$ LOQ - 1.64 & Turkey & (57) \\
\hline & 129.8 & & $222.7(\max )$ & 29.5 & & $71.6(\max )$ & UK & $(58)$ \\
\hline & & 66.3 & $18.2-243$ & & $9.3,5.8,22.1$ & $1-71.0$ & UK & (59) \\
\hline & & & & & & nd $-<$ MDL & US & $(60)$ \\
\hline & & & & & $<\mathrm{MDL}$ & $<$ MDL -1 & US & (61) \\
\hline & & & $88-119$ & & & & US & (62) \\
\hline & $\begin{array}{l}\text { nd, } 40, \text { nd, } \\
\text { nd }\end{array}$ & & & & & & US & (63) \\
\hline & 197,85 & & $<2-357$ & 4,3 & & $<0.5-9$ & Wales & (64) \\
\hline Citalopram & & & & & & $<0.1-2.6$ & Australia & $(65)$ \\
\hline & 203 & & & & & nd - 206 & Canada & (66) \\
\hline & & & & 119.49 & & $0.785-296$ & Canada & (46) \\
\hline & & & & & $<\mathrm{LOQ}$ & $<\mathrm{LOQ}-<\mathrm{LOQ}$ & China & (47) \\
\hline & $<\mathrm{LOQ}, \mathrm{nd}$ & & nd-5.1, nd & & & & China & (48) \\
\hline
\end{tabular}




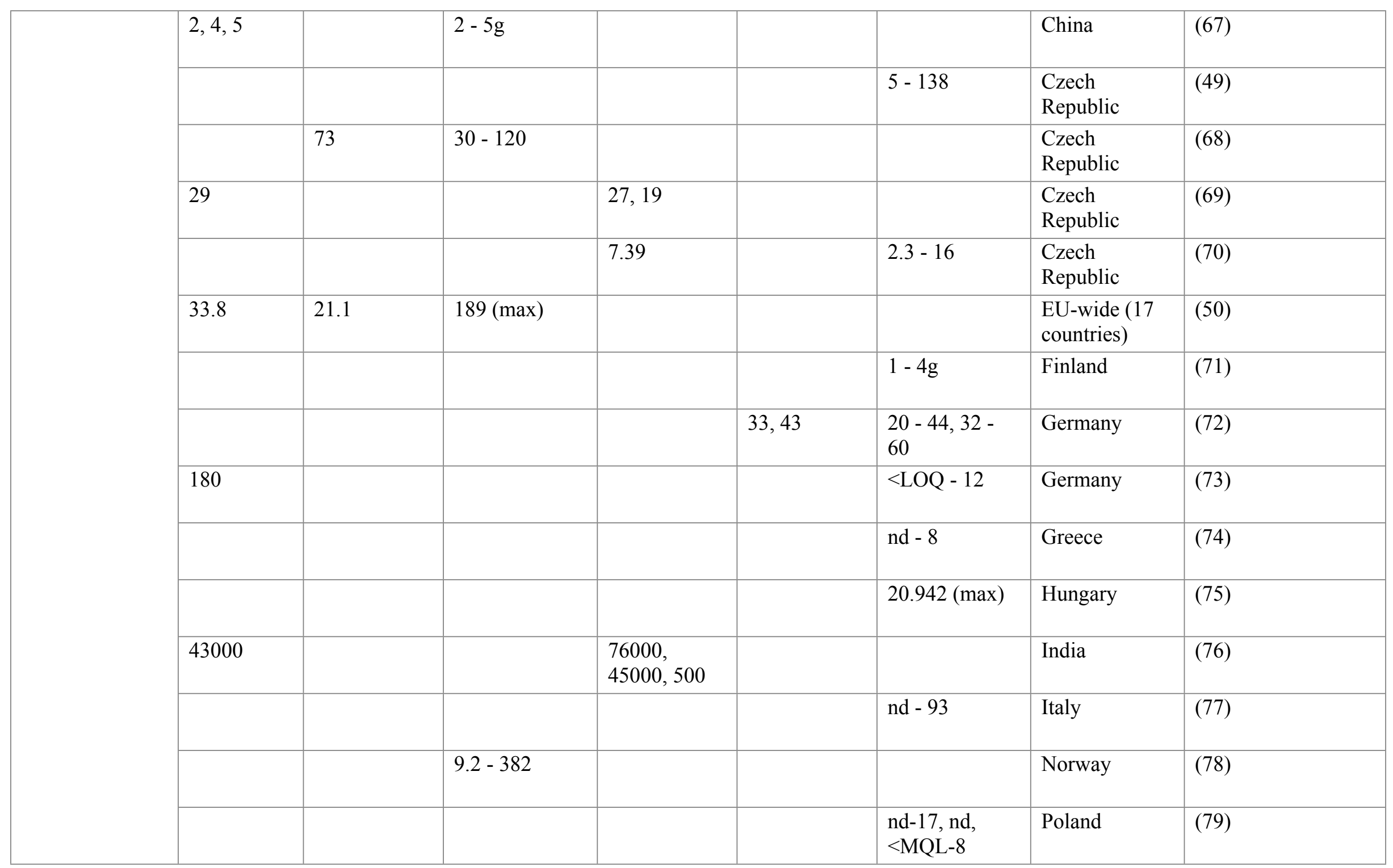




\begin{tabular}{|c|c|c|c|c|c|c|c|}
\hline & & & & & nd - 67.9 & Portugal & (80) \\
\hline & & & 39.21 & & $20.7-57.97$ & Portugal & (81) \\
\hline & 34 & $17.0-49.1$ & & & & Portugal & (82) \\
\hline & & & 90.02 & & $82.8-95.6$ & Portugal & (83) \\
\hline 55 & & & & & & Slovakia & (84) \\
\hline & & $136.2-139.8$ & & & $1.9-35.9$ & Spain & (85) \\
\hline 50 & & & & & & Spain & (86) \\
\hline & & $66.40(\max )$ & & & $<0.27-92.5$ & Spain & (87) \\
\hline & & & & 43 & & Spain & (88) \\
\hline & & $50-59$ & & & & Spain & (54) \\
\hline & & & $<1$ & & & Spain & (55) \\
\hline & & & & & $8-10 g$ & Spain & (89) \\
\hline & & $170-480$ & & & $6.6-210$ & Sweden & (56) \\
\hline & & & & & $<0.01-1.2$ & Sweden & (90) \\
\hline & & & 0.44 & & $<\mathrm{LOQ}-2.69$ & Turkey & (57) \\
\hline
\end{tabular}




\begin{tabular}{|c|c|c|c|c|c|c|c|c|}
\hline & & & & & & $426.6(\max )$ & US & (91) \\
\hline & & & & 85 & & & US & (92) \\
\hline & & & & $90,40,80$ & & & US & (93) \\
\hline & & & $23.7-219$ & & & $4.53-86.4$ & US & (94) \\
\hline \multirow[t]{5}{*}{ Clomipramine } & $0.5, \mathrm{nd}$ & & nd -3.2, nd & & & & China & (48) \\
\hline & 0.3 & 0 & $3.0(\max )$ & & & & $\begin{array}{l}\text { EU-wide (17 } \\
\text { countries) }\end{array}$ & $(50)$ \\
\hline & & & & & & $\mathrm{nd}, \mathrm{nd}, \mathrm{nd}$ & Poland & (79) \\
\hline & & & & 54 & & & Spain & (55) \\
\hline & & & $0.81-49$ & & & $<\mathrm{LOQ}-1.64$ & Sweden & (56) \\
\hline \multirow[t]{2}{*}{ Dosulepin } & 57.2 & & $121(\max )$ & 9.2 & & $32.2(\max )$ & UK & $(58)$ \\
\hline & & 24.9 & $3.1-125.1$ & & $3,1.6,5.4$ & $0.4-32.2$ & UK & (59) \\
\hline Doxepin & & & & & & nd-1.9, nd, nd & Poland & (79) \\
\hline Doxepin & & & & & & nd & Portugal & (52) \\
\hline \multirow[t]{2}{*}{ Duloxetine } & 0.3 & 0 & $6.3(\max )$ & & & & $\begin{array}{l}\text { EU-wide (17 } \\
\text { countries) }\end{array}$ & $(50)$ \\
\hline & & & & & & nd -0.3 & Greece & (74) \\
\hline
\end{tabular}




\begin{tabular}{|c|c|c|c|c|c|c|c|}
\hline & & $<$ LOQ - 14 & & & $<\mathrm{LOQ}$ & Sweden & (56) \\
\hline & & & $1.5,2,1.2$ & & & US & (93) \\
\hline & & $<\mathrm{LOQ}$ & & & nd $-<$ LOQ & US & (94) \\
\hline Escitalopram & & $25-1136$ & & & nd -520 & Brazil & (3) \\
\hline & & & 0.57 & & $<\mathrm{LOQ}-3.08$ & Turkey & $(57)$ \\
\hline & $\begin{array}{l}50,160,40, \\
70\end{array}$ & & & & & US & (63) \\
\hline Fluoxetine & & & & & $<0.1-36$ & Australia & $(65)$ \\
\hline & & & & & $<0.5-3.5$ & Brazil & (95) \\
\hline & & $25-160$ & & & $25-90$ & Brazil & (3) \\
\hline & 122 & & & & nd - 141 & Canada & (66) \\
\hline & & & 10.24 & & $0.76-25.1$ & Canada & $(46)$ \\
\hline & & & & $<\mathrm{LOQ}$ & $<$ LOQ - 0.24 & China & (47) \\
\hline & & & 2 & 0.9 & & China & $(96)$ \\
\hline & $9.3,26.6$ & $\begin{array}{l}2.3-42.9,22.8 \\
-33.7\end{array}$ & & & & China & (48) \\
\hline & $<\mathrm{MOQ}$ & & & & & China & (67) \\
\hline
\end{tabular}




\begin{tabular}{|c|c|c|c|c|c|c|c|}
\hline 2.1 & 0 & $21.5(\max )$ & & & & $\begin{array}{l}\text { EU-wide (17 } \\
\text { countries) }\end{array}$ & (50) \\
\hline 16 & & & & & $<$ LOQ - 3.8 & Germany & (73) \\
\hline & & nd -1.3 & & & & Norway & (78) \\
\hline & & & & & $\begin{array}{l}\text { nd-3.2, nd, } \\
<\text { MQL-5.5 }\end{array}$ & Poland & (79) \\
\hline & & & & & nd - 28.9 & Portugal & (80) \\
\hline & & & & & 1 to 2 & Portugal & (52) \\
\hline & & & 25.37 & & $25.37-25.37$ & Portugal & (81) \\
\hline & $<\mathrm{MQL}$ & nd - <MQL & & & & Portugal & (82) \\
\hline & & & & & $68.16-88.46$ & Portugal & (97) \\
\hline & & nd -30.3 & & & nd - 11.7 & Spain & (85) \\
\hline & & nd & & & nd - 1.6 & Spain & (53) \\
\hline & & & & & NQ - 66.1 & Spain & (98) \\
\hline & & 22.70 (max) & & & $<0.18-10.6$ & Spain & (87) \\
\hline & & & & 14 & & Spain & (88) \\
\hline & & 21 (max) & & & 410 (max) & Spain & (99) \\
\hline
\end{tabular}




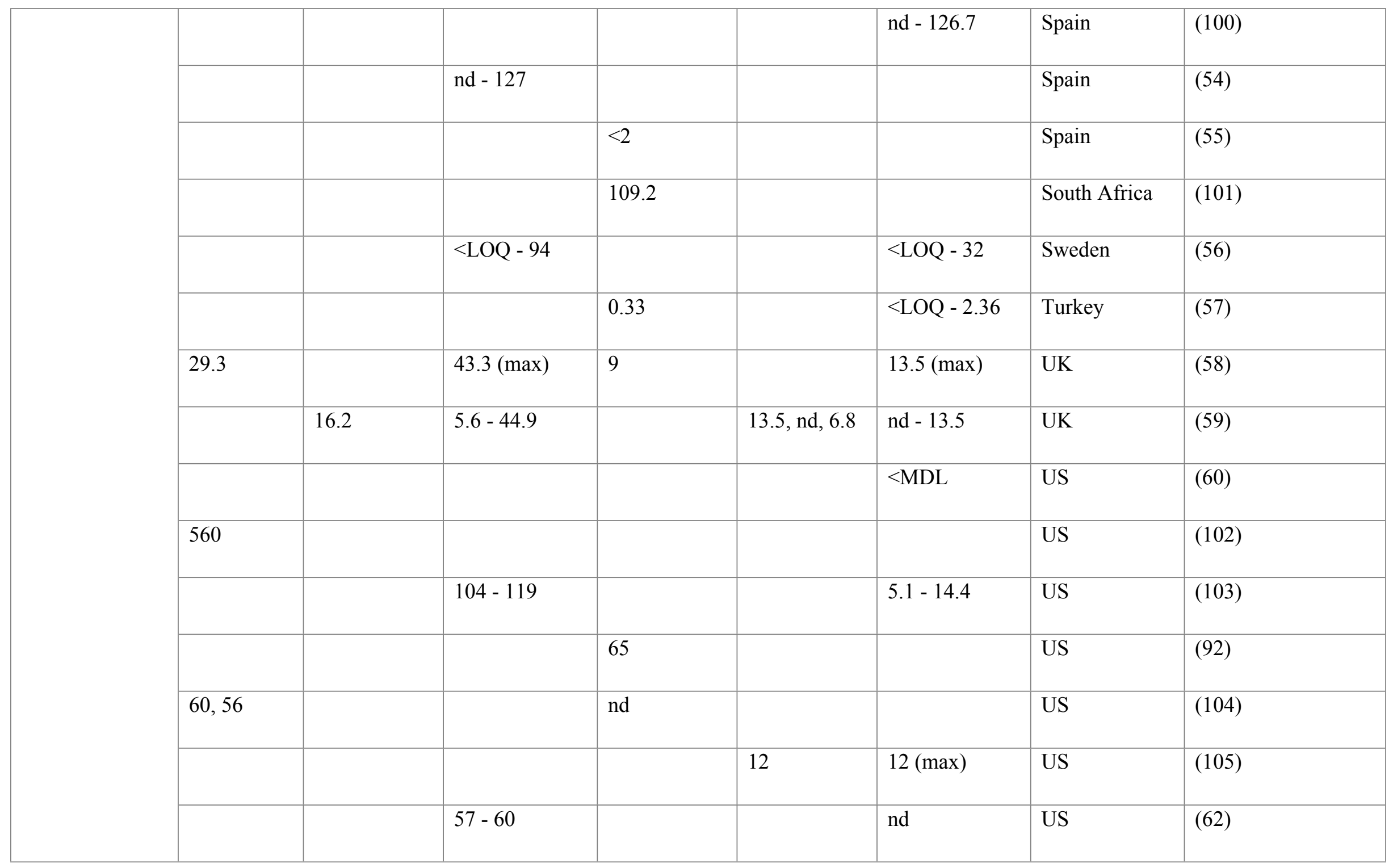




\begin{tabular}{|c|c|c|c|c|c|c|c|c|}
\hline & $\begin{array}{l}50,130, \mathrm{nd}, \\
40\end{array}$ & & & & & & US & (63) \\
\hline & & & & $12,20,12$ & & & US & (93) \\
\hline & & & $4.22-43.2$ & & & $<$ LOQ -7.8 & US & (94) \\
\hline \multirow[t]{3}{*}{ Fluvoxamine } & $<\mathrm{MOQ}$ & & & & & & China & (67) \\
\hline & & & nd -0.8 & & & & Norway & (78) \\
\hline & & & nd -4.6 & & & nd -0.83 & US & (94) \\
\hline \multirow[t]{2}{*}{ Imipramine } & $0.3, \mathrm{nd}$ & & nd-2.1, nd & & & & China & (48) \\
\hline & & & $30-55$ & & & & Spain & (54) \\
\hline \multirow[t]{3}{*}{ Nortriptyline } & & & nd - 786 & & & & Brazil & (3) \\
\hline & 32.9 & & $53.8(\max )$ & 6.8 & & $19.0(\max )$ & UK & $(58)$ \\
\hline & & 7.6 & $0.9-53.8$ & & $2.1,1,3$ & $0.2-19.0$ & UK & (59) \\
\hline \multirow[t]{4}{*}{ Paroxetine } & nd & & & & & nd -7 & Canada & (66) \\
\hline & & & & 5.41 & & $1.41-10.4$ & Canada & (46) \\
\hline & & & & & ND & $\mathrm{ND}-<\mathrm{LOQ}$ & China & (47) \\
\hline & $<\mathrm{LOQ}$, nd & & nd-2.1, nd & & & & China & (48) \\
\hline
\end{tabular}




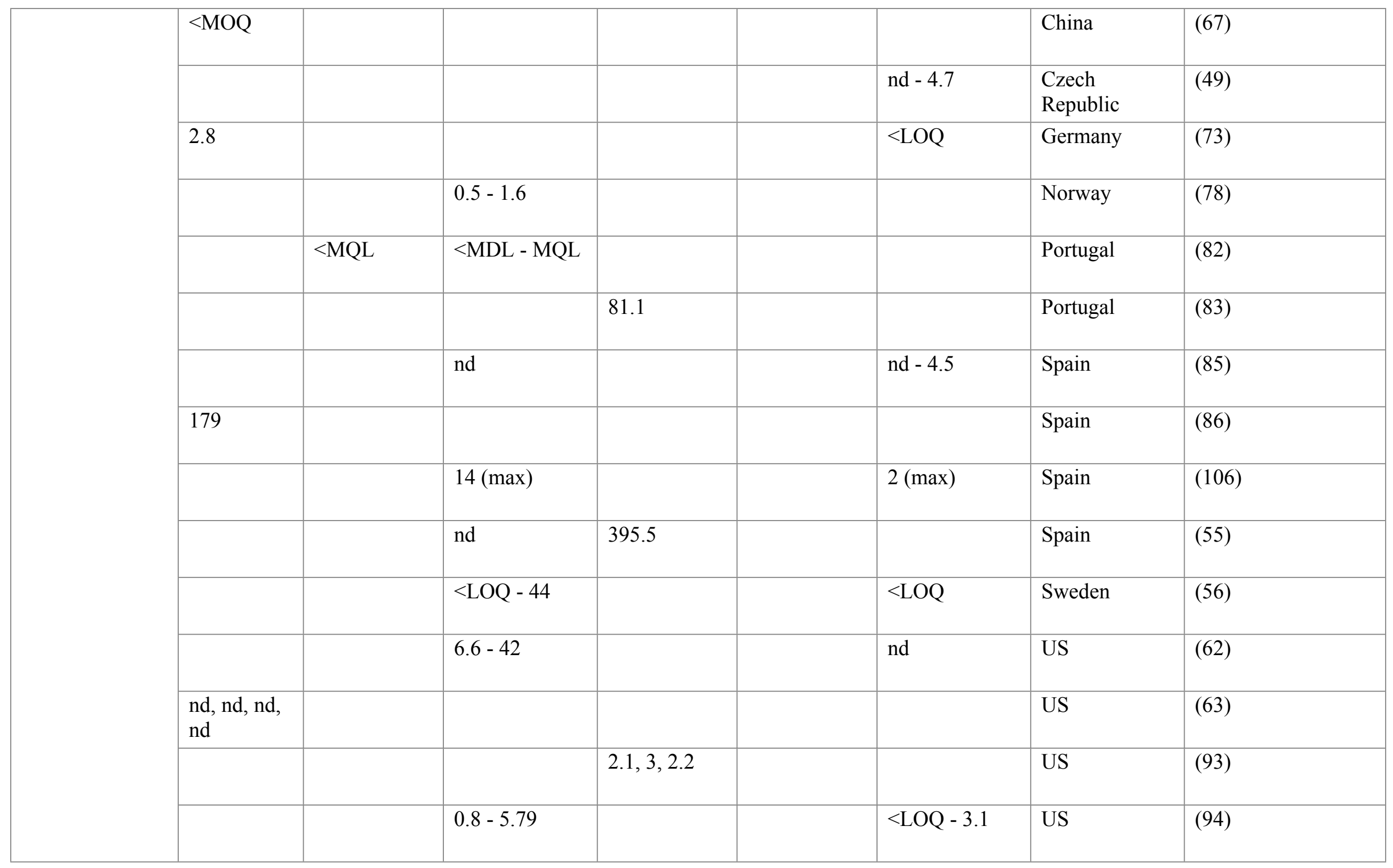




\begin{tabular}{|c|c|c|c|c|c|c|c|c|}
\hline \multirow[t]{15}{*}{ Sertraline } & & & nd -25 & & & & Brazil & (3) \\
\hline & 16 & & & & & nd -17 & Canada & (66) \\
\hline & & & & 16.01 & & $0.358-40.3$ & Canada & (46) \\
\hline & & & & & $<$ LOQ & ND $-<$ LOQ & China & (47) \\
\hline & $<\mathrm{LOQ}$, nd & & $\mathrm{nd}-5.0, \mathrm{nd}$ & & & & China & (48) \\
\hline & $<\mathrm{MOQ}$ & & & & & & China & (67) \\
\hline & & & & & & nd -42 & $\begin{array}{l}\text { Czech } \\
\text { Republic }\end{array}$ & (49) \\
\hline & & 3 & $3-6 g$ & & & & $\begin{array}{l}\text { Czech } \\
\text { Republic }\end{array}$ & (68) \\
\hline & 5 & & & 3,2 & & & $\begin{array}{l}\text { Czech } \\
\text { Republic }\end{array}$ & (69) \\
\hline & & & & 1.67 & & $<0.22-1.6$ & $\begin{array}{l}\text { Czech } \\
\text { Republic }\end{array}$ & (70) \\
\hline & 2.1 & 0 & $37.5(\max )$ & & & & $\begin{array}{l}\text { EU-wide (17 } \\
\text { countries) }\end{array}$ & $(50)$ \\
\hline & 7 & & & & & $<\mathrm{LOQ}$ & Germany & (73) \\
\hline & & & & & & $16-20$ & Japan & (107) \\
\hline & & & $0.9-2$ & & & & Norway & (78) \\
\hline & & & & & & $\begin{array}{l}\text { nd- }<\text { MQL, nd, } \\
\text { nd }<<\text { MQL }\end{array}$ & Poland & (79) \\
\hline
\end{tabular}




\begin{tabular}{|c|c|c|c|c|c|c|c|}
\hline & & & & & nd -5.4 & Portugal & (80) \\
\hline & & & & 23.3 & $23.3-23.6$ & Portugal & (81) \\
\hline & & $<\mathrm{MQL}$ & nd - <MQL & & & Portugal & $(82)$ \\
\hline & & & $23-26$ & & & Slovenia & (108) \\
\hline & & & nd & & nd -60.1 & Spain & (85) \\
\hline & & & $5.67(\max )$ & & $<0.35-15.3$ & Spain & (87) \\
\hline & & & $<$ LOQ - 28 & & $<$ LOQ - 28 & Sweden & (56) \\
\hline & & & & 0.4 & $<$ LOQ - 4.64 & Turkey & (57) \\
\hline & & & & & $<\mathrm{MDL}$ & US & (60) \\
\hline & & & & & $<\mathrm{MDL}$ & US & (61) \\
\hline & & & $89-116$ & & nd & US & $(62)$ \\
\hline & $\begin{array}{l}20,80, \mathrm{nd}, \\
20\end{array}$ & & & & & US & (63) \\
\hline & & & & $36,49,33$ & & US & (93) \\
\hline & & & $2.2-37.5$ & & $<$ LOQ -8.9 & US & (94) \\
\hline Venlafaxine & & & & & $<0.1-86.2$ & Australia & $(65)$ \\
\hline
\end{tabular}




\begin{tabular}{|c|c|c|c|c|c|c|c|}
\hline & & & & & nd - 2653 & Canada & (109) \\
\hline 808 & & & & & $4-901$ & Canada & (66) \\
\hline & & & 244.11 & & $0.796-573$ & Canada & (46) \\
\hline & & & & 0.53 & $<$ LOQ - 3.03 & China & (47) \\
\hline & & & 23.9 & 25.4 & & China & (96) \\
\hline$<\mathrm{LOQ}, 2.0$ & & $\begin{array}{l}\text { nd - } 4.1 \text {, nd - } \\
4.9\end{array}$ & & & & China & (48) \\
\hline & & & & & $9-198$ & $\begin{array}{l}\text { Czech } \\
\text { Republic }\end{array}$ & (49) \\
\hline & 280 & $120-1110$ & & & & $\begin{array}{l}\text { Czech } \\
\text { Republic }\end{array}$ & (68) \\
\hline 74 & & & 76,55 & & & $\begin{array}{l}\text { Czech } \\
\text { Republic }\end{array}$ & (69) \\
\hline & & & 56.92 & & $11-110$ & $\begin{array}{l}\text { Czech } \\
\text { Republic }\end{array}$ & (70) \\
\hline 119 & 97 & $548(\max )$ & & & & $\begin{array}{l}\text { EU-wide (17 } \\
\text { countries) }\end{array}$ & (50) \\
\hline & & & & & $1-15$ & Finland & (71) \\
\hline & & & & & $<$ LOQ - 122 & Germany & (110) \\
\hline 220 & & & & & $<$ LOQ - 100 & Germany & (73) \\
\hline & & & & & nd - 197 & Italy & (77) \\
\hline
\end{tabular}




\begin{tabular}{|c|c|c|c|c|c|c|c|}
\hline & & & & & nd - 641 & Portugal & (80) \\
\hline & 272 & $184-322$ & & & & Portugal & (82) \\
\hline & & & & & $13.68-25.80$ & Portugal & (97) \\
\hline & & & & & $\begin{array}{l}27-250,5- \\
22,80-140\end{array}$ & Poland & (79) \\
\hline 200 & & & & & & Slovakia & (84) \\
\hline & & nd - 461 & 94.6 & & & South Africa & (101) \\
\hline & & $582.7-999.5$ & & & $4.1-177.7$ & Spain & (85) \\
\hline & & & & 57 & & Spain & (88) \\
\hline & & 300 (max) & & & & Spain & (111) \\
\hline & 140,290 & $\begin{array}{l}60-300,200- \\
550\end{array}$ & & & & Spain & (112) \\
\hline & & & 1.98 & & $<\mathrm{LOQ}-7.68$ & Turkey & (57) \\
\hline 2659 & & & & & & Spain & (86) \\
\hline & & & & & $800(\max )$ & Spain & (113) \\
\hline & & 205 (max) & & & $0.42-291$ & Spain & (87) \\
\hline & & & $<2$ & & & Spain & (55) \\
\hline
\end{tabular}




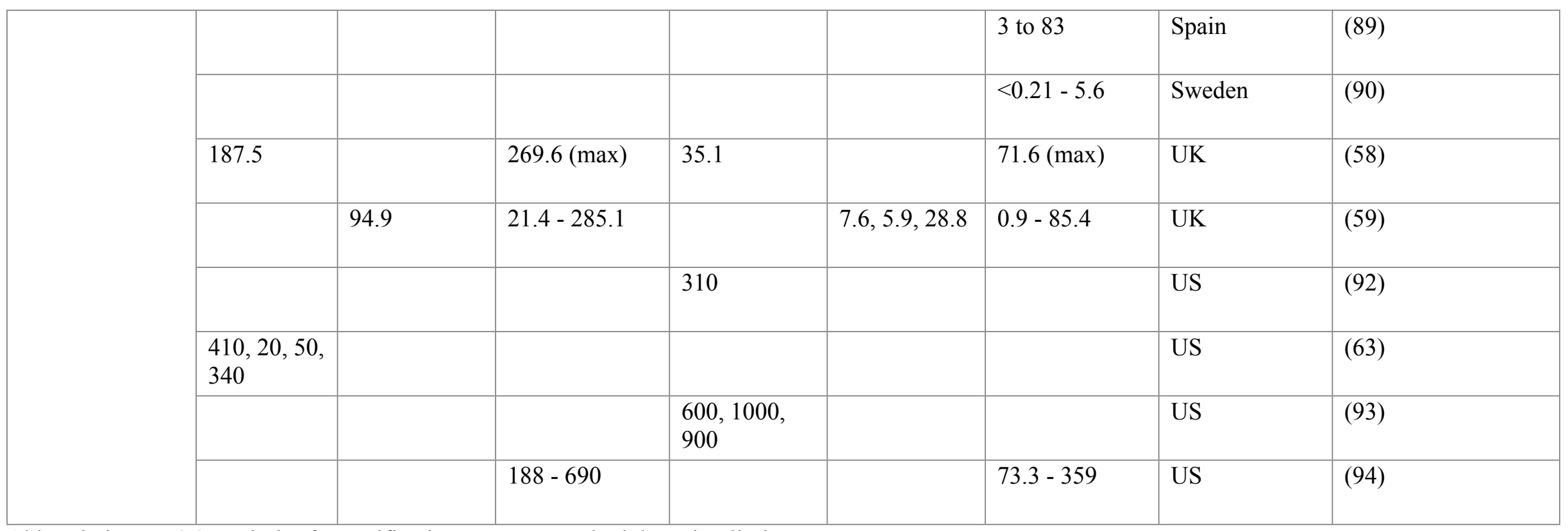

Abbreviations: $\mathrm{LOQ}=$ Limit of quantification; $\mathrm{MDL}=$ Method detection limit. 
Table S4. Bioaccumulation of antidepressants in fish tissues and biofluids.

\begin{tabular}{|c|c|c|c|c|c|c|}
\hline Antidepressant & Species - life stage & $\begin{array}{l}\text { Exposure } \\
\text { duration }\end{array}$ & $\begin{array}{l}\text { Exposure } \\
\text { concentration }\end{array}$ & Analysed tissue(s) & $\begin{array}{l}\text { Tissue } \\
\text { concentration }\end{array}$ & Reference \\
\hline \multirow[t]{11}{*}{ Amitriptyline } & $\begin{array}{l}\text { White perch, Atlantic } \\
\text { menhaden, channel } \\
\text { catfish - adult }\end{array}$ & Lifetime & River and bay & Plasma & ND - <MDL & $(60)$ \\
\hline & Roach - adult & 15 days & $\begin{array}{l}298-421 \mathrm{ng} \mathrm{L}^{-1} \\
\text { (effluent) }\end{array}$ & $\begin{array}{l}\text { Plasma; brain ( } 4 \\
\text { regions) }\end{array}$ & $\begin{array}{l}0.9-2.2 \mathrm{ng} \mathrm{ml}^{-1} \\
3.2-11 \mathrm{ng} \mathrm{g}^{-1}\end{array}$ & $(114)$ \\
\hline & $\begin{array}{l}\text { Walleye, yellow perch, } \\
\text { lake trout, cisco, black } \\
\text { crappie - adult }\end{array}$ & Lifetime & $\begin{array}{l}\text { Effluent impacted, } \\
\text { developed and } \\
\text { undeveloped sites }\end{array}$ & Whole body & $0.1-0.6 \mathrm{ng} \mathrm{g}^{-1}$ & $(115)$ \\
\hline & Brook trout - adult & 3 months & $3.7 \mathrm{ng} \mathrm{L}^{-1}$ (effluent) & $\begin{array}{l}\text { Brain; liver; } \\
\text { muscle }\end{array}$ & $\begin{array}{l}\text { ND; ND - 0.29; } \\
\text { ND ng g }{ }^{-1}\end{array}$ & $(116)$ \\
\hline & $\begin{array}{l}\text { Chinook salmon, } \\
\text { pacific staghorn } \\
\text { sculpin - adult }\end{array}$ & Lifetime & $\begin{array}{l}\text { WWTP outfalls and } \\
\text { estuary }\end{array}$ & Whole body & $0.58-0.68 \mathrm{ng} \mathrm{g}^{-1}$ & $(62)$ \\
\hline & $\begin{array}{l}\text { Chinook salmon - } \\
\text { adult }\end{array}$ & Lifetime & 88-119 ng L-1 (effluent) & Whole body & $0.68 \mathrm{ng} \mathrm{g}^{-1}$ & $(117)$ \\
\hline & $\begin{array}{l}\text { Chinook salmon - } \\
\text { adult }\end{array}$ & Lifetime & $\begin{array}{l}\text { Estuaries (receives } \\
\text { WWTP effluent) }\end{array}$ & Whole body & $0.68 \mathrm{ng} \mathrm{g}^{-1}(\max )$ & $(118)$ \\
\hline & Gilt-head bream - adult & 7 days & $\begin{array}{l}300 \mathrm{ng} \mathrm{L}^{-1} \text { (mixture } \\
\text { with } 9 \text { other non- } \\
\text { antidepressant } \\
\text { compounds) }\end{array}$ & $\begin{array}{l}\text { Brain; gill; liver; } \\
\text { bile; muscle; } \\
\text { plasma }\end{array}$ & $\begin{array}{l}58 ; 16 ; 18 ; \mathrm{ND} ; 7.1 \\
\mathrm{ng} \mathrm{g}^{-1} ; 15 \mathrm{ng} \mathrm{ml}^{-1}\end{array}$ & $(119)$ \\
\hline & $\begin{array}{l}\text { Caged goldfish, wild } \\
\text { goldfish, cootes carp - } \\
\text { adult }\end{array}$ & 21 days & $\begin{array}{l}\text { Caged: river } \\
\text { downstream from } \\
\text { WWTP }\end{array}$ & Plasma & $\begin{array}{l}\text { Caged: } 0.04-0.15 \\
\text { ng g }^{-1}\end{array}$ & $(46)$ \\
\hline & & & Wild: marsh & & $\begin{array}{l}\text { Wild: } 0.02-0.02 \\
\text { ng g }^{-1}\end{array}$ & \\
\hline & Gilt-head bream - adult & 7 days & $0.2,10 \mu \mathrm{g} \mathrm{L}^{-1}$ & $\begin{array}{l}\text { Brain; gill; liver; } \\
\text { plasma; bile; } \\
\text { muscle }\end{array}$ & Graph only & $(120)$ \\
\hline Citalopram & $\begin{array}{l}\text { Mullet, flounder - } \\
\text { adult }\end{array}$ & Lifetime & Estuaries & Whole body & $<\mathrm{MDL}$ & $(121)$ \\
\hline
\end{tabular}




\begin{tabular}{|c|c|c|c|c|c|}
\hline $\begin{array}{l}\text { Smallmouth bass, } \\
\text { largemouth bass, rudd, } \\
\text { rock bass, white bass, } \\
\text { white perch, walleye, } \\
\text { bowfin, steel head, } \\
\text { yellow perch - adult }\end{array}$ & Lifetime & $\begin{array}{l}\text { River (impacted by } \\
\text { WWTP effluent) }\end{array}$ & $\begin{array}{l}\text { Brain; gonad; liver; } \\
\text { muscle }\end{array}$ & $\begin{array}{l}\mathrm{ND}-3.3 ; \mathrm{ND}- \\
1.7 ; \mathrm{ND}-3.7 ; \mathrm{ND} \\
-0.4 \mathrm{ng} \mathrm{g}^{-1}\end{array}$ & (122) \\
\hline Carp, bream - adult & Lifetime & $\begin{array}{l}\text { Various (WWTP } \\
\text { impacted pond, canal } \\
\text { and river) }\end{array}$ & Fillet, liver & $\begin{array}{l}<\mathrm{LOQ} ;<\mathrm{LOQ}- \\
22.1 \mathrm{ng} \mathrm{g}^{-1}\end{array}$ & (123) \\
\hline Roach - adult & 15 days & $\begin{array}{l}211-340 \mathrm{ng} \mathrm{L}^{-1} \\
\text { (effluent) }\end{array}$ & $\begin{array}{l}\text { Plasma; brain ( } 4 \\
\text { regions) }\end{array}$ & $\begin{array}{l}3.3-15 \mathrm{ng} \mathrm{ml}^{-1} \\
0.1-1 \mathrm{ng} \mathrm{g}^{-1}\end{array}$ & (114) \\
\hline $\begin{array}{l}\text { Walleye, yellow perch, } \\
\text { lake trout, cisco, black } \\
\text { crappie - adult }\end{array}$ & Lifetime & $\begin{array}{l}\text { Effluent impacted, } \\
\text { developed and } \\
\text { undeveloped sites }\end{array}$ & Whole body & $0.2-0.4 \mathrm{ng} \mathrm{g}^{-1}$ & (115) \\
\hline Bull shark - adult & Lifetime & $\begin{array}{l}\text { River (impacted by } \\
\text { WWTP effluent) }\end{array}$ & Plasma & $\begin{array}{l}<\mathrm{MQL}-0.4 \mathrm{ng} \mathrm{ml}^{-} \\
\end{array}$ & (124) \\
\hline Rainbow trout - adult & 13 days & $\begin{array}{l}260 \mathrm{ng} \mathrm{L}^{-1} \text { (treated } \\
\text { effluent) }\end{array}$ & $\begin{array}{l}\text { Liver; brain; } \\
\text { muscle; plasma }\end{array}$ & $\begin{array}{l}12 ; 2.2 ;<\text { LOQ ng } \\
\mathrm{g}^{-1} ;<\text { LOQ ng ml- }\end{array}$ & (125) \\
\hline Brown trout - adult & $1,3,6,18$ months & $\begin{array}{l}\text { Stream (impacted by } \\
\text { WWTP effluent) }\end{array}$ & Liver; kidney & $\begin{array}{l}<\mathrm{LOQ}-31 ; 0.35- \\
164 \mathrm{ng} \mathrm{g}^{-1}\end{array}$ & (126) \\
\hline Common carp - adult & Lifetime & Effluent polluted pond & $\begin{array}{l}\text { Liver; kidney; } \\
\text { muscle; brain; } \\
\text { plasma }\end{array}$ & $\begin{array}{l}3.1 ; 5.3 ; 1.3 ; 4.6 \\
0.21 \mathrm{ng} \mathrm{g}^{-1}\end{array}$ & (127) \\
\hline $\begin{array}{l}\text { Common carp, } \\
\text { pikeperch - adult }\end{array}$ & 6 months & $\begin{array}{l}\text { Pond (subject to } \\
\text { reclaimed wastewater) }\end{array}$ & $\begin{array}{l}\text { Liver; kidney; } \\
\text { brain; muscle; } \\
\text { plasma }\end{array}$ & $\begin{array}{l}\text { Carp: } 3 ; 3.1 ; 1.8 ; \\
0.95 \mathrm{ng} \mathrm{g}^{-1} ; \mathrm{ND} \text { ng } \\
\mathrm{ml}^{-1} \\
\text { Pikeperch: } 0.22 ; \\
0.67 ; \mathrm{ND} ; 0.031 \mathrm{ng} \\
\mathrm{g}^{-1} ; 0.19 \mathrm{ng} \mathrm{ml}^{-1}\end{array}$ & (128) \\
\hline Common carp - adult & Lifetime & River & Homogenate & $0.8 \mathrm{ng} \mathrm{g}^{-1}$ & (129) \\
\hline $\begin{array}{l}\text { Smallmouth bass, } \\
\text { largemouth bass, white } \\
\text { sucker, yellow perch, } \\
\text { channel catfish, }\end{array}$ & Lifetime & $\begin{array}{l}\text { Downstream from } \\
\text { WWTP }\end{array}$ & Fillet & $1.2 \mathrm{ng} \mathrm{g}^{-1}$ & (130) \\
\hline
\end{tabular}


common snook,

freshwater drum,

spotted bass - adult

\begin{tabular}{|c|c|c|c|c|c|}
\hline Common carp - adult & 1 month to a year & Effluent impacted pond & Liver & $0.18-1.6 \mathrm{ng} \mathrm{g}^{-1}$ & $(70)$ \\
\hline Brook trout - adult & 3 months & $10.5 \mathrm{ng} \mathrm{L}^{-1}$ (effluent) & $\begin{array}{l}\text { Brain; liver; } \\
\text { muscle }\end{array}$ & $\begin{array}{l}\mathrm{ND}-0.43 ; \mathrm{ND}- \\
0.18 ; \mathrm{ND} \mathrm{ng} \mathrm{g}^{-1}\end{array}$ & (116) \\
\hline Chub, barbel - adult & Lifetime & Effluent impacted sites & Plasma & $\mathrm{ND}-55.7 \mathrm{ng} \mathrm{L}^{-1}$ & $(131)$ \\
\hline Round goby - adult & 28 days & $\begin{array}{l}50 \% \text { and } 100 \% \text { of } \\
\text { WWTP effluent }\end{array}$ & $\begin{array}{l}\text { Brain; gonad; liver; } \\
\text { muscle; plasma }\end{array}$ & $\begin{array}{l}\text { 50\%: <LOQ; } \\
<\text { LOQ; <LOQ; } \\
<\text { LOQ ng g- }^{-1} ; 6.37 \\
\text { ng ml } \\
\\
\text { 100\%: } \\
<\text { LOQ; } \\
<\text { LOQ }_{\text {L }}^{-1} \text { ng g }^{-1} ; 8.04 \\
\text { ng ml }^{-1}\end{array}$ & (132) \\
\hline $\begin{array}{l}\text { Caged goldfish, wild } \\
\text { goldfish, cootes carp - } \\
\text { adult }\end{array}$ & 21 days & $\begin{array}{l}\text { Caged: river } \\
\text { downstream from } \\
\text { WWTP } \\
\text { Wild: marsh }\end{array}$ & Plasma & $\begin{array}{l}\text { Caged: } 0.04-0.13 \\
\text { ng g-1 }^{-1} \\
\text { Wild: ND - } 0.16 \\
\text { ng g }^{-1}\end{array}$ & $(46)$ \\
\hline Andalusian barbell, & Lifetime & River basins & Whole body & $\mathrm{ND}-1.38 \mathrm{ng} \mathrm{g}^{-1}$ & $(133)$ \\
\hline
\end{tabular}

Andalusian barb

River basins

Whole body

$\mathrm{ND}-1.38 \mathrm{ng} \mathrm{g}^{-1}$

iberian gudgeon, black

bass, mediterranean

barbel, pumpkinseed

sunfish, bleak, eel,

pile, ebro barbell,

european catfish -

adult

White sucker - adult

Lifetime

Effluent impacted

Brain

ND $-0.07 n g g^{-1}$

(94)

Grass carp, common

Lifetime

streams

Whole body

$1.1-2.2 \mathrm{ng} \mathrm{g}^{-1}$

(134)

crucian carp

silver carp, bighead 
carp, whitebait, yellow

catfish, catfish, loach -

adult

\begin{tabular}{|c|c|c|c|}
\hline $\begin{array}{l}\text { Brown trout - } \\
\text { larvae/juvenile }\end{array}$ & 5 months, 4 weeks $\quad 1,10,100,1000 \mu \mathrm{g} \mathrm{L}^{-1}$ & Tailfin & $\begin{array}{l}\text { Larvae: } 0.07,0.69 \\
1.57,55.87 \mu \mathrm{g} \mathrm{g}^{-1} \\
\left(11^{\circ} \mathrm{C}\right) ; 0.2,0.97 \\
5.63,142.15 \mu \mathrm{g} \mathrm{g}^{-1} \\
\left(7^{\circ} \mathrm{C}\right)\end{array}$ \\
\hline
\end{tabular}

(135)

Juvenile: $8.2,38.3$, 340.63, $2966.83 \mu \mathrm{g}$ $\mathrm{g}^{-1}\left(7^{\circ} \mathrm{C}\right)$

\begin{tabular}{|c|c|c|c|c|c|c|}
\hline \multirow[t]{3}{*}{ Clomipramine } & $\begin{array}{l}\text { Bream, roach, chub - } \\
\text { adult }\end{array}$ & Lifetime & $\begin{array}{l}\text { Effluent dominated and } \\
\text { less impacted sites }\end{array}$ & Plasma & $<0.5-13 \mathrm{ng} \mathrm{ml}^{-1}$ & (136) \\
\hline & Brown trout - adult & $1,3,6,18$ months & $\begin{array}{l}\text { Stream (impacted by } \\
\text { WWTP effluent) }\end{array}$ & Liver; kidney & $\begin{array}{l}<\mathrm{LOQ}-1.2 ; \\
<\mathrm{LOQ}-1.8 \mathrm{ng} \mathrm{g}^{-1}\end{array}$ & $(126)$ \\
\hline & Common carp - adult & Lifetime & Effluent polluted pond & $\begin{array}{l}\text { Liver; kidney; } \\
\text { muscle; brain; } \\
\text { plasma }\end{array}$ & $\begin{array}{l}0.23 ; 0.39 ;<\text { LOQ; } \\
<\text { LOQ; <LOQ ng } \\
\mathrm{g}^{-1}\end{array}$ & $(127)$ \\
\hline \multirow[t]{6}{*}{ Fluoxetine } & $\begin{array}{l}\text { White perch, Atlantic } \\
\text { menhaden, channel } \\
\text { catfish - adult }\end{array}$ & Lifetime & River and bay & Plasma & ND - <MDL & $(60)$ \\
\hline & Perch - adult & Lifetime & $\begin{array}{l}\text { Polish Baltic fishing } \\
\text { areas }\end{array}$ & Muscle & $0.57 \mathrm{ng} \mathrm{g}^{1}$ & $(137)$ \\
\hline & $\begin{array}{l}\text { Nine-spine stickleback } \\
\text { - adult }\end{array}$ & 14 days & $10 \mu \mathrm{g} \mathrm{L}^{-1}$ & Whole body & $\begin{array}{l}41 \mathrm{~L} \mathrm{~kg}^{-1}(\mathrm{BAF} \\
\text { only) }\end{array}$ & $(138)$ \\
\hline & $\begin{array}{l}\text { Bluegill, channel } \\
\text { catfish, black crappie - } \\
\text { adult }\end{array}$ & Lifetime & $\begin{array}{l}\text { Downstream from } \\
\text { WWTP effluent } \\
\text { discharge }\end{array}$ & $\begin{array}{l}\text { Brain; liver; } \\
\text { muscle }\end{array}$ & $\begin{array}{l}1.58 ; 1.34 ; 0.11 \mathrm{ng} \\
\mathrm{g}^{-1}\end{array}$ & (139) \\
\hline & Carp, bream - adult & Lifetime & $\begin{array}{l}\text { Various (WWTP } \\
\text { impacted pond, canal } \\
\text { and river) }\end{array}$ & Fillet, liver & $\begin{array}{l}<\mathrm{LOQ}-10 ;<\mathrm{LOQ} \\
-25.8 \mathrm{ng} \mathrm{g}^{-1}\end{array}$ & $(123)$ \\
\hline & $\begin{array}{l}\text { White perch, gizzard } \\
\text { shad and brown } \\
\text { bullhead - adult }\end{array}$ & Lifetime & $\begin{array}{l}\text { Harbour heavily } \\
\text { impacted by WWTP } \\
\text { discharge }\end{array}$ & Whole body & $\mathrm{ND}-1.02 \mu \mathrm{g} \mathrm{kg}^{-1}$ & $(140)$ \\
\hline
\end{tabular}




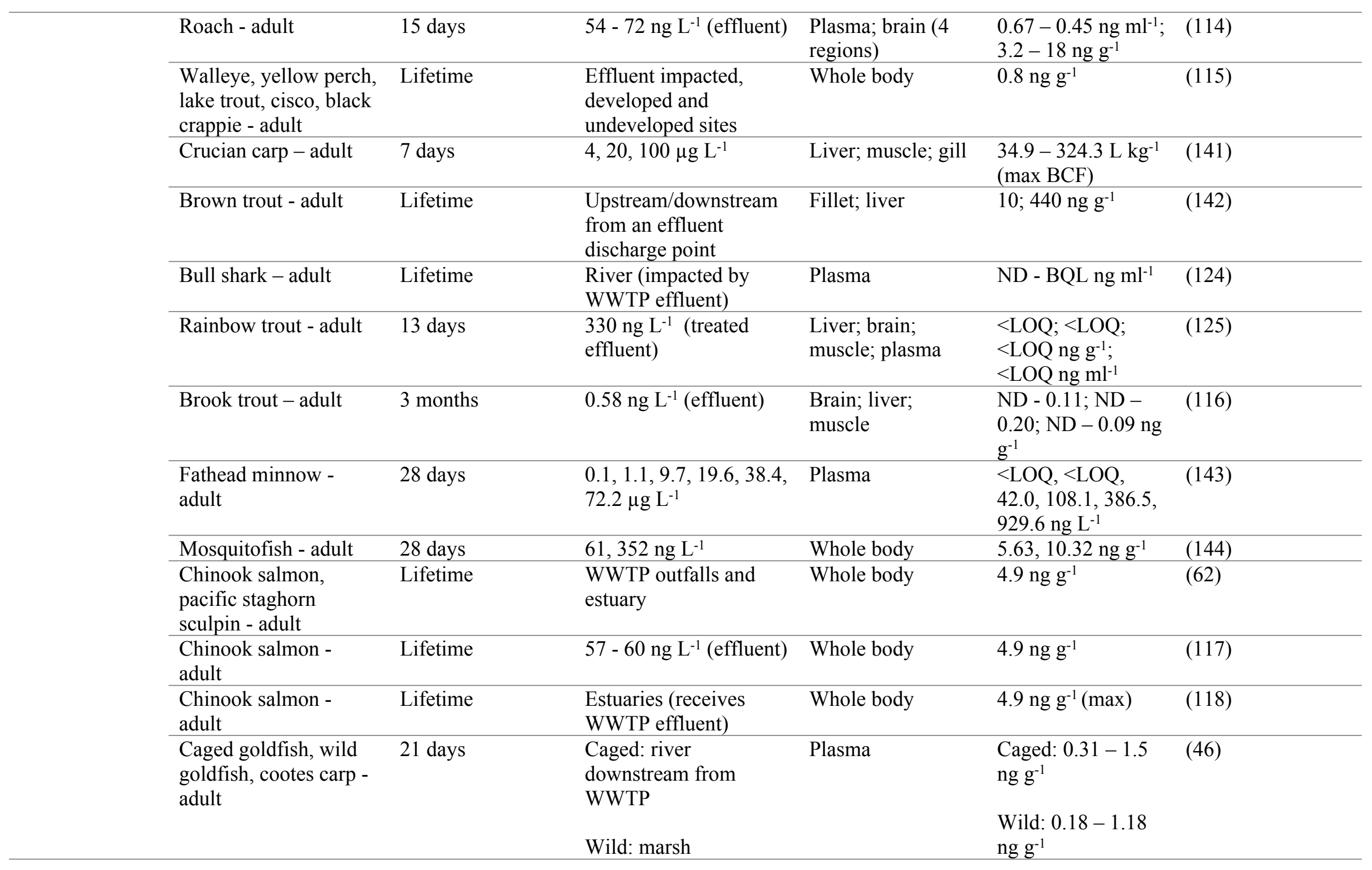




\begin{tabular}{|c|c|c|c|c|c|}
\hline $\begin{array}{l}\text { Japanese medaka - } \\
\text { juvenile }\end{array}$ & 30 days & $10 \mu \mathrm{g} \mathrm{L}^{-1}$ & Whole body; Liver & $\begin{array}{l}2.6-8.8 ; 3.1-5.8 \\
\text { (BCF only) }\end{array}$ & $(145)$ \\
\hline $\begin{array}{l}\text { Zebrafish - embryo- } \\
\text { larvae }\end{array}$ & 96 hours & $10 \mu \mathrm{g} \mathrm{L}^{-1}$ & Whole body & $\begin{array}{l}94-170 \mathrm{~L} \mathrm{~kg}^{-1} \\
\text { (BCF only) }\end{array}$ & $(146)$ \\
\hline Crucian carp - adult & 30 days & $\begin{array}{l}0.1,1,10,100,1000 \\
\mu \mathrm{g} \mathrm{L}^{-1}\end{array}$ & $\begin{array}{l}\text { Brain; liver; } \\
\text { muscle }\end{array}$ & $\begin{array}{l}11,33.8,124,2580 \\
12800 ; 13.7,63.5 \\
282,2770.11100 ; \\
16.6,23.8,121, \\
3350,15000 \mathrm{ng} \mathrm{g}^{-1}\end{array}$ & $(147)$ \\
\hline $\begin{array}{l}\text { Zebrafish - } \\
\text { embryo/larvae }\end{array}$ & 120 hours & $\begin{array}{l}0.1,1,10,100,1000 \\
\mu \mathrm{g} \mathrm{L}^{-1}\end{array}$ & Whole body & $\begin{array}{l}0.688,2.51,24.0 \\
173,2840 \mathrm{ng} \mathrm{g}^{-1}\end{array}$ & $(147)$ \\
\hline $\begin{array}{l}\text { Japanese medaka - } \\
\text { adult }\end{array}$ & 7 days & $0.55 \mu \mathrm{g} \mathrm{L}^{-1}$ & Whole body & $49.4 \mu \mathrm{g} \mathrm{kg}^{-1}$ (max) & (148) \\
\hline $\begin{array}{l}\text { Sonora sucker, } \\
\text { largemouth bass, } \\
\text { common carp, bowfin, } \\
\text { white sucker, } \\
\text { smallmouth buffalo - } \\
\text { adult }\end{array}$ & Lifetime & $\begin{array}{l}\text { Effluent dominated } \\
\text { rivers }\end{array}$ & Liver & $\mathrm{ND}-80 \operatorname{ng~g}^{-1}$ & (149) \\
\hline White sucker - adult & Lifetime & $\begin{array}{l}\text { Effluent impacted } \\
\text { streams }\end{array}$ & Brain & $\mathrm{ND}-0.6 \mathrm{ng} \mathrm{g}^{-1}$ & (94) \\
\hline $\begin{array}{l}\text { Fathead minnow - } \\
\text { adult }\end{array}$ & 21 days & $2.5,28 \mathrm{ng} \mathrm{L}^{-1}$ & Brain & $0.108,0.173 \mathrm{ng} \mathrm{g}^{-1}$ & $(150)$ \\
\hline Rainbow trout - adult & 7 days & $\begin{array}{l}\text { Caged upstream and } \\
\text { downstream from } \\
\text { effluent discharge }\end{array}$ & Whole body & $0.61-5.5 \mu \mathrm{g} \mathrm{kg}^{-1}$ & (151) \\
\hline $\begin{array}{l}\text { Zebrafish - } \\
\text { embryo/larvae }\end{array}$ & 48 hours & $5 \mathrm{mg} \mathrm{L}^{-1}$ & Whole body & $472 \mathrm{mg} \mathrm{L}^{-1}$ & $(152)$ \\
\hline $\begin{array}{l}\text { Fathead minnow - } \\
\text { adult }\end{array}$ & 2 weeks & $\begin{array}{l}\text { Caged up and } \\
\text { downstream of WWTP }\end{array}$ & Bile; muscle & $\begin{array}{l}<\mathrm{LOQ} \mu \mathrm{g} \mathrm{L}^{-1} ; \\
<\mathrm{LOQ}-4 \mathrm{ng} \mathrm{g}^{-1}\end{array}$ & (153) \\
\hline Rainbow trout - adult & 7 days & $3.2,32,320 \mathrm{~g} \mathrm{ml}^{-1}$ & Bile; muscle & $\begin{array}{l}132.9,3171.3 \\
8519.4 \mathrm{ng} \mathrm{ml}^{-1} \\
0.92,428.8 \mathrm{ng} \mathrm{g}^{-1}\end{array}$ & (153) \\
\hline
\end{tabular}




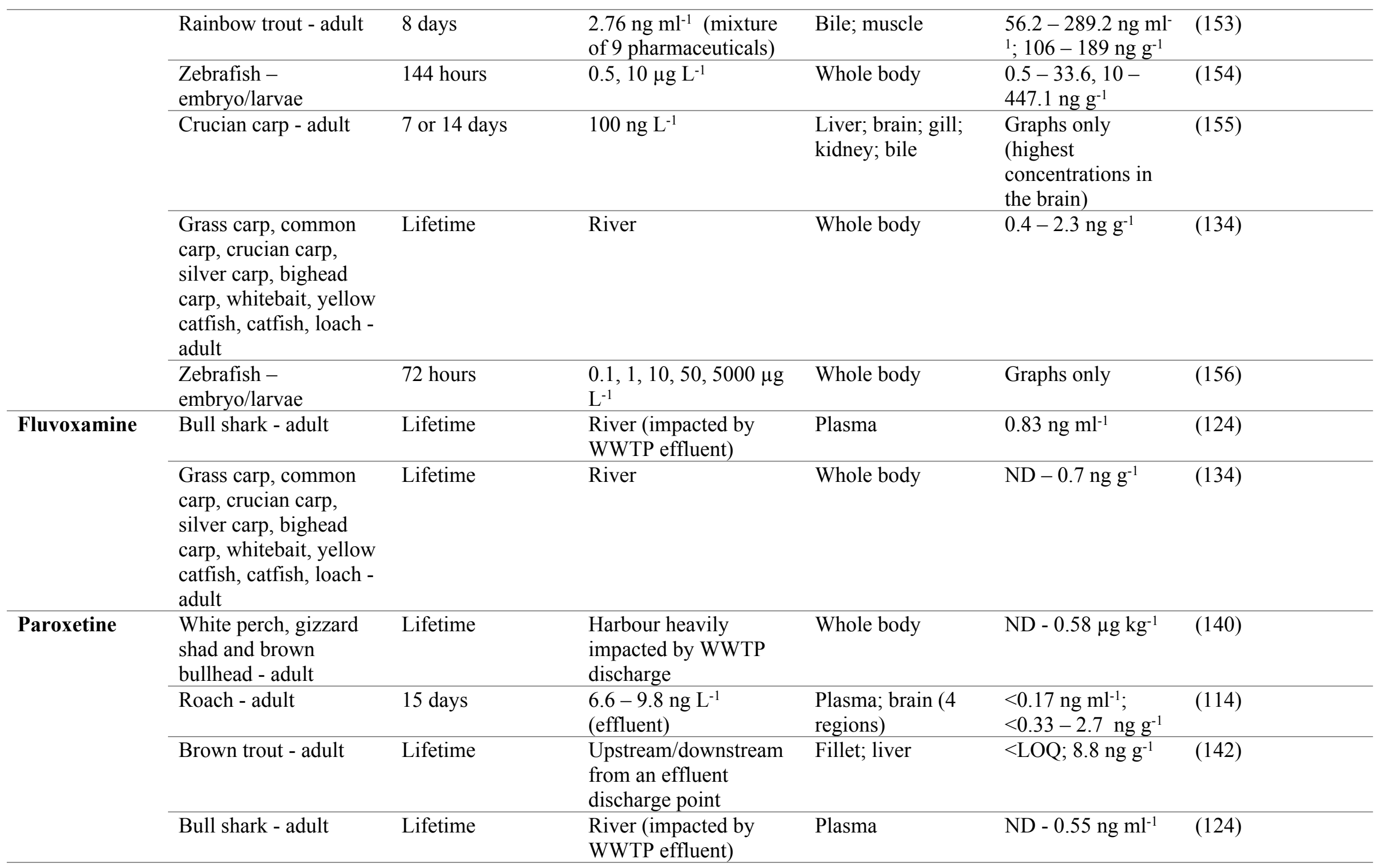




\begin{tabular}{|c|c|c|c|c|c|c|}
\hline & Brown trout - adult & $1,3,6,18$ months & $\begin{array}{l}\text { Stream (impacted by } \\
\text { WWTP effluent) }\end{array}$ & Liver; kidney & $\begin{array}{l}<\mathrm{LOQ}-2.9 \\
<\mathrm{LOQ}-9.5 \mathrm{ng} \mathrm{g}^{-1}\end{array}$ & $(126)$ \\
\hline & Brook trout - adult & 3 months & $0.96 \mathrm{ng} \mathrm{L}^{-1}$ (effluent) & $\begin{array}{l}\text { Brain; liver; } \\
\text { muscle }\end{array}$ & $\begin{array}{l}\text { ND - } 0.19 ; \mathrm{ND}- \\
0.35 ; \mathrm{ND}-<\mathrm{LOQ} \\
\mathrm{ng} \mathrm{g}^{-1}\end{array}$ & (116) \\
\hline & $\begin{array}{l}\text { Zebrafish - embryo- } \\
\text { larvae }\end{array}$ & 96 hours & $10 \mu \mathrm{g} \mathrm{L}^{-1}$ & Whole body & $\begin{array}{l}190-290 \mathrm{~L} \mathrm{~kg}^{-1} \\
\text { (BCF only) }\end{array}$ & (146) \\
\hline & White sucker - adult & Lifetime & $\begin{array}{l}\text { Effluent impacted } \\
\text { streams }\end{array}$ & Brain & $\mathrm{ND}-0.083 \mathrm{ng} \mathrm{g}^{-1}$ & (94) \\
\hline & $\begin{array}{l}\text { Fathead minnow - } \\
\text { adult }\end{array}$ & 2 weeks & $\begin{array}{l}\text { Caged up and } \\
\text { downstream of WWTP }\end{array}$ & Bile; muscle & $\begin{array}{l}\mathrm{ND}-2.84 \mu \mathrm{g} \mathrm{L}^{-1} \\
<\mathrm{LOQ}-0.40 \mathrm{ng} \mathrm{g}^{-}\end{array}$ & (153) \\
\hline \multirow[t]{8}{*}{ Sertraline } & $\begin{array}{l}\text { Mullet, flounder - } \\
\text { adult }\end{array}$ & Lifetime & Estuaries & Whole body & $<\mathrm{MDL}$ & (121) \\
\hline & $\begin{array}{l}\text { Smallmouth bass, } \\
\text { largemouth bass, rudd, } \\
\text { rock bass, white bass, } \\
\text { white perch, walleye, } \\
\text { bowfin, steel head, } \\
\text { yellow perch - adult }\end{array}$ & Lifetime & $\begin{array}{l}\text { River (impacted by } \\
\text { WWTP effluent) }\end{array}$ & $\begin{array}{l}\text { Brain; gonad; liver; } \\
\text { muscle }\end{array}$ & $\begin{array}{l}\mathrm{ND}-16.9 ; \mathrm{ND}- \\
6.7 ; \mathrm{ND} ; \mathrm{ND} \mathrm{ng}^{-1}\end{array}$ & (122) \\
\hline & $\begin{array}{l}\text { Nine-spine stickleback } \\
\text { - adult }\end{array}$ & 14 days & $10 \mu \mathrm{g} \mathrm{L}^{-1}$ & Whole body & $\begin{array}{l}49 \mathrm{~L} \mathrm{~kg}^{-1}(\mathrm{BAF} \\
\text { only) }\end{array}$ & (138) \\
\hline & $\begin{array}{l}\text { Bluegill, channel } \\
\text { catfish, black crappie - } \\
\text { adult }\end{array}$ & Lifetime & $\begin{array}{l}\text { Downstream from } \\
\text { WWTP effluent } \\
\text { discharge }\end{array}$ & $\begin{array}{l}\text { Brain; liver; } \\
\text { muscle }\end{array}$ & $\begin{array}{l}4.27 ; 3.59 ; 0.34 \mathrm{ng} \\
\mathrm{g}^{-1}\end{array}$ & (139) \\
\hline & Carp, bream - adult & Lifetime & $\begin{array}{l}\text { Various (WWTP } \\
\text { impacted pond, canal } \\
\text { and river) }\end{array}$ & Fillet, liver & $\begin{array}{l}<\mathrm{LOQ} ;<\mathrm{LOQ}- \\
12 \mathrm{ng} \mathrm{g}^{-1}\end{array}$ & (123) \\
\hline & Yellow catfish - adult & 14 days & $100 \mu \mathrm{g} \mathrm{L}^{-1}$ & $\begin{array}{l}\text { Liver; brain; } \\
\text { muscle }\end{array}$ & $\begin{array}{l}\text { 10633; 19880; } \\
4812 \mathrm{ng} \mathrm{g}^{-1}\end{array}$ & (157) \\
\hline & Roach - adult & 15 days & $\begin{array}{l}47-65 \mathrm{ng} \mathrm{L}^{-1} \\
\text { (effluent) }\end{array}$ & $\begin{array}{l}\text { Plasma; brain ( } 4 \\
\text { regions) }\end{array}$ & $\begin{array}{l}0.5-1 \mathrm{ng} \mathrm{ml}^{-1} ; 9.4 \\
-36 \mathrm{ng} \mathrm{g}^{-1}\end{array}$ & (114) \\
\hline & $\begin{array}{l}\text { Walleye, yellow perch, } \\
\text { lake trout, cisco, black } \\
\text { crappie - adult }\end{array}$ & Lifetime & $\begin{array}{l}\text { Effluent impacted, } \\
\text { developed and } \\
\text { undeveloped sites }\end{array}$ & Whole body & $0.4-1 \mathrm{ng} \mathrm{g}^{-1}$ & (115) \\
\hline
\end{tabular}




\begin{tabular}{|c|c|c|c|c|c|}
\hline Brown trout - adult & Lifetime & $\begin{array}{l}\text { Upstream/downstream } \\
\text { from an effluent } \\
\text { discharge point }\end{array}$ & Fillet; liver & $\mathrm{ND} ; 92 \mathrm{ng} \mathrm{g}^{-1}$ & (142) \\
\hline Rainbow trout - adult & 14 days & Treated effluent & Plasma & $<\mathrm{LOQ}-1.2 \mathrm{ng} \mathrm{ml}^{-}$ & $(158)$ \\
\hline Bull shark - adult & Lifetime & $\begin{array}{l}\text { River (impacted by } \\
\text { WWTP effluent) }\end{array}$ & Plasma & $\mathrm{ND}-0.48 \mathrm{ng} \mathrm{ml}^{-1}$ & (124) \\
\hline Rainbow trout - adult & 13 days & $\begin{array}{l}53 \mathrm{ng} \mathrm{L}^{-1} \text { (treated } \\
\text { effluent) }\end{array}$ & $\begin{array}{l}\text { Liver; brain; } \\
\text { muscle; fillet; } \\
\text { plasma }\end{array}$ & $\begin{array}{l}4.5 ; 9.4 ;<\text { LOQ ng } \\
\mathrm{g}^{-1} ;<\text { LOQ ng ml-1 }\end{array}$ & $(125)$ \\
\hline Brown trout - adult & $1,3,6,18$ months & $\begin{array}{l}\text { Stream (impacted by } \\
\text { WWTP effluent) }\end{array}$ & $\begin{array}{l}\text { Liver; brain; } \\
\text { kidney }\end{array}$ & $\begin{array}{l}<\mathrm{LOQ}-24 ;<\mathrm{LOQ} \\
-15 ;<\mathrm{LOQ}-48 \\
\mathrm{ng} \mathrm{g}^{-1}\end{array}$ & $(126)$ \\
\hline Common carp - adult & Lifetime & Effluent polluted pond & $\begin{array}{l}\text { Liver; kidney; } \\
\text { muscle; brain; } \\
\text { plasma }\end{array}$ & $\begin{array}{l}1.2 ; 1 ; 0.24 ; 5 \\
<\text { LOQ ng g }\end{array}$ & (127) \\
\hline $\begin{array}{l}\text { Common carp, } \\
\text { pikeperch - adult }\end{array}$ & 6 months & $\begin{array}{l}\text { Pond (subject to } \\
\text { reclaimed wastewater) }\end{array}$ & $\begin{array}{l}\text { Liver; kidney; } \\
\text { brain; muscle; } \\
\text { plasma }\end{array}$ & $\begin{array}{l}\text { Carp: } 2.4 ; 1.1 ; 6.7 ; \\
0.18 \mathrm{ng} \mathrm{g}^{-1} ; \mathrm{ND} \text { ng } \\
\mathrm{ml}^{-1} \\
\text { Pikeperch: } 1.4 ; 1.4 ; \\
\text { 2.0; } 0.11 \mathrm{ng} \mathrm{g}^{-1} ; \\
\text { ND ng ml-1 }\end{array}$ & $(128)$ \\
\hline $\begin{array}{l}\text { Smallmouth bass, } \\
\text { largemouth bass, white } \\
\text { sucker, yellow perch, } \\
\text { channel catfish, } \\
\text { common snook, } \\
\text { freshwater drum, } \\
\text { spotted bass - adult }\end{array}$ & Lifetime & $\begin{array}{l}\text { Downstream from } \\
\text { WWTP }\end{array}$ & Fillet & $17.1 \mathrm{ng} \mathrm{g}^{-1}$ & $(130)$ \\
\hline Common carp - adult & 1 month to a year & Effluent impacted pond & Liver & $0.45-61 \mathrm{ng} \mathrm{g}^{-1}$ & $(70)$ \\
\hline Brook trout - adult & 3 months & $1.1 \mathrm{ng} \mathrm{L}^{-1}$ (effluent) & $\begin{array}{l}\text { Brain; liver; } \\
\text { muscle }\end{array}$ & $\begin{array}{l}<\mathrm{LOQ}-0.21 ; 0.1- \\
0.29 ;<\mathrm{LOQ}-0.12 \\
\mathrm{ng} \mathrm{g}^{-1}\end{array}$ & (116) \\
\hline
\end{tabular}




\begin{tabular}{|c|c|c|c|c|c|}
\hline $\begin{array}{l}\text { Chinook salmon, } \\
\text { pacific staghorn } \\
\text { sculpin - adult }\end{array}$ & Lifetime & $\begin{array}{l}\text { WWTP outfalls and } \\
\text { estuary }\end{array}$ & Whole body & $0.2-17 \mathrm{ng} \mathrm{g}^{-1}$ & (62) \\
\hline $\begin{array}{l}\text { Chinook salmon - } \\
\text { adult }\end{array}$ & Lifetime & $\begin{array}{l}89-116 \text { ng L L }^{-1} \\
\text { (effluent) }\end{array}$ & Whole body & $0.68 \mathrm{ng} \mathrm{g}^{-1}$ & $(117)$ \\
\hline $\begin{array}{l}\text { Chinook salmon - } \\
\text { adult }\end{array}$ & Lifetime & $\begin{array}{l}\text { Estuaries (receives } \\
\text { WWTP effluent) }\end{array}$ & Whole body & $4.9 \operatorname{ng~g}^{-1}(\max )$ & $(118)$ \\
\hline $\begin{array}{l}\text { Caged goldfish, wild } \\
\text { goldfish, cootes carp - } \\
\text { adult }\end{array}$ & 21 days & $\begin{array}{l}\text { Caged: river } \\
\text { downstream from } \\
\text { WWTP }\end{array}$ & Plasma & $\begin{array}{l}\text { Caged: } 0.04-0.24 \\
\text { ng g }^{-1}\end{array}$ & (46) \\
\hline & & Wild: marsh & & $\begin{array}{l}\text { Wild: } 0.04-0.13 \\
\text { ng g }^{-1}\end{array}$ & \\
\hline $\begin{array}{l}\text { Zebrafish - embryo- } \\
\text { larvae }\end{array}$ & 96 hours & $10 \mu \mathrm{g} \mathrm{L}^{-1}$ & Whole body & $\begin{array}{l}1130 \text { - } 2280 \mathrm{~L} \mathrm{~kg}^{-1} \\
\text { (BCF only) }\end{array}$ & $(146)$ \\
\hline $\begin{array}{l}\text { Sonora sucker, } \\
\text { largemouth bass, } \\
\text { common carp, bowfin, } \\
\text { white sucker, } \\
\text { smallmouth buffalo - } \\
\text { adult }\end{array}$ & Lifetime & $\begin{array}{l}\text { Effluent dominated } \\
\text { rivers }\end{array}$ & Fillets; Liver & $\begin{array}{l}<\mathrm{MDL}-19 \mathrm{ng} \mathrm{g}^{-1} \\
21-545 \mathrm{ng} \mathrm{g}^{-1}\end{array}$ & (149) \\
\hline White sucker - adult & Lifetime & $\begin{array}{l}\text { Effluent impacted } \\
\text { streams }\end{array}$ & Brain & $\mathrm{ND}-1.8 \mathrm{ng} \mathrm{g}^{-1}$ & (94) \\
\hline $\begin{array}{l}\text { Fathead minnow - } \\
\text { adult }\end{array}$ & 21 days & $1.6,5.2 \mathrm{ng} \mathrm{L}^{-1}$ & Brain & $0.023,0.06 \mathrm{ng} \mathrm{g}^{-1}$ & $(150)$ \\
\hline $\begin{array}{l}\text { Fathead minnow - } \\
\text { adult }\end{array}$ & 2 weeks & $\begin{array}{l}\text { Caged up and } \\
\text { downstream of WWTP }\end{array}$ & Bile; muscle & $\begin{array}{l}0.22-1.14 \mu \mathrm{g} \mathrm{L}^{-1} \\
<\mathrm{LOQ}-2.09 \mathrm{ng} \mathrm{g}^{-}\end{array}$ & $(153)$ \\
\hline $\begin{array}{l}\text { Crucian carp, common } \\
\text { carp and three-lips - } \\
\text { adult }\end{array}$ & Lifetime & $\begin{array}{l}\text { Effluent dominated } \\
\text { stream and lake }\end{array}$ & Plasma; liver;brain & $\begin{array}{l}0.31 \mathrm{ng} \mathrm{ml}^{-1} ; 1.4 ; \\
1.7 \mathrm{ng} \mathrm{g}^{-1}\end{array}$ & $(159)$ \\
\hline $\begin{array}{l}\text { Crucian, common carp } \\
\text { - adult }\end{array}$ & Lifetime & $\begin{array}{l}\text { Wastewater impacted } \\
\text { stream }\end{array}$ & $\begin{array}{l}\text { Brain: liver: } \\
\text { kidney; muscle }\end{array}$ & $\underset{1}{22 ; 17 ; 43 ; 1.6 \mathrm{ng} \mathrm{g}^{-}}$ & $(160)$ \\
\hline $\begin{array}{l}\text { Common carp, crucian } \\
\text { carp, Japanese }\end{array}$ & Lifetime & $\begin{array}{l}\text { Wastewater impacted } \\
\text { stream }\end{array}$ & $\begin{array}{l}\text { Whole body; } \\
\text { plasma }\end{array}$ & $\begin{array}{l}1.3-6.0 \mathrm{ng} \mathrm{g}^{-1} \\
0.11-0.98 \mathrm{ng} \mathrm{ml}^{-1}\end{array}$ & (161) \\
\hline
\end{tabular}




\begin{tabular}{|c|c|c|c|c|c|c|}
\hline & \multicolumn{6}{|l|}{$\begin{array}{l}\text { medaka, mosquitofish } \\
\text { - adult }\end{array}$} \\
\hline & Crucian carp - adult & 7 days & $4.36,21.3,116 \mu \mathrm{g} \mathrm{L}^{-1}$ & $\begin{array}{l}\text { Liver; brain; gill; } \\
\text { muscle }\end{array}$ & $\begin{array}{l}2682-7250 ; 1244 \\
-4411 ; 639- \\
1586 ; 27.7-535 \\
\text { ng g }^{-1} \text { (maximum } \\
\text { concentrations) }\end{array}$ & $(162)$ \\
\hline & $\begin{array}{l}\text { Grass carp, common } \\
\text { carp, crucian carp, } \\
\text { silver carp, bighead } \\
\text { carp, whitebait, yellow } \\
\text { catfish, catfish, loach - } \\
\text { adult }\end{array}$ & Lifetime & River & Whole body & $3.2-18.2 \mathrm{ng} \mathrm{g}^{-1}$ & (134) \\
\hline \multirow[t]{8}{*}{ Venlafaxine } & $\begin{array}{l}\text { Mullet, flounder - } \\
\text { adult }\end{array}$ & Lifetime & Estuaries & Whole body & $<\mathrm{MDL}$ & (121) \\
\hline & $\begin{array}{l}\text { Smallmouth bass, } \\
\text { largemouth bass, rudd, } \\
\text { rock bass, white bass, } \\
\text { white perch, walleye, } \\
\text { bowfin, steel head, } \\
\text { yellow perch - adult }\end{array}$ & Lifetime & $\begin{array}{l}\text { River (impacted by } \\
\text { WWTP effluent) }\end{array}$ & $\begin{array}{l}\text { Brain; gonad; liver; } \\
\text { muscle }\end{array}$ & $\begin{array}{l}\mathrm{ND} ; \mathrm{ND}-5.5 ; \mathrm{ND} \\
-56.8 ; \mathrm{ND}-0.6 \\
\mathrm{ng} \mathrm{g}^{-1}\end{array}$ & $(122)$ \\
\hline & Carp, bream - adult & Lifetime & $\begin{array}{l}\text { Various (WWTP } \\
\text { impacted pond, canal } \\
\text { and river) }\end{array}$ & Fillet, liver & $\begin{array}{l}<\mathrm{LOQ} ;<\mathrm{LOQ}- \\
3.46 \mathrm{ng} \mathrm{g}^{-1}\end{array}$ & $(123)$ \\
\hline & $\begin{array}{l}\text { Bream, roach, chub - } \\
\text { adult }\end{array}$ & Lifetime & $\begin{array}{l}\text { Effluent dominated and } \\
\text { less impacted sites }\end{array}$ & Plasma & $<0.5-11 \mathrm{ng} \mathrm{ml}^{-1}$ & (136) \\
\hline & Roach - adult & 15 days & $\begin{array}{l}295-393 \mathrm{ng} \mathrm{L}^{-1} \\
\text { (effluent) }\end{array}$ & $\begin{array}{l}\text { Plasma; brain ( } 4 \\
\text { regions) }\end{array}$ & $\begin{array}{l}0.017-0.83 \mathrm{ng} \mathrm{ml}^{-} \\
1 ; 3.2-11 \mathrm{ng} \mathrm{g}^{-1}\end{array}$ & (114) \\
\hline & $\begin{array}{l}\text { Walleye, yellow perch, } \\
\text { lake trout, cisco, black } \\
\text { crappie - adult }\end{array}$ & Lifetime & $\begin{array}{l}\text { Effluent impacted, } \\
\text { developed and } \\
\text { undeveloped sites }\end{array}$ & Whole body & $0.2-0.3 \mathrm{ng} \mathrm{g}^{-1}$ & $(115)$ \\
\hline & Bull shark - adult & Lifetime & $\begin{array}{l}\text { River (impacted by } \\
\text { WWTP effluent) }\end{array}$ & Plasma & $\mathrm{BQL}-0.24 \mathrm{ng} \mathrm{ml}^{-1}$ & (124) \\
\hline & Rainbow trout - adult & 13 days & $\begin{array}{l}330 \mathrm{ng} \mathrm{L}^{-1} \text { (treated } \\
\text { effluent) }\end{array}$ & $\begin{array}{l}\text { Liver; brain; } \\
\text { muscle; plasma }\end{array}$ & $\begin{array}{l}21 ; 3.1 ;<\text { LOQ ng } \\
\mathrm{g}^{-1} ; 2.6 \mathrm{ng} \mathrm{ml}^{-1}\end{array}$ & $(125)$ \\
\hline
\end{tabular}




\begin{tabular}{|c|c|c|c|c|c|}
\hline Common carp - adult & Lifetime & Effluent polluted pond & $\begin{array}{l}\text { Liver; kidney; } \\
\text { muscle; brain; } \\
\text { plasma }\end{array}$ & $\begin{array}{l}1.1 ; 3.6 ; 0.22 ; \\
<\text { LOQ; <LOQ ng } \\
\mathrm{g}^{-1}\end{array}$ & $(127)$ \\
\hline $\begin{array}{l}\text { Common carp, } \\
\text { pikeperch - adult }\end{array}$ & 6 months & $\begin{array}{l}\text { Pond (subject to } \\
\text { reclaimed wastewater) }\end{array}$ & $\begin{array}{l}\text { Liver; kidney; } \\
\text { brain; muscle; } \\
\text { plasma }\end{array}$ & $\begin{array}{l}\text { Carp: } 1.4 ; 2.2 ; \mathrm{ND} \text {; } \\
\text { ND ng } \mathrm{g}^{-1} ; 0.25 \mathrm{ng} \\
\mathrm{ml}^{-1} \\
\text { Pikeperch: } 0.42 ; \\
0.78 ; 1.0 ; 0.034 \mathrm{ng} \\
\mathrm{g}^{-1} ; 0.32 \mathrm{ng} \mathrm{ml}^{-1}\end{array}$ & $(128)$ \\
\hline Common carp - adult & Lifetime & River & Homogenate & $0.6 \mathrm{ng} \mathrm{g}^{-1}$ & $(129)$ \\
\hline $\begin{array}{l}\text { Smallmouth bass, } \\
\text { largemouth bass, white } \\
\text { sucker, yellow perch, } \\
\text { channel catfish, } \\
\text { common snook, } \\
\text { freshwater drum, } \\
\text { spotted bass - adult }\end{array}$ & Lifetime & $\begin{array}{l}\text { Downstream from } \\
\text { WWTP }\end{array}$ & Fillet & $4.6 \mathrm{ng} \mathrm{g}^{-1}$ & $(130)$ \\
\hline Common carp - adult & 1 month to a year & Effluent impacted pond & Liver & $0.47-3.9 \mathrm{ng} \mathrm{g}^{-1}$ & $(70)$ \\
\hline Brook trout - adult & 3 months & $38.5 \mathrm{ng} \mathrm{L}^{-1}$ (effluent) & $\begin{array}{l}\text { Brain; liver; } \\
\text { muscle }\end{array}$ & $\begin{array}{l}\mathrm{ND}-0.43 ; \mathrm{ND}- \\
0.69 ; \mathrm{ND}-0.08 \mathrm{ng} \\
\mathrm{g}^{-1}\end{array}$ & $(116)$ \\
\hline Round goby - adult & 28 days & $\begin{array}{l}50 \text { and } 100 \% \text { of } \\
\text { WWTP effluent }\end{array}$ & $\begin{array}{l}\text { Brain; gonad; liver; } \\
\text { muscle; plasma }\end{array}$ & $\begin{array}{l}50 \%: 2.75 ;<\mathrm{LOQ} ; \\
<\mathrm{LOQ} ;<\mathrm{LOQ} \mathrm{ng} \\
\mathrm{g}^{1} ;<\mathrm{LOQ} \mathrm{ng} \mathrm{m} \mathrm{m}^{-1} \\
100 \%: 10.79 ; 1.94 ; \\
0.92 ; 0.90 \mathrm{ng} \mathrm{g}^{-1} ; \\
3.27 \mathrm{ng} \mathrm{ml}^{-1}\end{array}$ & $(132)$ \\
\hline $\begin{array}{l}\text { Golden grey mullet - } \\
\text { adult }\end{array}$ & Lifetime & $\begin{array}{l}\text { Effluent impacted } \\
\text { watercourse }\end{array}$ & Liver & $<\mathrm{LOQ}-3.1 \mathrm{ng} \mathrm{g}^{-1}$ & $(163)$ \\
\hline $\begin{array}{l}\text { Caged goldfish, wild } \\
\text { goldfish, cootes carp - } \\
\text { adult }\end{array}$ & 21 days & $\begin{array}{l}\text { Caged: river } \\
\text { downstream from } \\
\text { WWTP }\end{array}$ & Plasma & $\begin{array}{l}\text { Caged: } 0.04-0.26 \\
\text { ng g }^{-1}\end{array}$ & $(46)$ \\
\hline
\end{tabular}




\begin{tabular}{|c|c|c|c|c|c|}
\hline & & Wild: marsh & & $\begin{array}{l}\text { Wild: } 0.04-0.27 \\
\text { ng g }^{-1}\end{array}$ & \\
\hline $\begin{array}{l}\text { Andalusian barbell, } \\
\text { common carp, trout, } \\
\text { iberian gudgeon, black } \\
\text { bass, mediterranean } \\
\text { barbel, pumpkinseed } \\
\text { sunfish, bleak, eel, } \\
\text { pile, ebro barbell, } \\
\text { european catfish - } \\
\text { adult }\end{array}$ & Lifetime & River basins & Whole body & $\mathrm{ND}-0.63 \mathrm{ng} \mathrm{g}^{-1}$ & (133) \\
\hline Loach - adult & 40 days & $500 \mu \mathrm{g} \mathrm{L}^{-1}$ & Liver & $15 \mathrm{ng} \mathrm{g}^{-1}(\max )$ & (164) \\
\hline White sucker - adult & Lifetime & $\begin{array}{l}\text { Effluent impacted } \\
\text { streams }\end{array}$ & Brain & $\mathrm{ND}-0.1 \mathrm{ng} \mathrm{g}^{-1}$ & (94) \\
\hline $\begin{array}{l}\text { Fathead minnow - } \\
\text { adult }\end{array}$ & 2 weeks & $\begin{array}{l}\text { Caged up and } \\
\text { downstream of WWTP }\end{array}$ & Bile; muscle & $\begin{array}{l}0.30-0.44 \mu \mathrm{g} \mathrm{L}^{-1} \\
;<\mathrm{LOQ}-17 \mathrm{ng} \mathrm{g}^{-1}\end{array}$ & (153) \\
\hline $\begin{array}{l}\text { Headstander, dourado, } \\
\text { streaked prochilod - } \\
\text { adult }\end{array}$ & Lifetime & River & Muscle & $0.21 \mu \mathrm{g} \mathrm{kg}^{-1}$ & $(165)$ \\
\hline
\end{tabular}

*Only aqueous exposures were included (exposure through food or injection were excluded).

*Only bioaccumulation of parent compound are included (metabolites excluded).

*Where no exposure concentration is outlined, this was not given in the paper.

*Graph only - no exact measured concentrations supplied in the paper or supplementary material.

Abbreviations: $\mathrm{ND}=$ not detected; $\mathrm{LOQ}=$ limit of quantification; $\mathrm{MDL}=$ method detection limit; $\mathrm{MQL}=\mathrm{method}$ quantification limit; $\mathrm{BQL}=$ below quantifiable levels. 
Table S5. Summary of in vivo data on sub-lethal effects reported in fish with aqueous antidepressant exposure.

\begin{tabular}{|c|c|c|c|c|c|}
\hline Antidepressant & Species and life stage & Exposure duration & Tested concentrations & $\begin{array}{l}\text { Main endpoints assessed } \\
\text { (where biological effects } \\
\text { were found) }\end{array}$ & Reference \\
\hline \multirow[t]{13}{*}{ Amitriptyline } & $\begin{array}{l}\text { Zebrafish - } \\
\text { embryo/larvae }\end{array}$ & 96 hours & $\begin{array}{l}1,10,100 \text { and } 1000 \\
\mathrm{mg} \mathrm{L}^{-1}\end{array}$ & Locomotor activity & (166) \\
\hline & Zebrafish - adult & 20 minutes & $1,5,10 \mathrm{mg} \mathrm{L}^{-1}$ & $\begin{array}{l}\text { Locomotor activity } \\
\text { (including anxiety-related } \\
\text { parameters) }\end{array}$ & $(167)$ \\
\hline & & & & $\begin{array}{l}\text { Brain monoamine } \\
\text { concentrations }\end{array}$ & \\
\hline & Zebrafish - adult & 20 minutes & $1,1.5,2 \mathrm{mg} \mathrm{L}^{-1}$ & Locomotor activity & $(168)$ \\
\hline & & & & $\begin{array}{l}\text { Brain monoamine } \\
\text { concentrations }\end{array}$ & \\
\hline & Zebrafish - adult & 14 days & $10,50 \mu \mathrm{g} \mathrm{L}^{-1}$ & $\begin{array}{l}\text { Locomotor activity } \\
\text { (including anxiety-related } \\
\text { parameters) }\end{array}$ & (169) \\
\hline & & & & $\begin{array}{l}\text { Brain monoamine } \\
\text { concentrations }\end{array}$ & \\
\hline & $\begin{array}{l}\text { Brown trout - } \\
\text { embryo/larvae }\end{array}$ & 60 days & $300 \mu \mathrm{g} \mathrm{L}^{-1}$ & Hatch rate & $(170)$ \\
\hline & & & & Body length/weight & \\
\hline & & & & Locomotor activity & \\
\hline & & & & AChE activity & \\
\hline & $\begin{array}{l}\text { Common carp - } \\
\text { embryo/larvae }\end{array}$ & 30 days & $10,100,500 \mu \mathrm{g} \mathrm{L}^{-1}$ & Hatch rate & (171) \\
\hline & & & & Development & \\
\hline
\end{tabular}




\begin{tabular}{|c|c|c|c|c|c|}
\hline & & & & $\begin{array}{l}\text { Morphological } \\
\text { abnormalities } \\
\text { Antioxidant and } \\
\text { biotransformation enzyme } \\
\text { activity }\end{array}$ & \\
\hline & $\begin{array}{l}\text { Zebrafish - } \\
\text { embryo/larvae }\end{array}$ & 144 hours & $\begin{array}{l}0.3,3,30,300,3000 \\
\mu \mathrm{g} \mathrm{L}^{-1}\end{array}$ & Hatch rate & $(172)$ \\
\hline & & & & Locomotor activity & \\
\hline & $\begin{array}{l}\text { Zebrafish - } \\
\text { embryo/larvae }\end{array}$ & 144 hours & $30,300 \mu \mathrm{g} \mathrm{L}^{-1}$ & $\begin{array}{l}\text { Antioxidant/detoxification } \\
\text { enzyme mRNA } \\
\text { expression }\end{array}$ & $(173)$ \\
\hline & $\begin{array}{l}\text { Zebrafish - } \\
\text { embryo/larvae }\end{array}$ & 120 hours & $0.1,1,10 \mu \mathrm{g} \mathrm{L}^{-1}$ & Transcriptomic analysis & $(174)$ \\
\hline & $\begin{array}{l}\text { Zebrafish - } \\
\text { embryo/larvae }\end{array}$ & 120 hours & $\begin{array}{l}1,10,100 \mathrm{ng} \mathrm{L}^{-1}, 1,10 \\
100 \mu \mathrm{g} \mathrm{L}^{-1}, 1 \mathrm{mg} \mathrm{L}^{-1}\end{array}$ & Hatch rate & $(175)$ \\
\hline & & & & Body length & \\
\hline & & & & $\begin{array}{l}\text { Antioxidant and oxidative } \\
\text { stress parameters }\end{array}$ & \\
\hline & & & & NO and TNOS activity & \\
\hline & Gilt-head bream & 7 days & $0.2 \mu \mathrm{g} \mathrm{L}^{-1}$ & Metabolic profiles & (176) \\
\hline Citalopram & $\begin{array}{l}\text { Zebrafish - } \\
\text { embryo/larvae }\end{array}$ & 140 hours & $\begin{array}{l}31,125,500,2000 \\
8000 \mu \mathrm{g} \mathrm{L}^{-1}\end{array}$ & Locomotor activity & (177) \\
\hline & Japanese medaka & 72 hours & $\begin{array}{l}10,100,1000,10000 \\
\mu \mathrm{g} \mathrm{L}^{-1}\end{array}$ & $\begin{array}{l}\text { Locomotor activity } \\
\text { (including anxiety-related } \\
\text { parameters) }\end{array}$ & $(178)$ \\
\hline & Zebrafish - adult & 5 minutes & $30,50,100 \mathrm{mg} \mathrm{L}^{-1}$ & $\begin{array}{l}\text { Locomotor activity } \\
\text { (including anxiety-related } \\
\text { parameters) }\end{array}$ & (179) \\
\hline & $\begin{array}{l}\text { Zebrafish - } \\
\text { embryo/larvae }\end{array}$ & 94 hours & $10,20,50 \mu \mathrm{M}$ & Bone mineralisation & $(180)$ \\
\hline & & & & Bone calcification & \\
\hline
\end{tabular}


Osteoblastic and apoptotic gene regulation

\begin{tabular}{|c|c|c|c|c|}
\hline & & & & \\
\hline $\begin{array}{l}\text { Three-spined } \\
\text { stickleback - adult }\end{array}$ & 10 or 20 days & $0.15,1.5 \mu \mathrm{g} \mathrm{L}^{-1}$ & $\begin{array}{l}\text { Response to simulated } \\
\text { predator (locomotor } \\
\text { activity) }\end{array}$ & $(181)$ \\
\hline $\begin{array}{l}\text { Three-spined } \\
\text { stickleback - adult }\end{array}$ & 3 weeks & $0.15,1.5 \mu \mathrm{g} \mathrm{L}^{-1}$ & Feeding & (182) \\
\hline $\begin{array}{l}\text { Three-spined } \\
\text { stickleback - adult }\end{array}$ & 21 days & $1.5,15 \mu \mathrm{g} \mathrm{L}^{-1}$ & $\begin{array}{l}\text { Locomotor activity } \\
\text { (including anxiety-related } \\
\text { parameters) }\end{array}$ & (183) \\
\hline & & & Boldness & \\
\hline Three-spined & 30 days & $1.5 \mu \mathrm{g} \mathrm{L}^{-1}$ & Feeding & (184) \\
\hline embryo/larvae & & & Aggression & \\
\hline & & & $\begin{array}{l}\text { Locomotor activity } \\
\text { (including anxiety-related } \\
\text { parameters) }\end{array}$ & \\
\hline Three-spined & 3 weeks & $350-380 \mathrm{ng} \mathrm{L}^{-1}$ & Feeding & (185) \\
\hline & & & Aggression & \\
\hline & & & Boldness & \\
\hline Endler guppy & 28 days & $0.2,2.3 .15 \mu \mathrm{g} \mathrm{L}^{-1}$ & $\begin{array}{l}\text { Locomotor activity } \\
\text { (including anxiety-related } \\
\text { parameters) }\end{array}$ & (186) \\
\hline Zebrafish - adult & 14 days & $0.1,0.4 \mu \mathrm{g} \mathrm{L}^{-1}$ & $\begin{array}{l}\text { Locomotor activity } \\
\text { (including anxiety-related } \\
\text { parameters) }\end{array}$ & (187) \\
\hline & & & Shoaling & \\
\hline Zebrafish - adult & 2 or 4 weeks & $4,40,100 \mu \mathrm{g} \mathrm{L}-1$ & Spermatogenesis & (188) \\
\hline
\end{tabular}




\begin{tabular}{|c|c|c|c|c|c|}
\hline & & & & $\begin{array}{l}\text { Expression levels of } \\
\text { GnRH, gonadotropins and } \\
\text { 5-HT related genes }\end{array}$ & \\
\hline & Zebrafish - adult & 3 minutes & $10 \mathrm{mg} \mathrm{L}^{-1}$ & $\begin{array}{l}\text { Locomotor activity } \\
\text { (including anxiety-related } \\
\text { parameters) }\end{array}$ & (189) \\
\hline & $\begin{array}{l}\text { Zebrafish and fathead } \\
\text { minnows - } \\
\text { embryo/larvae }\end{array}$ & 96 hours & $\begin{array}{l}1.92,3.84,7.68,15.36 \\
\mathrm{mg} \mathrm{L}^{-1} \text { and } 0.465,0.93 \text {, } \\
1.86,3.72 \mathrm{mg} \mathrm{L}^{-1}\end{array}$ & Locomotor activity & (190) \\
\hline & $\begin{array}{l}\text { Brown trout - } \\
\text { larvae/juvenile }\end{array}$ & 5 months or 4 weeks & $1,10,100,1000 \mu \mathrm{g} \mathrm{L}^{-1}$ & $\begin{array}{l}\text { Body length and weight } \\
\text { Locomotor activity } \\
\text { (including anxiety-related } \\
\text { parameters) }\end{array}$ & (135) \\
\hline & $\begin{array}{l}\text { Brown trout - } \\
\text { larvae/juvenile }\end{array}$ & 5 months or 4 weeks & $1,10,100,1000 \mu \mathrm{g} \mathrm{L}^{-1}$ & $\begin{array}{l}\text { Liver health } \\
\text { Energy storage }\end{array}$ & (191) \\
\hline & $\begin{array}{l}\text { Zebrafish - } \\
\text { embryo/larvae }\end{array}$ & 96 hours & $\begin{array}{l}25,50,100,200,400 \\
\mathrm{mg} \mathrm{L}^{-1}\end{array}$ & Tail coiling & (192) \\
\hline & & & & Cardiovascular toxicity & \\
\hline & & & & Physical deformities & \\
\hline & $\begin{array}{l}\text { Zebrafish - } \\
\text { embryo/larvae }\end{array}$ & 107 hours & $\begin{array}{l}0.01,1.2,12.3,123.4 \\
\mu \mathrm{M}\end{array}$ & Locomotor activity & (193) \\
\hline Clomipramine & $\begin{array}{l}\text { Common carp - } \\
\text { embryo/larvae }\end{array}$ & 30 days & $10,100,500 \mu \mathrm{g} \mathrm{L}^{-1}$ & Hatch rate & $(171)$ \\
\hline & & & & Development & \\
\hline & & & & $\begin{array}{l}\text { Morphological } \\
\text { abnormalities }\end{array}$ & \\
\hline & & & & $\begin{array}{l}\text { Antioxidant and } \\
\text { biotransformation enzyme } \\
\text { activity }\end{array}$ & \\
\hline
\end{tabular}




\begin{tabular}{|c|c|c|c|c|c|}
\hline & $\begin{array}{l}\text { Zebrafish - } \\
\text { embryo/larvae }\end{array}$ & 24 hours & $\begin{array}{l}0.1,1,10,100,1000 \\
\mu \mathrm{M}\end{array}$ & Cardiovascular toxicity & (194) \\
\hline Duloxetine & $\begin{array}{l}\text { Zebrafish - } \\
\text { embryo/larvae }\end{array}$ & 5 days & $0.01,0.1,1,10 \mu \mathrm{g} \mathrm{L}^{-1}$ & $\begin{array}{l}\text { Locomotor activity } \\
\text { (including anxiety-related } \\
\text { parameters) }\end{array}$ & (195) \\
\hline Escitalopram & Zebrafish - adult & 3 weeks & $0.15,1.5 \mu \mathrm{g} \mathrm{L}^{-1}$ & $\begin{array}{l}\text { Body length and weight } \\
\text { Locomotor activity } \\
\text { (including anxiety-related } \\
\text { parameters) }\end{array}$ & (196) \\
\hline \multirow[t]{12}{*}{ Fluoxetine } & Zebrafish - adult & 15 minutes & $1,25,50 \mu \mathrm{g} \mathrm{L}^{-1}$ & Cortisol levels & (197) \\
\hline & Zebrafish - adult & 30 or 75 minutes & $1 \mu \mathrm{g} \mathrm{L}^{-1}$ & Cortisol levels & (198) \\
\hline & & & & $\begin{array}{l}\text { Sodium/potassium ion } \\
\text { influx }\end{array}$ & \\
\hline & & & & Stress response & \\
\hline & Zebrafish - adult & 15 minutes & $50 \mu \mathrm{g} \mathrm{L}^{-1}$ & Cortisol levels & (199) \\
\hline & $\begin{array}{l}\text { Zebrafish - } \\
\text { embryo/larvae }\end{array}$ & 24 hours & $4.6 \mu \mathrm{M}$ & Locomotor activity & $(200)$ \\
\hline & & & & $\begin{array}{l}\text { Monoamine } \\
\text { receptor/transporter } \\
\text { transcript levels }\end{array}$ & \\
\hline & Goldfish - adult & 5 weeks & $100 \mu \mathrm{g} \mathrm{L}^{-1}$ & $\begin{array}{l}\text { Locomotor activity } \\
\text { (including anxiety-related } \\
\text { parameters) }\end{array}$ & (201) \\
\hline & Gulf toadfish & $15 \pm 1.5$ days & $0.01,8.5 \mu \mathrm{g} \mathrm{L}^{-1}$ & Monoamine concentration & (202) \\
\hline & $\begin{array}{l}\text { Murry-Darling } \\
\text { rainbowfish - adult }\end{array}$ & 4 days & $1,100 \mu \mathrm{g} \mathrm{L}^{-1}$ & E2 plasma levels & (203) \\
\hline & & & & $\begin{array}{l}\text { mRNA levels in the liver } \\
\text { and ovaries }\end{array}$ & \\
\hline & $\begin{array}{l}\text { Arabian killifish - } \\
\text { adult }\end{array}$ & 7 days & $0.03,0.3,3 \mu \mathrm{g} \mathrm{L}^{-1}$ & Chasing behaviour & (204) \\
\hline
\end{tabular}


Locomotor activity

(including anxiety-related

parameters)

\begin{tabular}{|c|c|c|c|c|}
\hline Mosquitofish - adult & 30 days & $40,400 \mathrm{ng} \mathrm{L}^{-1}$ & Mating attempts & $(205)$ \\
\hline & & & Sperm count & \\
\hline $\begin{array}{l}\text { Zebrafish - } \\
\text { embryo/larvae }\end{array}$ & 11 days & $100 \mathrm{ng} \mathrm{L}^{-1}$ & Cardiovascular toxicity & (206) \\
\hline Topmouth gudgeon - & 42 days & $50,200 \mu \mathrm{g} \mathrm{L}^{-1}$ & Lipid peroxidation & (207) \\
\hline & & & EROD activity & \\
\hline & & & Intestine protease activity & \\
\hline & & & Hepatosomatic index & \\
\hline $\begin{array}{l}\text { Zebrafish - } \\
\text { embryo/larvae }\end{array}$ & 80 hours & $\begin{array}{l}0.0015,0.05,0.1,0.5 \\
0.8 \mu \mathrm{M}\end{array}$ & Development & (208) \\
\hline & & & $\begin{array}{l}\text { Morphological } \\
\text { abnormalities }\end{array}$ & \\
\hline & & & $\begin{array}{l}\text { Detoxification gene } \\
\text { expression }\end{array}$ & \\
\hline $\begin{array}{l}\text { Zebrafish - } \\
\text { embryo/larvae }\end{array}$ & 80 hours & $\begin{array}{l}0.0015,0.05,0.1,0.5 \\
0.8 \mu \mathrm{M}\end{array}$ & $\begin{array}{l}\text { Monoamine } \\
\text { receptor/transporter } \\
\text { transcript levels }\end{array}$ & $(209)$ \\
\hline
\end{tabular}




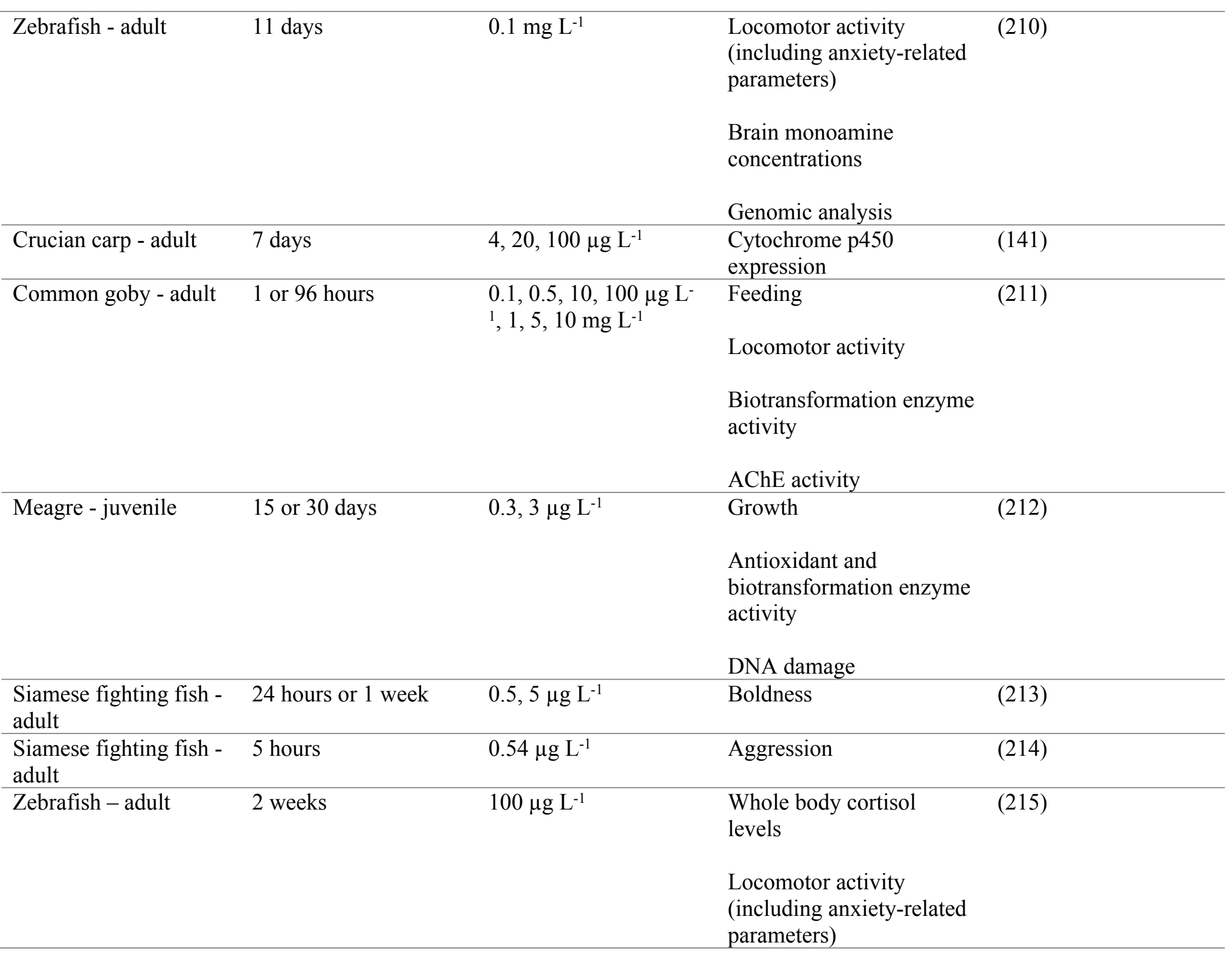




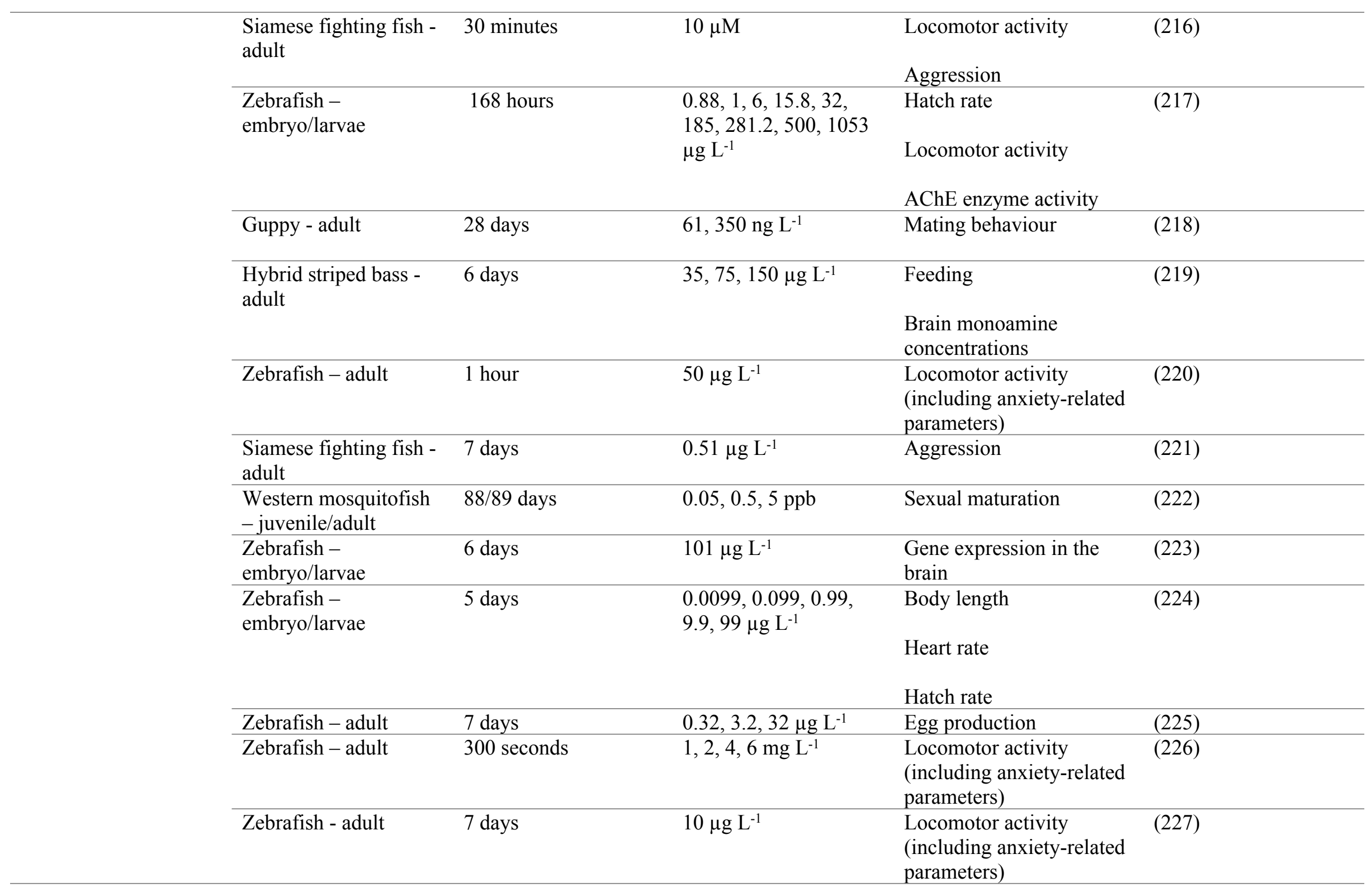




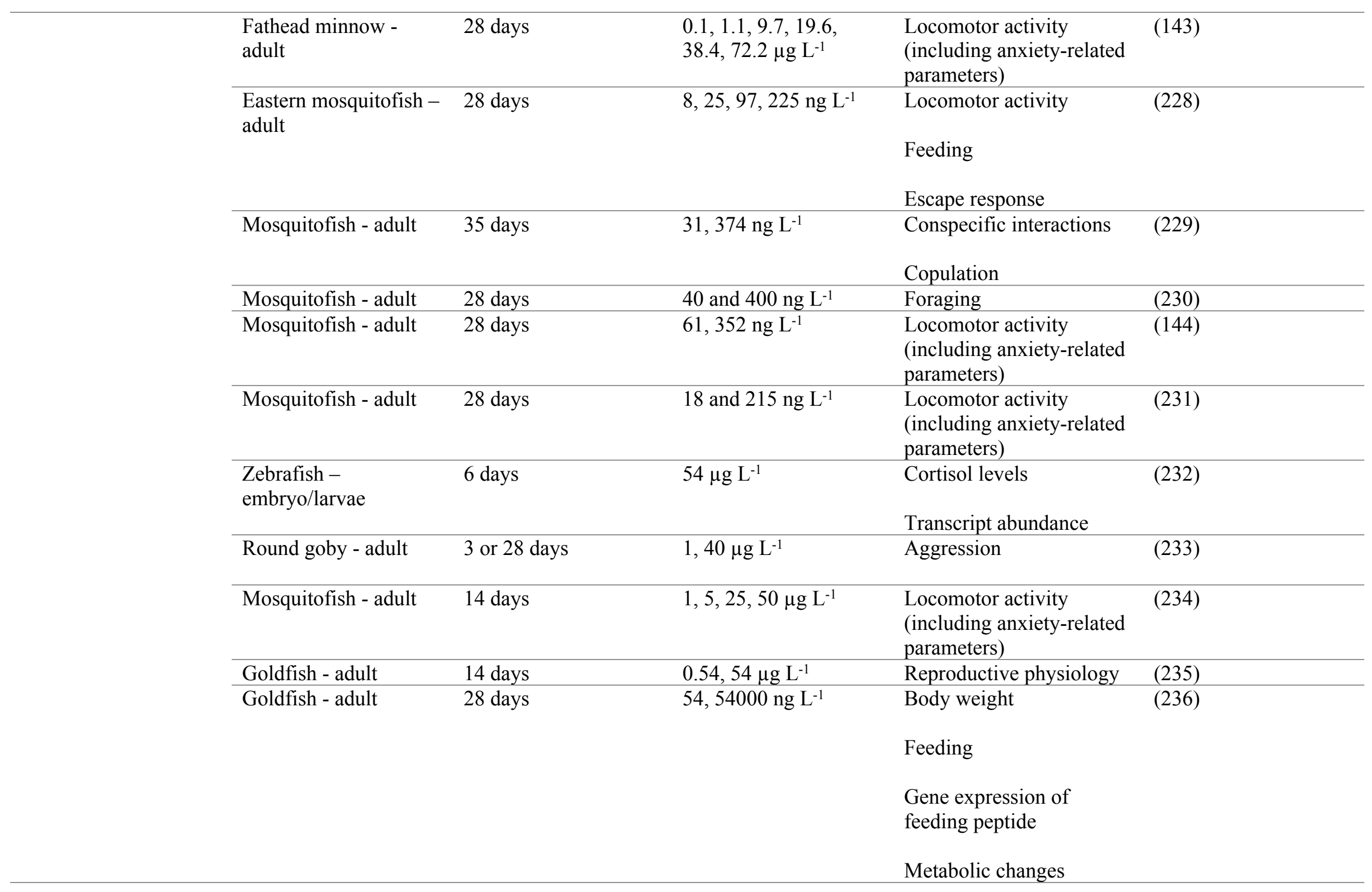




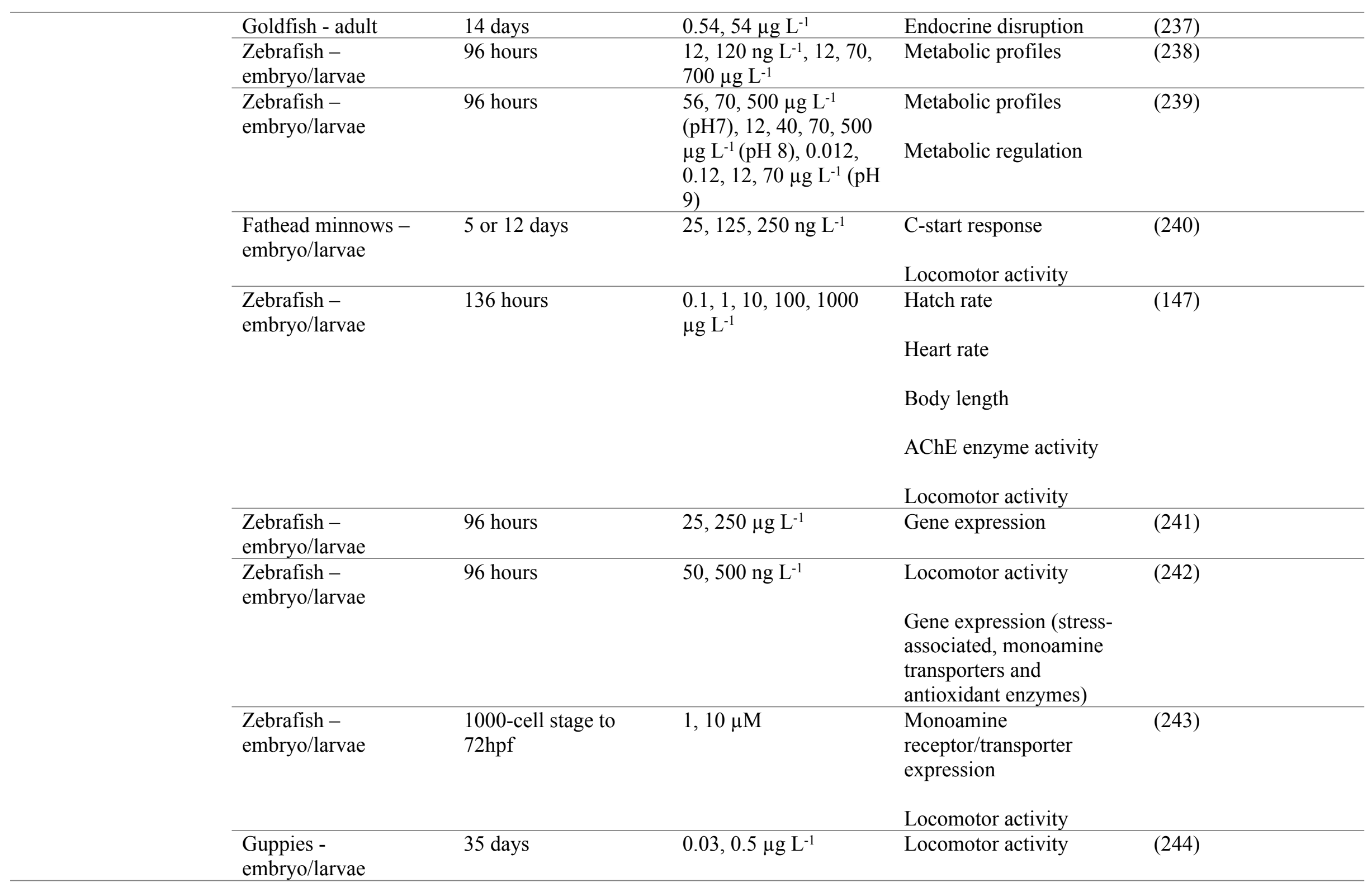


Development

Predator evasion

\begin{tabular}{|c|c|c|c|c|}
\hline & & & & \\
\hline Wild guppies - adult & 28 days & $4,16 \mathrm{ng} \mathrm{L}^{-1}$ & Boldness & (245) \\
\hline & & & Locomotor activity & \\
\hline Zebrafish - juvenile & 20 minutes & $2.8 \mu \mathrm{M}$ & Engagement & (246) \\
\hline Zebrafish - adult & 4 weeks & $\begin{array}{l}5,10,50,100,500 \\
1000,5000 \mathrm{ng} \mathrm{L}^{-1}\end{array}$ & Locomotor activity & (247) \\
\hline Zebrafish - adult & 3 minutes & $10 \mathrm{mg} \mathrm{L}^{-1}$ & $\begin{array}{l}\text { Locomotor activity } \\
\text { (including anxiety-related } \\
\text { parameters) }\end{array}$ & (248) \\
\hline Zebrafish - adult & 3 hours & $0.25 \mathrm{mg} \mathrm{L}^{-1}$ & $\begin{array}{l}\text { Locomotor activity } \\
\text { (including anxiety-related } \\
\text { parameters) }\end{array}$ & (249) \\
\hline & & & $\begin{array}{l}\text { Brain monoamine } \\
\text { concentrations }\end{array}$ & \\
\hline $\begin{array}{l}\text { Fathead minnow - } \\
\text { adult }\end{array}$ & 7 days & $\begin{array}{l}1,10,50,100,250 \mu \mathrm{g} \\
\mathrm{L}^{-1}\end{array}$ & Feeding & $(250)$ \\
\hline & & & Growth & \\
\hline Guppy - adult & 15 months & $30,300 \mathrm{ng} \mathrm{L}^{-1}$ & Individual variation & (251) \\
\hline & & & Metabolic rate & \\
\hline Zebrafish - adult & 2 hours & $5 \mathrm{mg} \mathrm{L}^{-1}$ & Aggression & (252) \\
\hline & & & Cortisol levels & \\
\hline $\begin{array}{l}\text { Fathead minnow - } \\
\text { adult }\end{array}$ & 14 days & $10,50,100 \mu \mathrm{g} \mathrm{L}^{-1}$ & $\begin{array}{l}\text { Gene expression } \\
\text { (neuronal development, } \\
\text { regulation and growth) }\end{array}$ & (253) \\
\hline & & & $\begin{array}{l}\text { Locomotor activity } \\
\text { (predator avoidance) }\end{array}$ & \\
\hline $\begin{array}{l}\text { Killlifish - } \\
\text { embryo/adult }\end{array}$ & 14 weeks & $0.7,5.3 \mu \mathrm{g} \mathrm{L}^{-1}$ & Body size & (254) \\
\hline
\end{tabular}


Mating frequency

Egg production

\begin{tabular}{|c|c|c|c|c|}
\hline & & & Sociality & \\
\hline \multirow[t]{4}{*}{ Turquoise killifish } & Full life cycle & $0.5 \mu \mathrm{g} \mathrm{L}^{-1}$ & Growth & $(255)$ \\
\hline & & & Fecundity & \\
\hline & & & $\begin{array}{l}\text { Locomotor activity } \\
\text { (including anxiety-related } \\
\text { parameters) }\end{array}$ & \\
\hline & & & Feeding & \\
\hline Cichlids - adult & 2 weeks & $50 \mu \mathrm{g} \mathrm{L}^{-1}$ & $\begin{array}{l}\text { Macrophage activity in } \\
\text { the spleen and kidney }\end{array}$ & $(256)$ \\
\hline \multirow{4}{*}{$\begin{array}{l}\text { Zebrafish - } \\
\text { embryo/larvae }\end{array}$} & 6 days & $0.54,54 \mu \mathrm{g} \mathrm{L}^{-1}$ & Transgenerational effects & (257) \\
\hline & & & Cortisol levels & \\
\hline & & & $\begin{array}{l}\text { Locomotor activity } \\
\text { (including anxiety-related } \\
\text { parameters) }\end{array}$ & \\
\hline & & & $\begin{array}{l}\text { Cortisol-related biological } \\
\text { pathways }\end{array}$ & \\
\hline \multirow{3}{*}{$\begin{array}{l}\text { Zebrafish - } \\
\text { embryo/larvae }\end{array}$} & 6 days & $0.54,54 \mu \mathrm{g} \mathrm{L}^{-1}$ & Cortisol levels & $(258)$ \\
\hline & & & $\begin{array}{l}\text { Expression of stress- } \\
\text { related genes }\end{array}$ & \\
\hline & & & Multigenerational effects & \\
\hline \multirow{2}{*}{$\begin{array}{l}\text { Fathead minnow - } \\
\text { adult }\end{array}$} & 4 weeks & $0.1,1,10,100 \mu \mathrm{g} \mathrm{L}^{-1}$ & Feeding & (259) \\
\hline & & & Predator evasion & \\
\hline
\end{tabular}




\begin{tabular}{|c|c|c|c|c|c|}
\hline & & & & Mating behaviour & \\
\hline & & & & Nest attendance & \\
\hline & & & & Reproduction (eggs laid) & \\
\hline & Guppy - adult & 15 months & $38,312 \mathrm{ng} \mathrm{L}^{-1}$ & Mating behaviour & $(260)$ \\
\hline & $\begin{array}{l}\text { Sheepshead minnow - } \\
\text { juvenile/adult }\end{array}$ & 56 hours & $0.3,3,30,300 \mu \mathrm{g} \mathrm{L}^{-1}$ & Locomotor activity & (261) \\
\hline & Zebrafish - adult & 7 or 12 days & $100 \mu \mathrm{g} \mathrm{L}^{-1}$ & $\begin{array}{l}\text { Locomotor activity } \\
\text { (including anxiety-related } \\
\text { parameters) }\end{array}$ & $(262)$ \\
\hline & & & & $\begin{array}{l}\text { Differential gene } \\
\text { expression in the brain }\end{array}$ & \\
\hline & $\begin{array}{l}\text { Zebrafish - } \\
\text { embryo/larvae }\end{array}$ & 120 hours & $0.1,1,10 \mu \mathrm{g} \mathrm{L}^{-1}$ & Transcriptomic analysis & (174) \\
\hline & & & & Body length & \\
\hline & Crucian carp & 7 or 14 days & $100 \mathrm{ng} \mathrm{L}^{-1}$ & $\begin{array}{l}\text { Monoamine } \\
\text { receptor/transporter } \\
\text { expression }\end{array}$ & $(155)$ \\
\hline & & & & AChE enzyme activity & \\
\hline & & & & $\begin{array}{l}\text { Metabolomics gene } \\
\text { expression }\end{array}$ & \\
\hline & $\begin{array}{l}\text { Zebrafish - } \\
\text { embryo/larvae }\end{array}$ & 47 or 96 hours & $\begin{array}{l}3,6,8,10,12,24,48 \\
\mathrm{mg} \mathrm{L}^{-1}\end{array}$ & Tail coiling & (192) \\
\hline & & & & Cardiovascular toxicity & \\
\hline & & & & $\begin{array}{l}\text { Morphological } \\
\text { deformations }\end{array}$ & \\
\hline & $\begin{array}{l}\text { Zebrafish - } \\
\text { embryo/larvae }\end{array}$ & 107 hours & $\begin{array}{l}0.001,0.1,1.4,14.5 \\
\mu \mathrm{M}\end{array}$ & Locomotor activity & (193) \\
\hline Nortriptyline & Zebrafish - adult & 7 days & $0.01 \mathrm{mg} \mathrm{L}^{-1}$ & Cortisol levels & (227) \\
\hline
\end{tabular}




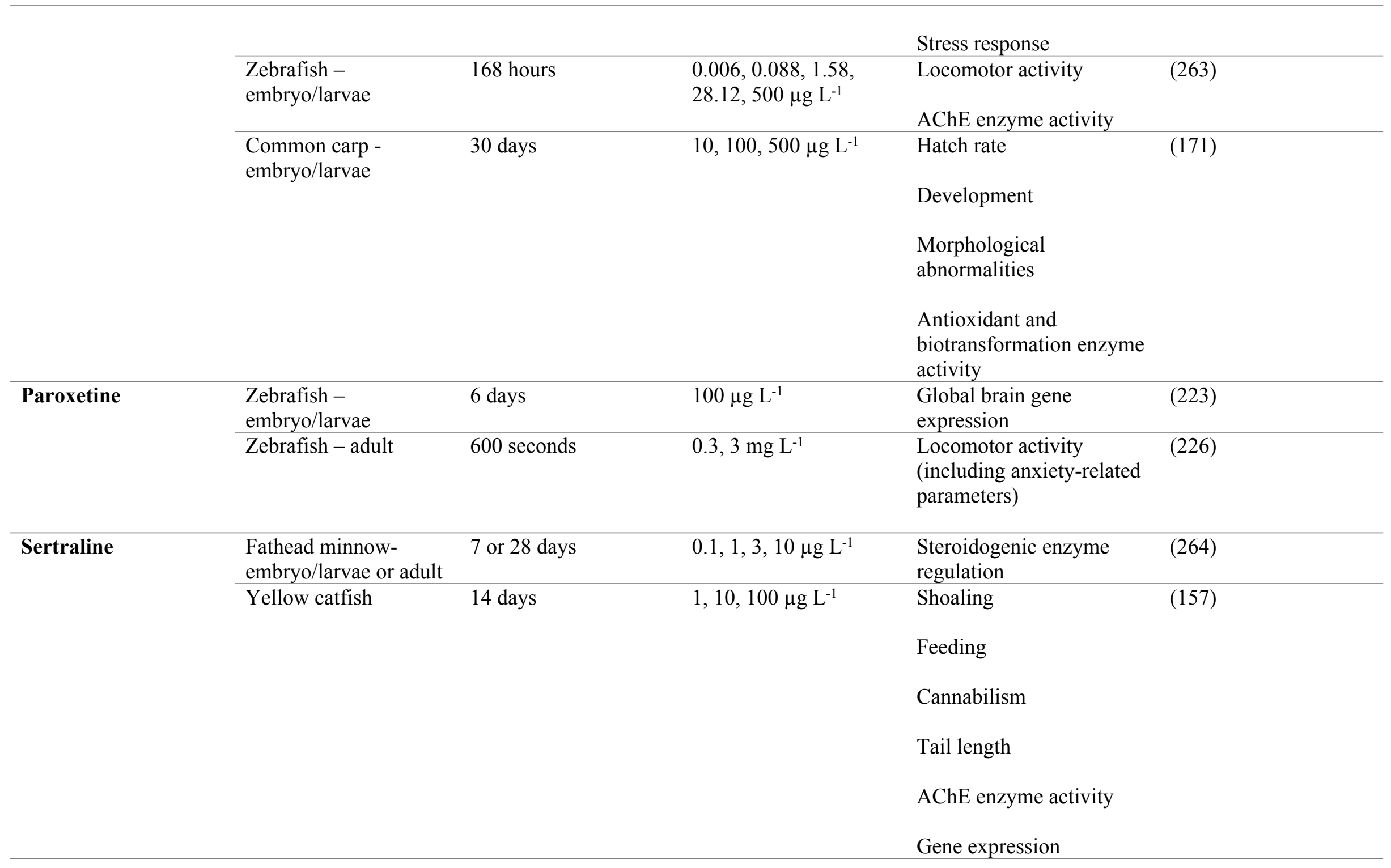




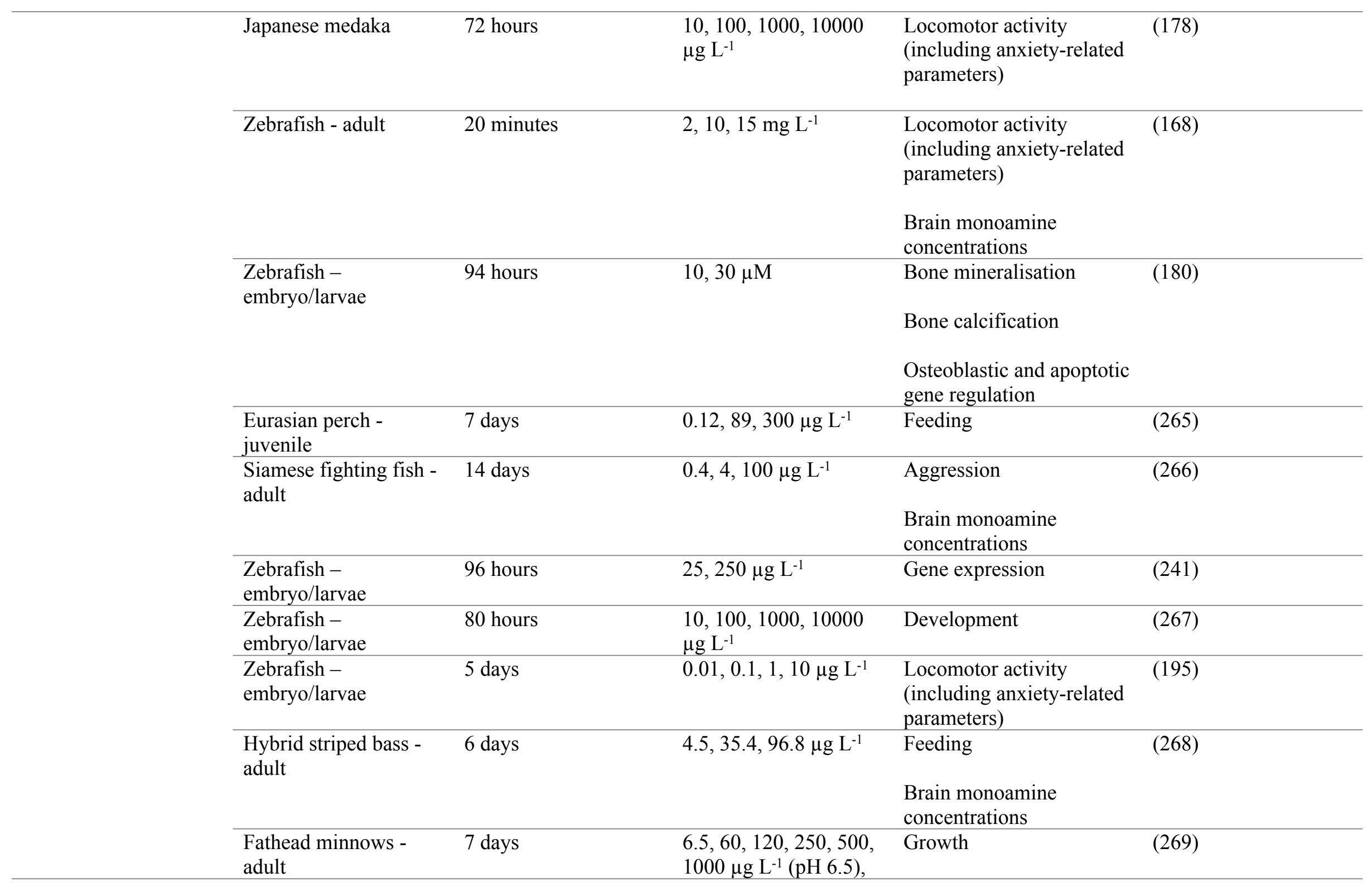




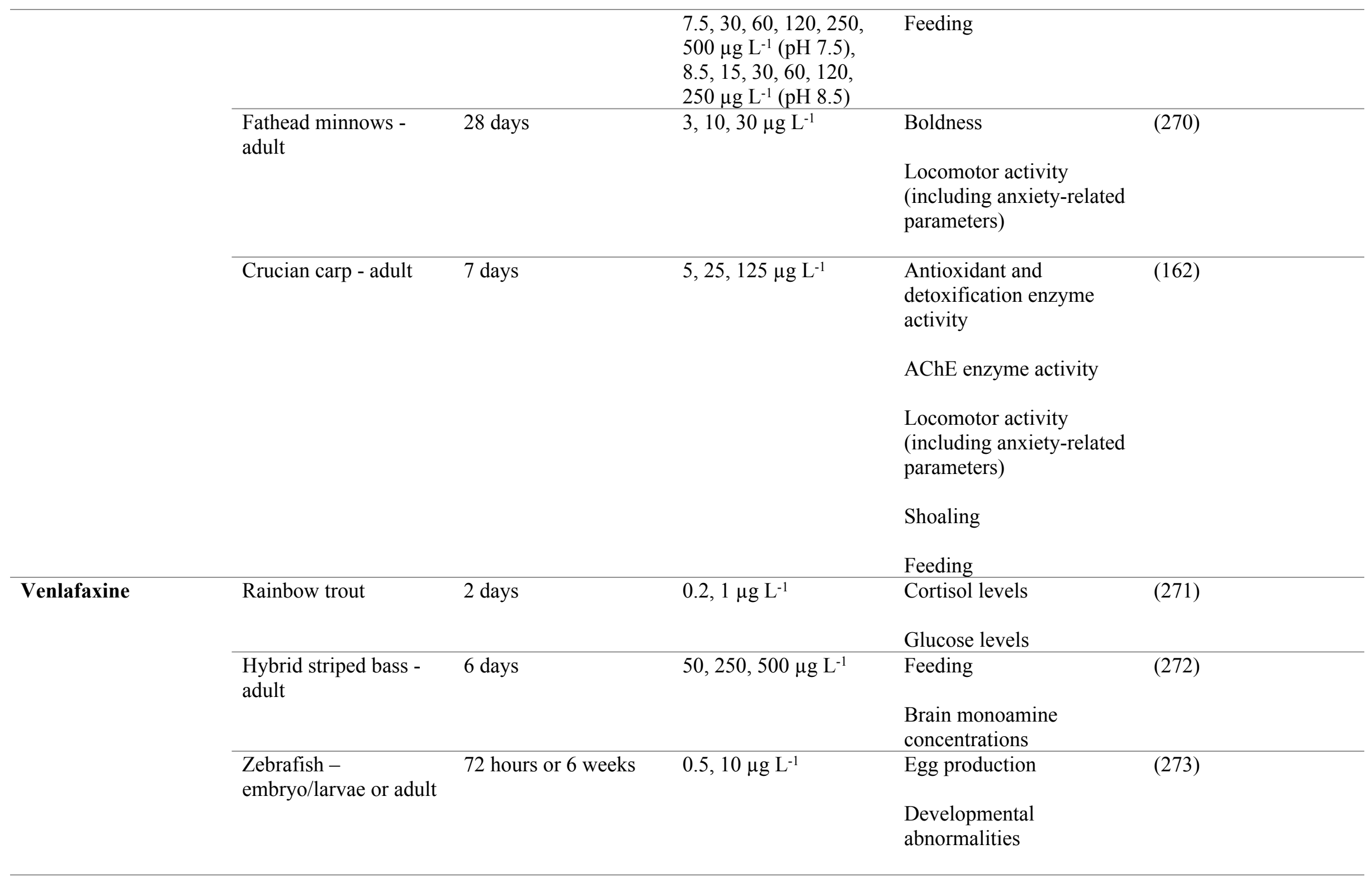




\begin{tabular}{|c|c|c|c|c|}
\hline & & & Histopathological changes & \\
\hline $\begin{array}{l}\text { Zebrafish - } \\
\text { embryo/larvae }\end{array}$ & 144 hours & $0.3,30 \mu \mathrm{g} \mathrm{L}^{-1}$ & $\begin{array}{l}\text { Biotransformation enzyme } \\
\text { gene expression }\end{array}$ & $(274)$ \\
\hline Zebrafish - adult & 21 days & $1 \mu \mathrm{g} \mathrm{L}^{-1}$ & $\begin{array}{l}\text { MicroRNA levels in } \\
\text { reproductive tissue }\end{array}$ & $(275)$ \\
\hline Rainbow trout - adult & 24 hours & $100,1000 \mathrm{nM}$ & Glucose production & $(276)$ \\
\hline Meagre - adult & 28 days & $20 \mu \mathrm{g} \mathrm{L}^{-1}$ & $\begin{array}{l}\text { Locomotor activity } \\
\text { (including anxiety-related } \\
\text { parameters) } \\
\text { Shoaling }\end{array}$ & $(277)$ \\
\hline Rainbow trout - adult & 7 days & $0.2,1 \mu \mathrm{g} \mathrm{L}^{-1}$ & $\begin{array}{l}\text { Brain monoamine } \\
\text { concentrations } \\
\text { Feeding } \\
\text { Cortisol levels }\end{array}$ & $(278)$ \\
\hline Mosquitofish & 7 days & $1,10,100 \mu \mathrm{g} \mathrm{L}^{-1}$ & $\begin{array}{l}\text { Circadian rhythm } \\
\text { Locomotor activity }\end{array}$ & $(279)$ \\
\hline $\begin{array}{l}\text { Fathead minnows - } \\
\text { embryo/larvae }\end{array}$ & 5 or 12 days & $500,2500,5000 \mathrm{ng} \mathrm{L}^{-1}$ & $\begin{array}{l}\text { C-start response } \\
\text { Locomotor activity }\end{array}$ & $(240)$ \\
\hline $\begin{array}{l}\text { Fathead minnows - } \\
\text { embryo/larvae to adult }\end{array}$ & 168 days & $1,9.3,75 \mu \mathrm{g} \mathrm{L}^{-1}$ & Egg production & $(280)$ \\
\hline $\begin{array}{l}\text { Fathead minnows - } \\
\text { embryo/larvae to adult }\end{array}$ & 168 days & $0.88,8.8,88 \mu \mathrm{g} \mathrm{L}^{-1}$ & Nest-defence & $(281)$ \\
\hline $\begin{array}{l}\text { White seabream - } \\
\text { larvae }\end{array}$ & 48 hours & $10,100 \mu \mathrm{g} \mathrm{L}^{-1}$ & Feeding & $(282)$ \\
\hline $\begin{array}{l}\text { Zebrafish - } \\
\text { embryo/larvae }\end{array}$ & 80 hours & $\begin{array}{l}16,80,400,2000, \\
10000 \mu \mathrm{g} \mathrm{L}^{-1}\end{array}$ & $\begin{array}{l}\text { Morphological } \\
\text { abnormalities } \\
\text { Monoamine } \\
\text { receptors/transporter } \\
\text { expression }\end{array}$ & $(283)$ \\
\hline
\end{tabular}




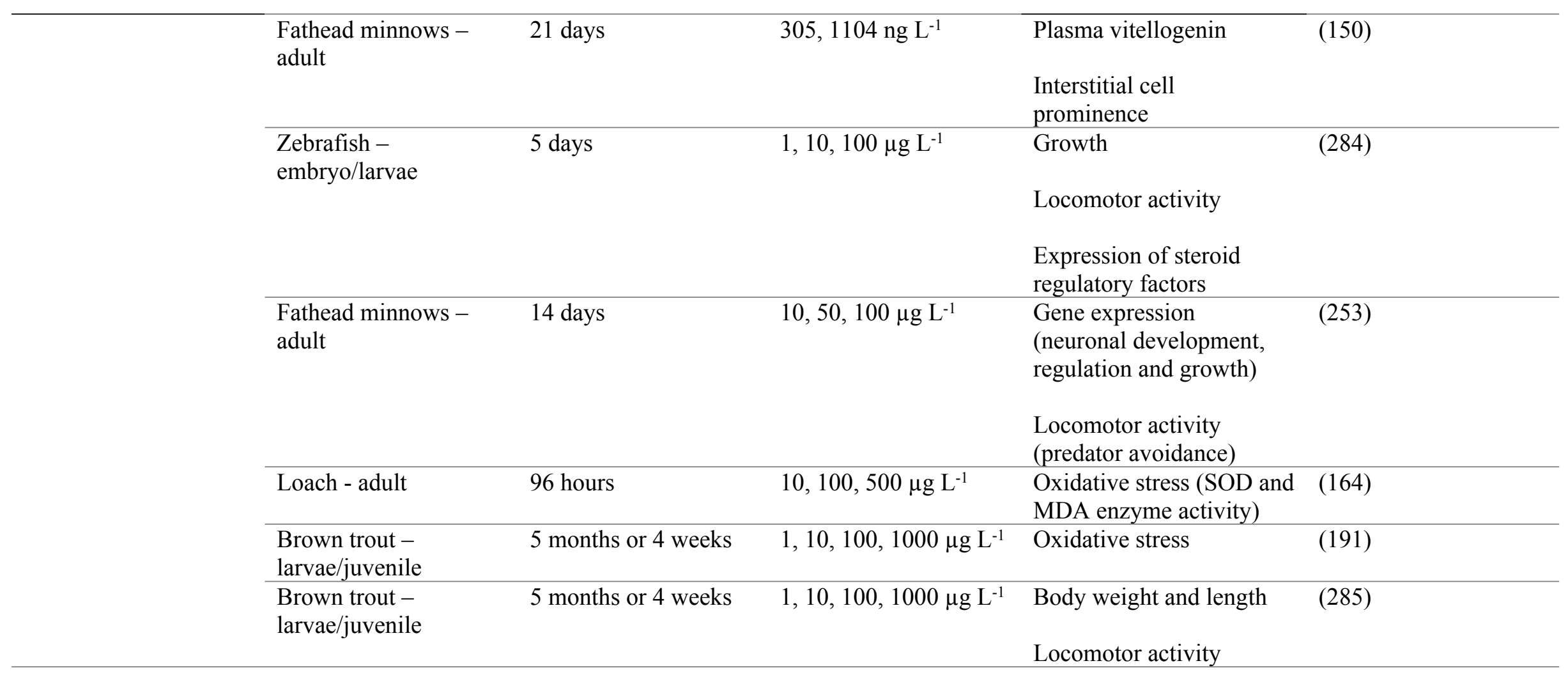


Table S6. Risk quotient calculations for assessing potential risk of antidepressant exposure in fish. Risk quotients were calculated by dividing the highest reported Measured Environmental Concentration (MEC) for: amitriptyline ${ }^{3}$, venlafaxine ${ }^{93}$, sertraline $e^{93}$, fluoxetine ${ }^{99}$, citalopram ${ }^{46}$, clomipramine ${ }^{48}$, nortriptyline ${ }^{58}$, duloxetine ${ }^{93}$, paroxetine ${ }^{286}$ and escitalopram ${ }^{57}$, with the No Observed Effect Concentration (NOEC) reported for fish. Effects were classified as being either physiological or behavioural and if multiple effects from either grouping were reported in the same study, the lowest NOEC was used to calculate the RQ. Where values are stated to be ' $<$ ' this is where effects were reported at the lowest tested concentration and therefore an exact NOEC could not be calculated. Only studies whereby fish were subjected to aqueous exposure were used (excluded those where drug was administrated via intraperitoneal injection or feed).

\begin{tabular}{|c|c|c|c|c|c|c|}
\hline Compound & $\operatorname{MEC~}\left(\mu \mathrm{g} \mathrm{L}^{-1}\right)$ & $\operatorname{NOEC}\left(\mu \mathrm{g} \mathrm{L}^{-1}\right)$ & Risk Quotient & Median RQ & $\begin{array}{l}\text { Category of } \\
\text { effect }\end{array}$ & Reference \\
\hline Amitriptyline & 0.196 & $\begin{array}{r}<2000 \\
<1000 \\
<5000 \\
<1000 \\
<1000 \\
<10 \\
<10 \\
<300 \\
<300 \\
<10 \\
30 \\
30 \\
<30 \\
<1 \\
<0.001 \\
<0.2\end{array}$ & $\begin{array}{r}0.000098 \\
0.000196 \\
0.0000392 \\
0.000196 \\
0.000196 \\
0.0196 \\
0.0196 \\
0.000653 \\
0.000653 \\
0.0196 \\
0.0065 \\
0.0065 \\
0.0065 \\
0.196 \\
196 \\
0.98\end{array}$ & 0.065 & $\begin{array}{l}\text { Behaviour } \\
\text { Behaviour } \\
\text { Physiology } \\
\text { Behaviour } \\
\text { Physiology } \\
\text { Behaviour } \\
\text { Physiology } \\
\text { Physiology } \\
\text { Behaviour } \\
\text { Physiology } \\
\text { Physiology } \\
\text { Behaviour } \\
\text { Physiology } \\
\text { Physiology } \\
\text { Physiology } \\
\text { Physiology }\end{array}$ & $\begin{array}{l}(166) \\
(167) \\
(168) \\
(169) \\
(170) \\
(171) \\
(172) \\
(172) \\
(174) \\
(175) \\
(176)\end{array}$ \\
\hline Citalopram & 0.296 & $\begin{array}{r}98 \\
<10 \\
<30000 \\
<1713.45\end{array}$ & $\begin{array}{r}0.003 \\
0.0427 \\
0.0000142 \\
0.000249\end{array}$ & 0.0427 & $\begin{array}{l}\text { Behaviour } \\
\text { Behaviour } \\
\text { Behaviour } \\
\text { Physiology }\end{array}$ & $\begin{array}{l}(177) \\
(178) \\
(179) \\
(180)\end{array}$ \\
\hline
\end{tabular}




\begin{tabular}{|c|c|c|c|c|c|c|}
\hline & & $\begin{array}{r}0.15 \\
<1.5 \\
<0.15 \\
<1.5 \\
<1.5 \\
0.2 \\
<0.1 \\
<4 \\
100000 \\
<20 \\
100 \\
10 \\
10 \\
50000 \\
50 \\
3\end{array}$ & $\begin{array}{r}2.847 \\
0.285 \\
2.847 \\
0.285 \\
0.285 \\
2 / 135 \\
4.27 \\
0.107 \\
0.00000427 \\
0.02135 \\
0.00427 \\
0.0427 \\
0.0427 \\
0.0000854 \\
0.00854 \\
0.142\end{array}$ & & $\begin{array}{l}\text { Behaviour } \\
\text { Behaviour } \\
\text { Behaviour } \\
\text { Behaviour } \\
\text { Behaviour } \\
\text { Behaviour } \\
\text { Behaviour } \\
\text { Physiology } \\
\text { Behaviour } \\
\text { Behaviour } \\
\text { Physiology } \\
\text { Behaviour } \\
\text { Physiology } \\
\text { Behaviour } \\
\text { Physiology } \\
\text { Behaviour }\end{array}$ & $\begin{array}{l}(181) \\
(185) \\
(182) \\
(183) \\
(184) \\
(186) \\
(187) \\
(188) \\
(189) \\
(190) \\
(135) \\
(191) \\
(192) \\
\\
(193)\end{array}$ \\
\hline Clomipramine & 0.0032 & $\begin{array}{r}<10 \\
<10 \\
1637.272\end{array}$ & $\begin{array}{r}0.00032 \\
0.00032 \\
0.00000195\end{array}$ & 0.0003 & $\begin{array}{l}\text { Physiology } \\
\text { Behaviour } \\
\text { Physiology }\end{array}$ & $\begin{array}{l}(171) \\
(194)\end{array}$ \\
\hline Duloxetine & 0.002 & 2.97 & 0.00067 & 0.0007 & Behaviour & (195) \\
\hline Escitalopram & 0.003 & $\begin{array}{l}0.15 \\
0.15\end{array}$ & $\begin{array}{l}0.02 \\
0.02\end{array}$ & 0.02 & $\begin{array}{l}\text { Behaviour } \\
\text { Physiology }\end{array}$ & (196) \\
\hline Fluoxetine & 0.41 & $\begin{array}{r}<1 \\
1 \\
<50 \\
<4.6 \\
2.3 \\
100 \\
8.5 \\
1\end{array}$ & $\begin{array}{r}0.41 \\
0.41 \\
0.0082 \\
0.089 \\
0.178 \\
0.0041 \\
0.048 \\
0.41\end{array}$ & & $\begin{array}{l}\text { Physiology } \\
\text { Physiology } \\
\text { Physiology } \\
\text { Physiology } \\
\text { Behaviour } \\
\text { Behaviour } \\
\text { Physiology } \\
\text { Physiology }\end{array}$ & $\begin{array}{l}(197) \\
(198) \\
(199) \\
(200) \\
(201) \\
(202) \\
(203)\end{array}$ \\
\hline
\end{tabular}




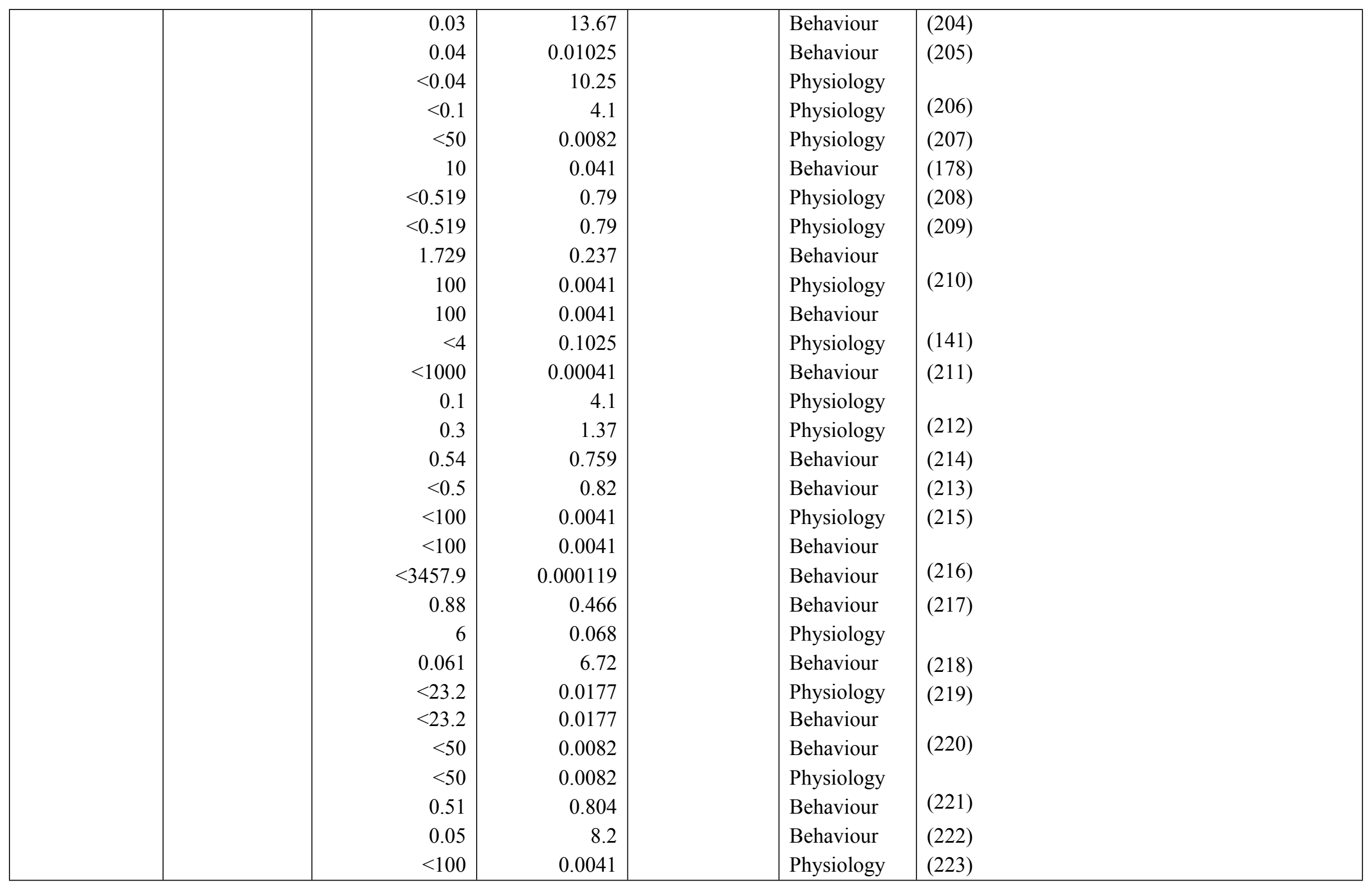




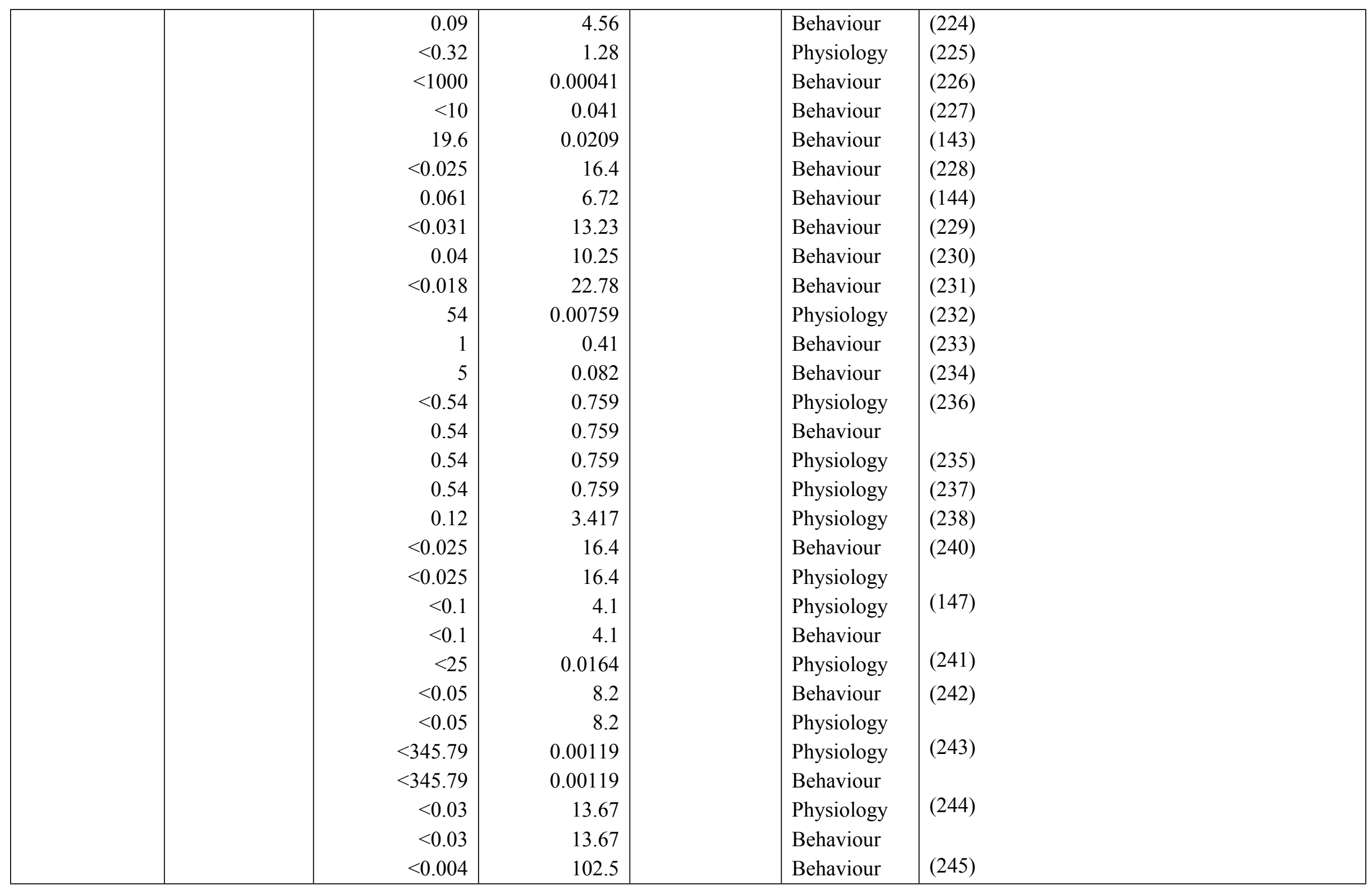




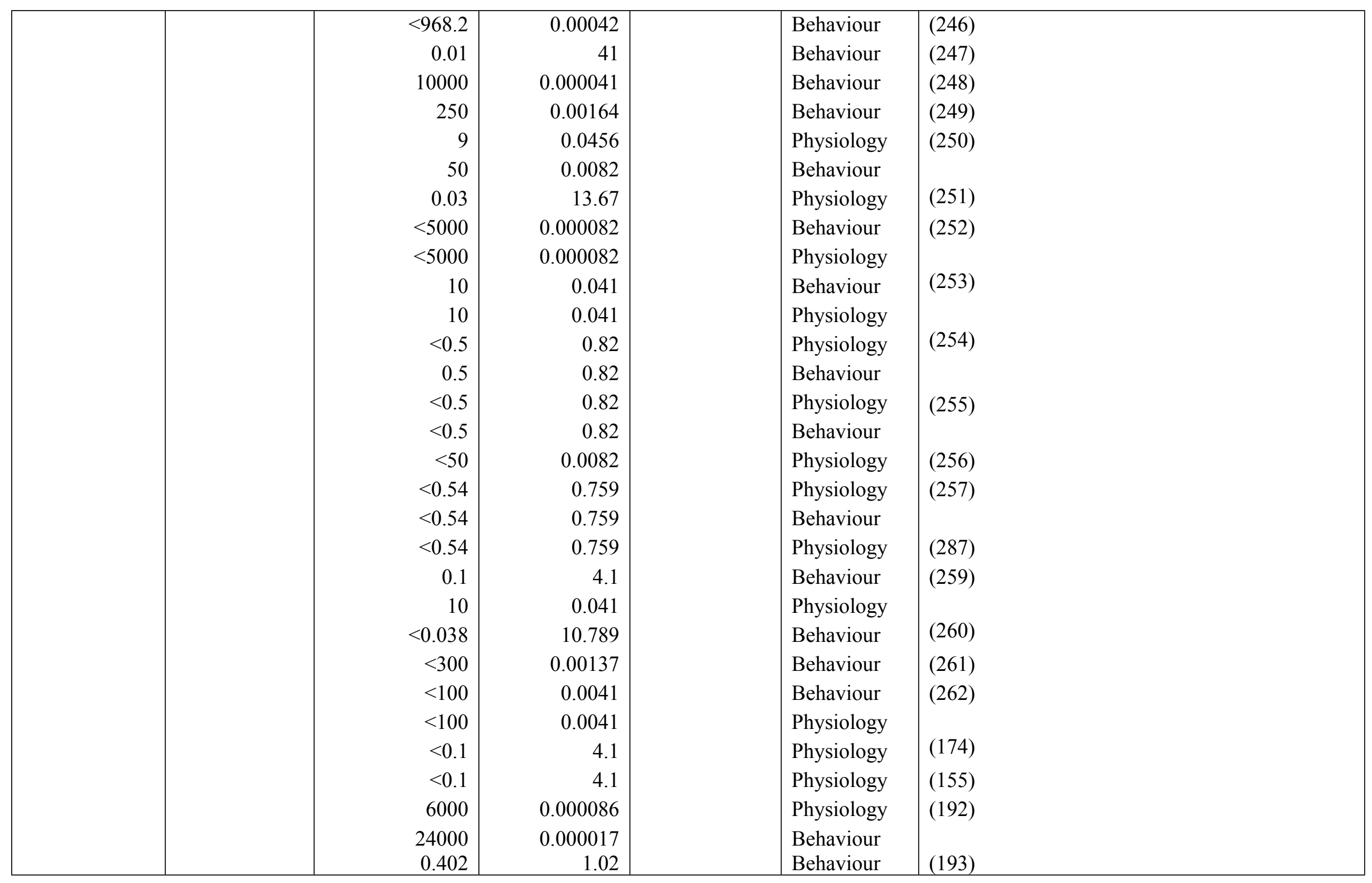




\begin{tabular}{|c|c|c|c|c|c|c|}
\hline Nortriptyline & 0.019 & $\begin{array}{r}<10 \\
<10 \\
500 \\
1.58 \\
<10 \\
100\end{array}$ & $\begin{array}{r}0.0019 \\
0.0019 \\
0.000038 \\
0.012 \\
0.0019 \\
0.00019 \\
\end{array}$ & 0.0019 & $\begin{array}{l}\text { Physiology } \\
\text { Behaviour } \\
\text { Physiology } \\
\text { Behaviour } \\
\text { Physiology } \\
\text { Behaviour }\end{array}$ & $\begin{array}{l}(227) \\
(263) \\
(171)\end{array}$ \\
\hline Paroxetine & 0.09 & $\begin{array}{l}<100 \\
<300\end{array}$ & $\begin{array}{l}0.0009 \\
0.0003 \\
\end{array}$ & 0.15 & $\begin{array}{l}\text { Physiology } \\
\text { Behaviour }\end{array}$ & $\begin{array}{l}(223) \\
(226)\end{array}$ \\
\hline Sertraline & 0.049 & $\begin{array}{r}<0.1 \\
1 \\
1 \\
<10 \\
2000 \\
<15000 \\
3426.9 \\
0.12 \\
0.4 \\
<25 \\
10 \\
0.1 \\
4.5 \\
<4.5 \\
60 \\
60 \\
<3 \\
<220 \\
<4.36 \\
\end{array}$ & $\begin{array}{r}0.49 \\
0.049 \\
0.049 \\
0.0049 \\
0.0000245 \\
0.00000327 \\
0.0000143 \\
0.408 \\
0.1225 \\
0.00196 \\
0.0049 \\
0.49 \\
0.0109 \\
0.0109 \\
0.000816 \\
0.000816 \\
0.0163 \\
0.000223 \\
0.0112 \\
\end{array}$ & & $\begin{array}{l}\text { Physiology } \\
\text { Physiology } \\
\text { Behaviour } \\
\text { Behaviour } \\
\text { Behaviour } \\
\text { Physiology } \\
\text { Physiology } \\
\text { Behaviour } \\
\text { Behaviour } \\
\text { Physiology } \\
\text { Physiology } \\
\text { Behaviour } \\
\text { Physiology } \\
\text { Behaviour } \\
\text { Behaviour } \\
\text { Physiology } \\
\text { Behaviour } \\
\text { Physiology } \\
\text { Behaviour }\end{array}$ & $\begin{array}{l}(264) \\
(157) \\
(178) \\
(168) \\
(180) \\
(265) \\
(266) \\
(241) \\
(267) \\
(195) \\
(268) \\
(269) \\
(270) \\
(162)\end{array}$ \\
\hline Venlafaxine & 1.31 & $\begin{array}{l}<0.2 \\
<50 \\
<50\end{array}$ & $\begin{array}{r}6.55 \\
0.0262 \\
0.0262\end{array}$ & 0.66 & $\begin{array}{l}\text { Physiology } \\
\text { Behaviour } \\
\text { Physiology }\end{array}$ & $\begin{array}{l}(271) \\
(272)\end{array}$ \\
\hline
\end{tabular}




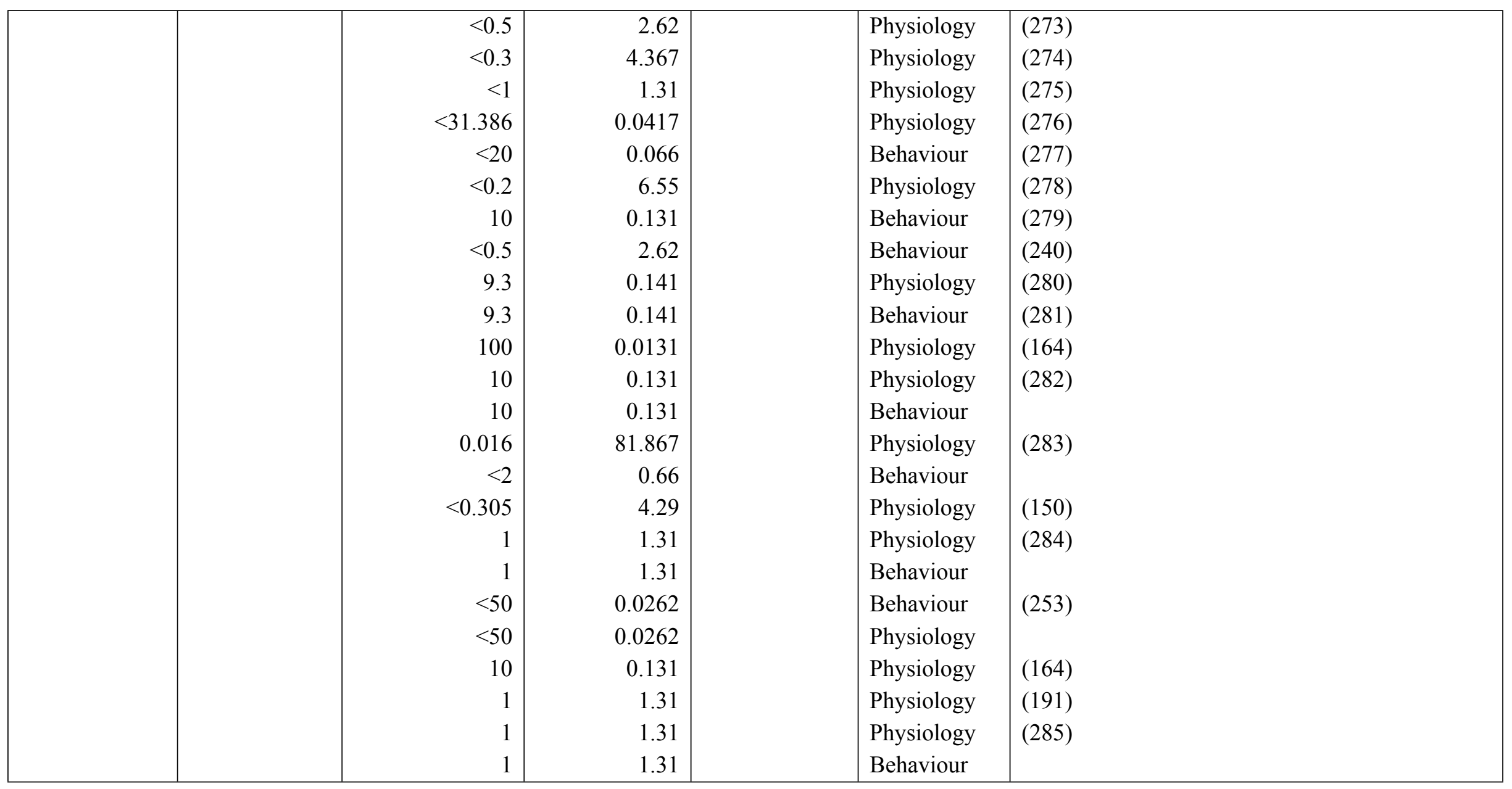




\section{References}

1. Agency for Healthcare Research and Quality. Medical Expenditure Panel Survey: Total purchases in thousands by prescribed drug, United States, 1996-2018. https://meps.ahrq.gov/mepstrends/hc_pmed/\#plot-tab (accessed: 05.04.21).

2. NHS Digital. Prescription Cost Analysis - England, 2018. https://digital.nhs.uk/data-and-information/publications/statistical/prescription-costanalysis/2018 (accessed: 13.07.21).

3. Pivetta RC.; Rodrigues-Silva C.; Ribeiro AR.; Rath S. Tracking the occurrence of psychotropic pharmaceuticals in Brazilian wastewater treatment plants and surface water, with assessment of environmental risks. Sci Total Environ. 2020, 727, 138661. DOI: 10.1016/j.scitotenv.2020.138661

4. $\quad$ Eek E.; Driel M.; Falk M.; Hollingworth SA.; Merlo G. Antidepressant use in Australia and Sweden - A cross-country comparison. Pharmacoepidemiol Drug Saf. 2020, 1-9. DOI: 10.1002/pds.5158

5. Hall H.; Lundkvist C.; Halldin C.; Farde L.; Pike VW.; McCarron JA.; Fletcher A.; Cliffe IA.; Barf T.; Wikström H.; Sedvall G. Autoradiographic localization of 5-HT(1A) receptors in the post-mortem human brain using [3H]WAY-100635. Brain Res. 1997, 745, 96-108. DOI: 10.1016/S00068993(96)01131-6

6. $\quad$ Norton WHJ.; Folchert A.; Bally-Cuif L. Comparative analysis of serotonin receptor (HTR1A/HTR1B families) and transporter (slc6a4a/b) gene expression in the zebrafish brain. J Comp Neurol. 2008, 511, 521-42. DOI: 10.1002/cne.21831

7. Varnas K.; Hurd YL.; Hall H. Regional Expression of 5-HT 1B Receptor mRNA in the Human Brain. Synapse. 2005, 56, 21-8. DOI: $10.1002 /$ syn.20128

8. $\quad$ Nilsson T.; Longmore J.; Shaw D.; Jansen Olesen IJ.; Edvinsson L. Contractile 5-HT1B receptors in human cerebral arteries: Pharmacological characterization and localization with immunocytochemistry. Br J Pharmacol. 1999, 128, 1133-40. DOI: 10.1038/sj.bjp.0702773

9. Hannon J.; Hoyer D. Molecular biology of 5-HT receptors. Behav Brain Res. 2008, 195, 198-213. DOI: 10.1016/j.bbr.2008.03.020

10. Hoyer D.; Hannon JP.; Martin GR. Molecular, pharmacological and functional diversity of 5-HT receptors. Pharmacol Biochem Behav. 2002, 71, 533-54. DOI: 10.1016/S0091-3057(01)00746-8

11. Pasqualetti M.; Ori M.; Castagna M.; Marazziti D.; Cassano GB.; Nardi I. Distribution and cellular localization of the serotonin type 2C receptor messenger RNA in human brain. Neuroscience. 1999, 92, 601-11. DOI: 10.1016/S0306-4522(99)00011-1

12. Schneider H.; Fritzky L.; Williams J.; Heumann C.; Yochum M.; Pattar K.; Noppert G.; Mock V.; Hawley E. Cloning and expression of a zebrafish 5HT2C receptor gene. Gene. 2012, 502, 108-17. DOI: 10.1016/j.gene.2012.03.070

13. Barnes NM.; Hales TG.; Lummis SCR.; Peters JA. The 5-HT 3 receptor - the relationship between structure and function. Neuropharmacology. 2009, 56, 273-84. DOI: 10.1016/j.neuropharm.2008.08.003.The 
14. Holbrook JD.; Gill CH.; Zebda N.; Spencer JP.; Leyland R.; Rance KH.; Trinh H.; Balmer G.; Kelly FM.; Yusaf SP.; Courtenay N.; Luck J.; Rhodes A.; Modha S.; Moore SE.; Sanger GJ.; Gunthorpe MJ. Characterisation of 5-HT3C, 5-HT3D and 5-HT 3E receptor subunits: Evolution, distribution and function. $J$ Neurochem. 2009, 108, 384-96. DOI: 10.1111/j.1471-4159.2008.05775.x

15. Eglen RM.; Wong EHF.; Dumuis A.; Bockaert J. Central 5-HT4 receptors. Trends Pharmacol Sci. 1995, 16, 391-8. DOI: 10.1016/S01656147(00)89081-1

16. Blondel O.; Gastineau M.; Dahmoune Y.; Langlois M.; Fischmeister R. Cloning, expression, and pharmacology of four human 5-hydroxytryptamine4 receptor isoforms produced by alternative splicing in the carboxyl terminus. J Neurochem. 1998, 70, 2252-61. DOI: 10.1046/j.14714159.1998.70062252.x

17. Pasqualetti M.; Ori M.; Nardi I.; Castagna M.; Cassano GB.; Marazziti D. Distribution of the 5-HT5A serotonin receptor mRNA in the human brain. Mol Brain Res. 1998, 56, 1-8. DOI: 10.1016/S0169-328X(98)00003-5

18. Grailhe R.; Grabtree GW.; Hen R. Human 5-HT5 receptors: The 5-HT5A receptor is functional but the 5-HT5B receptor was lost during mammalian evolution. Eur J Pharmacol. 2001, 418, 157-67. DOI: 10.1016/S0014-2999(01)00933-5

19. Kohen R.; Metcalf MA.; Khan N.; Druck T.; Huebner K.; Lachowicz JE.; Meltzer HY.; Sibley DR.; Roth BL.; Hamblin MW. Cloning, characterization, and chromosomal localization of a human 5-HT6 serotonin receptor. J Neurochem. 1996, 66, 47-56. DOI: 10.1046/j.14714159.1996.66010047.x

20. Martin-Cora FJ.; Pazos A. Autoradiographic distribution of 5-HT 7 receptors in the human brain using [3H] mesulergine: comparison to other mammalian species. Br J Pharmacol. 2004, 141, 92-104. DOI: 10.1038/sj.bjp.0705576

21. Bard JA.; Zgombick J.; Adham N.; Vaysse P.; Branchek TA.; Weinshank RL. Cloning of a novel human serotonin receptor (5-HT7) positively linked to adenylate cyclase. J Biol Chem. 1993, 268, 23422-6. DOI: 10.1016/s0021-9258(19)49479-9

22. Faure C.; Gouhier C.; Salomon L.; Graham D. Quantification of $\alpha 1$-adrenoceptor subtypes in human tissues by competitive RT-PCR analysis. Biochem Biophys Res Commun. 1995, 213, 935-43. DOI: 10.1006/bbrc.1995.2219

23. De Vos H.; Vauquelin G.; De Keyser J.; De Backer JP.; Van Liefde I. Regional distribution of alpha 2A- and alpha 2B-adrenoceptor subtypes in postmortem human brain. J Neurochem. 1992, 58, 1555-60. DOI: 10.1111/j.1471-4159.1992.tb11378.x

24. Smith MS.; Schambra UB.; Wilson KH.; Page SO.; Schwinn DA. $\alpha 1$-Adrenergic receptors in human spinal cord: Specific localized expression of mRNA encoding $\alpha 1$-adrenergic receptor subtypes at four distinct levels. Mol Brain Res. 1995, 34, 109-17. DOI: 10.1016/S0169-328X(98)00287-3

25. Titinchi S.; Clark B. Alpha2-adrenoceptors in human lymphocytes: direct characterisation by [3H]yohimbine binding. Biochem Biophys Res Commun. 1984, 121, 1-7. DOI: 10.1016/0006-291x(84)90679-x

26. Bylund DB.; Chacko DM. Characterization of $\alpha 2$ adrenergic receptor subtypes in human ocular tissue homogenates. Investig Ophthalmol Vis Sci. 
1999, 40, 2299-306.

27. Ruuskanen JO.; Peitsaro N.; Kaslin JVM.; Panula P.; Scheinin M. Expression and function of $\alpha 2$-adrenoceptors in zebrafish: Drug effects, mRNA and receptor distributions. J Neurochem. 2005, 94, 1559-69. DOI: 10.1111/j.1471-4159.2005.03305.x

28. Fagerholm V.; Rokka J.; Nyman L.; Sallinen J.; Tiihonen J.; Tupala E.; Haaparanta M.; Hietala J. Autoradiographic Characterization of a 2CAdrenoceptors in the Human Striatum. Synapse. 2008, 62, 508-15. DOI: 10.1002/syn.20520

29. Eason MG.; Liggett SB. Human $\alpha 2$-adrenergic receptor subtype distribution: Widespread and subtype-selective expression of $\alpha 2 \mathrm{C} 10$, $\alpha 2 \mathrm{C} 4$, and $\alpha 2 \mathrm{C} 2$ mRNA in multiple tissues. Mol Pharmacol. 1993, 44, 70-5.

30. De Paermentier F.; Cheetham SC.; Crompton MR.; Horton RW. B-Adrenoceptors in human brain labelled with [3H]dihydroalprenolol and [3H]CGP 12177. Eur J Pharmacol. 1989, 167, 397-405. DOI: 10.1016/0014-2999(89)90448-2

31. Brodde OE.; Bruck H.; Leineweber K.; Seyfarth T. Presence, distribution and physiological function of adrenergic and muscarinic receptor subtypes in the human heart. Basic Res Cardiol. 2001, 96, 528-38. DOI: 10.1007/s003950170003

32. Wang Z.; Nishimura Y.; Shimada Y.; Umemoto N.; Hirano M.; Zang L.; Oka T.; Sakamoto C.; Kuroyanagi J.; Tanaka T. Zebrafish $\beta$-adrenergic receptor mRNA expression and control of pigmentation. Gene. 2009, 446, 18-27. DOI: 10.1016/j.gene.2009.06.005

33. Ampatzis K.; Dermon CR. Regional distribution and cellular localization of $\beta 2$ - adrenoceptors in the adult zebrafish brain (Danio rerio). $J$ Comp Neurol. 2010, 518, 1418-41. DOI: 10.1002/cne.22278

34. Strosberg AD. Structure and function of the B3-Adrenergic receptor. Annu Rev Pharmacol Toxicol. 1997, 37, 421-50. DOI: 10.1146/annurev.immunol.15.1.433

35. Hall H.; Sedvall G.; Magnusson O.; Kopp J.; Halldin C.; Farde L. Distribution of D1- and D2-Dopamine Receptors, and Dopamine and Its Metabolites in the Human Brain. Neuropsychopharmacology. 1994, 11, 245-56. DOI: 10.1038/sj.npp.1380111

36. Cheung PY.; Barrington KJ. Renal dopamine receptors: Mechanisms of action and developmental aspects. Cardiovasc Res. 1996, 31, 2-6. DOI: 10.1016/0008-6363(95)00206-5

37. Cavallotti C.; Mancone M.; Bruzzone P.; Sabbatini M.; Mignini F. Dopamine receptor subtypes in the native human heart. Heart Vessels. 2010, 25, 432-7. DOI: $10.1007 / \mathrm{s} 00380-009-1224-4$

38. Li P.; Shah S.; Huang L.; Carr AL.; Gao Y.; Thisse C.; Thisse B.; Li L. Cloning and spatial and temporal expression of the zebrafish dopamine D1 receptor. Dev Dyn. 2007, 236, 1339-46. DOI: 10.1002/dvdy.21130

39. Kirillova GP.; Hrutkay RJ.; Shurin MR.; Shurin G V.; Tourkova IL.; Vanyukov MM. Dopamine receptors in human lymphocytes : Radioligand binding and quantitative RT-PCR assays. $J$ Neurosci Methods. 2008, 174, 272-80. DOI: 10.1016/j.jneumeth.2008.07.018 
40. Dearry A.; Falardeau P.; Shores C.; Caron MG. D2 dopamine receptors in the human retina: Cloning of cDNA and localization of mRNA. Cell Mol Neurobiol. 1991, 11, 437-53. DOI: 10.1007/BF00734808

41. Boehmier W.; Obrecht-Pflumio S.; Canfield V.; Thisse C.; Thisse B.; Levenson R. Evolution and expression of D2 and D3 dopamine receptor genes in zebrafish. Dev Dyn. 2004, 230, 481-93. DOI: 10.1002/dvdy.20075

42. Herroelen L.; De Backer JP.; Wilczak N.; Flamez A.; Vauquelin G.; De Keyser J. Autoradiographic distribution of D3-type dopamine receptors in human brain using [3H]7-hydroxy-N,N-di-n-propyl-2-aminotetralin. Brain Res. 1994, 648, 222-8. DOI: 10.1016/0006-8993(94)91121-5

43. Matsumoto M.; Hidaka K.; Tada S.; Tasaki Y.; Yamaguchi T. Full-length cDNA cloning and distribution of human dopamine D4 receptor. Mol Brain Res. 1995, 29, 157-62. DOI: 10.1016/0169-328X(94)00245-A

44. Boehmler W.; Carr T.; Thisse C.; Thisse B.; Canfield VA.; Levenson R. D4 Dopamine receptor genes of zebrafish and effects of the antipsychotic clozapine on larval swimming behaviour. Genes, Brain Behav. 2007, 6, 155-66. DOI: 10.1111/j.1601-183X.2006.00243.x

45. Khan ZU.; Gutiérrez A.; Martín R.; Peafiel A.; Rivera A.; De La Calle A. Dopamine D5 receptors of rat and human brain. Neuroscience. 2000, 100, 689-99. DOI: 10.1016/S0306-4522(00)00274-8

46. Muir D.; Simmons D.; Wang X.; Peart T.; Villella M.; Miller J.; Sherry J. Bioaccumulation of pharmaceuticals and personal care product chemicals in fish exposed to wastewater effluent in an urban wetland. Sci Rep. 2017, 7, 16999. DOI: 10.1038/s41598-017-15462-x

47. Ma L dan.; Li J.; Li J jun.; Liu M.; Yan D zhi.; Shi W yan.; Xu G. Occurrence and source analysis of selected antidepressants and their metabolites in municipal wastewater and receiving surface water. Environ Sci Process Impacts. 2018, 20, 1020-9. DOI: 10.1039/c8em00077h

48. Wu M.; Xiang J.; Chen F.; Fu C.; Xu G. Occurrence and risk assessment of antidepressants in Huangpu River of Shanghai, China. Environ Sci Pollut Res. 2017, 24, 20291-9. DOI: 10.1007/s11356-017-9293-x

49. Fedorova G.; Randak T.; Golovko O.; Kodes V.; Grabicova K.; Grabic R. A passive sampling method for detecting analgesics, psycholeptics, antidepressants and illicit drugs in aquatic environments in the Czech Republic. Sci Total Environ. 2014, 487, 681-7. DOI: 10.1016/j.scitotenv.2013.12.091

50. $\quad$ Loos R.; Carvalho R.; António DC.; Comero S.; Locoro G.; Tavazzi S.; Paracchini B.; Ghiani M.; Lettieri T.; Blaha L.; Jarosova B.; Voorspoels S.; Servaes K.; Haglund P.; Fick J.; Lindberg RH.; Schwesig D.; Gawlik BM. EU-wide monitoring survey on emerging polar organic contaminants in wastewater treatment plant effluents. Water Res. 2013, 47, 6475-87. DOI: 10.1016/j.watres.2013.08.024

51. Togola A.; Budzinski H. Multi-residue analysis of pharmaceutical compounds in aqueous samples. J Chromatogr A. 2008, 1177, 150-8. DOI: 10.1016/j.chroma.2007.10.105

52. Gonzalez-Rey M.; Tapie N.; Le Menach K.; Dévier MH.; Budzinski H.; Bebianno MJ. Occurrence of pharmaceutical compounds and pesticides in aquatic systems. Mar Pollut Bull. 2015, 96, 384-400. DOI: 10.1016/j.marpolbul.2015.04.029 
53. Biel-Maeso M.; Baena-Nogueras RM.; Corada-Fernández C.; Lara-Martín PA. Occurrence, distribution and environmental risk of pharmaceutically active compounds (PhACs) in coastal and ocean waters from the Gulf of Cadiz (SW Spain). Sci Total Environ. 2018, 612, 649-59. DOI: 10.1016/j.scitotenv.2017.08.279

54. Unceta N.; Sampedro MC.; Kartini N.; Bakar A.; Gómez-caballero A.; Goicolea MA.; Barrio RJ. Multi-residue analysis of pharmaceutical compounds in wastewaters by dual solid-phase microextraction coupled to liquid chromatography electrospray ionization ion trap mass spectrometry. $J$ Chromatogr A. 2010, 1217, 3392-9. DOI: 10.1016/j.chroma.2010.03.008

55. Valcárcel Y.; González Alonso S.; Rodríguez-Gil JL.; Gil A.; Catalá M. Detection of pharmaceutically active compounds in the rivers and tap water of the Madrid Region (Spain) and potential ecotoxicological risk. Chemosphere. 2011, 84, 1336-48. DOI: 10.1016/j.chemosphere.2011.05.014

56. Fick J.; Lindberg RH. Results from the Swedish National Screening Programme 2010. Swedish Environ Res Inst. 2011 , 1-32.

57. Guzel EY.; Cevik F.; Daglioglu N. Determination of pharmaceutical active compounds in Ceyhan River, Turkey: Seasonal, spatial variations and environmental risk assessment. Hum Ecol Risk Assess An Int J. 2019, 25, 1980-95. DOI: 10.1080/10807039.2018.1479631

58. Baker DR.; Kasprzyk-Hordern B. Multi-residue analysis of drugs of abuse in wastewater and surface water by solid-phase extraction and liquid chromatography-positive electrospray ionisation tandem mass spectrometry. J Chromatogr A. 2011, 1218, 1620-31. DOI: 10.1016/j.chroma.2011.01.060

59. Baker DR.; Kasprzyk-Hordern B. Spatial and temporal occurrence of pharmaceuticals and illicit drugs in the aqueous environment and during wastewater treatment: New developments. Sci Total Environ. 2013, 454-455, 442-56. DOI: 10.1016/j.scitotenv.2013.03.043

60. Bean TG.; Rattner BA.; Lazarus RS.; Day DD.; Burket SR.; Brooks BW.; Haddad SP.; Bowerman WW. Pharmaceuticals in water, fish and osprey nestlings in Delaware River. Environ Pollut. 2018, 232, 533-45. DOI: 10.1016/j.envpol.2017.09.083

61. Klosterhaus SL.; Grace R.; Hamilton MC.; Yee D. Method validation and reconnaissance of pharmaceuticals, personal care products, and alkylphenols in surface waters, sediments, and mussels in an urban estuary. Environ Int. 2013, 54, 92-9. DOI: 10.1016/j.envint.2013.01.009

62. Meador JP.; Yeh A.; Young G.; Gallagher EP. Contaminants of emerging concern in a large temperate estuary. Environ Pollut. $2016,213,254-67$. DOI: 10.1016/j.envpol.2016.01.088

63. Oliveira TS.; Murphy M.; Mendola N.; Wong V.; Carlson D.; Waring L. Characterization of Pharmaceuticals and Personal Care products in hospital effluent and waste water influent/effluent by direct-injection LC-MS-MS. Sci Total Environ. 2015, 518-519, 459-78. DOI: 10.1016/j.scitotenv.2015.02.104

64. Kasprzyk-Hordern B.; Dinsdale RM.; Guwy AJ. The removal of pharmaceuticals, personal care products, endocrine disruptors and illicit drugs during wastewater treatment and its impact on the quality of receiving waters. Water Res. 2009, 43, 363-80. DOI: 10.1016/j.watres.2008.10.047

65. Anim AK.; Thompson K.; Duodu GO.; Tscharke B.; Birch G.; Goonetilleke A.; Ayoko GA.; Mueller JF. Pharmaceuticals, personal care products, 
food additive and pesticides in surface waters from three Australian east coast estuaries (Sydney, Yarra and Brisbane). Mar Pollut Bull. 2020, 153, 111014. DOI: 10.1016/j.marpolbul.2020.111014

66. Metcalfe CD.; Chu S.; Judt C.; Li H.; Oakes KD.; Servos MR.; Andrews DM. Antidepressants and their metabolites in municipal wastewater, and downstream exposure in an urban watershed. Environ Toxicol Chem. 2010, 29, 79-89. DOI: 10.1002/etc. 27

67. Yuan S.; Jiang X.; Xia X.; Zhang H.; Zheng S. Detection, occurrence and fate of 22 psychiatric pharmaceuticals in psychiatric hospital and municipal wastewater treatment plants in Beijing, China. Chemosphere. 2013, 90, 2520-5. DOI: 10.1016/j.chemosphere.2012.10.089

68. Golovko O.; Kumar V.; Fedorova G.; Randak T.; Grabic R. Seasonal changes in antibiotics, antidepressants/psychiatric drugs, antihistamines and lipid regulators in a wastewater treatment plant. Chemosphere. 2014, 111, 418-26. DOI: 10.1016/j.chemosphere.2014.03.132

69. Grabicova K.; Grabic R.; Blaha M.; Kumar V.; Cerveny D.; Fedorova G.; Randak T. Presence of pharmaceuticals in benthic fauna living in a small stream affected by effluent from a municipal sewage treatment plant. Water Res. 2015, 72, 145-53. DOI: 10.1016/j.watres.2014.09.018

70. Koba O.; Grabicova K.; Cerveny D.; Turek J.; Kolarova J.; Randak T.; Zlabek V.; Grabic R. Transport of pharmaceuticals and their metabolites between water and sediments as a further potential exposure for aquatic organisms. J Hazard Mater. 2018, 342, 401-7. DOI:

10.1016/j.jhazmat.2017.08.039

71. Brozinski J-M.; Lahti M.; Meierjohann A.; Oikari A.; Kronberg L. The Anti-Inflammatory Drugs Diclofenac, Naproxen and Ibuprofen are found in the Bile of Wild Fish Caught Downstream of a Wastewater Treatment Plant. Environ Sci Technol. 2013, 47, 342-8. DOI: 10.1021/es303013j

72. Nödler K.; Licha T.; Fischer S.; Wagner B.; Sauter M. A case study on the correlation of micro-contaminants and potassium in the Leine River (Germany). Appl Geochemistry. 2011, 26, 2172-80. DOI: 10.1016/j.apgeochem.2011.08.001

73. Schlüsener MP.; Hardenbicker P.; Nilson E.; Schulz M.; Viergutz C.; Ternes TA. Occurrence of venlafaxine, other antidepressants and selected metabolites in the Rhine catchment in the face of climate change. Environ Pollut. 2015, 196, 247-56. DOI: 10.1016/j.envpol.2014.09.019

74. Alygizakis NA.; Gago-Ferrero P.; Borova VL.; Pavlidou A.; Hatzianestis I.; Thomaidis NS. Occurrence and spatial distribution of 158 pharmaceuticals, drugs of abuse and related metabolites in offshore seawater. Sci Total Environ. 2016, 541, 1097-105. DOI: 10.1016/j.scitotenv.2015.09.145

75. $\quad$ Staszny A.; Dobosy P.; Maasz G.; Szalai Z.; Jakab G.; Pirger Z.; Szeberenyi J.; Molnar E.; Pap LO.; Juhasz V.; Weiperth A.; Urbanyi B.; Kondor AC.; Ferincz A. Effects of pharmaceutically active compounds (PhACs) on fish body and scale shape in natural waters. PeerJ. 2021, 9, e10642. DOI: 10.7717 peerj. 10642

76. Jerker Fick.; Söderström H.; Lindberg RH.; Phan C.; Tysklind M.; Larsson DGJ. Contamination of surface, ground, and drinking water from pharmaceutical production. Environ Toxicol Chem. 2009, 28, 2522-7. DOI: 10.1897/09-073.1. Epub

77. Mandaric L.; Diamantini E.; Stella E.; Cano-Paoli K.; Valle-Sistac J.; Molins-Delgado D.; Bellin A.; Chiogna G.; Majone B.; Diaz-Cruz MS.; Sabater 
S.; Barcelo D.; Petrovic M. Contamination sources and distribution patterns of pharmaceuticals and personal care products in Alpine rivers strongly affected by tourism. Sci Total Environ. 2017, 590-591, 484-94. DOI: 10.1016/j.scitotenv.2017.02.185

78. Vasskog T.; Berger U.; Samuelsen P-J.; Kallenborn R.; Jensen E. Selective serotonin reuptake inhibitors in sewage influents and effluents from Tromsø, Norway. J Chromatogr A. 2006, 1115, 187-95. DOI: 10.1016/j.chroma.2006.02.091

79. Giebułtowicz J.; Nałecz-Jawecki G. Occurrence of antidepressant residues in the sewage-impacted Vistula and Utrata rivers and in tap water in Warsaw (Poland). Ecotoxicol Environ Saf. 2014, 104, 103-9. DOI: 10.1016/j.ecoenv.2014.02.020

80. Fernandes MJ.; Paíga P.; Silva A.; Llaguno CP.; Carvalho M.; Vázquez FM.; Delerue-Matos C. Antibiotics and antidepressants occurrence in surface waters and sediments collected in the north of Portugal. Chemosphere. 2020, 239, 124729. DOI: 10.1016/j.chemosphere.2019.124729

81. Pereira AMPT.; Silva LJG.; Laranjeiro CSM.; Meisel LM.; Lino CM.; Pena A. Human pharmaceuticals in Portuguese rivers: The impact of water scarcity in the environmental risk. Sci Total Environ. 2017, 609, 1182-91. DOI: 10.1016/j.scitotenv.2017.07.200

82. Santos LHMLM.; Gros M.; Rodriguez-Mozaz S.; Delerue-Matos C.; Pena A.; Barceló D.; Montenegro MCBSM. Contribution of hospital effluents to the load of pharmaceuticals in urban wastewaters: Identification of ecologically relevant pharmaceuticals. Sci Total Environ. 2013, 461-462, 302-16. DOI: 10.1016/j.scitotenv.2013.04.077

83. Silva LJG.; Pereira AMPT.; Meisel LM.; Lino CM.; Pena A. A one-year follow-up analysis of antidepressants in Portuguese wastewaters: Occurrence and fate, seasonal influence, and risk assessment. Sci Total Environ. 2014, 490, 279-87. DOI: 10.1016/j.scitotenv.2014.04.131

84. Bírošová L.; Lépesová K.; Grabic R.; Mackul’ak TM. Non-antimicrobial pharmaceuticals can affect the development of antibiotic resistance in hospital wastewater. Environ Sci Pollut Res. 2020, 27, 13501-11. DOI: 10.1007/s11356-020-07950-x

85. Acuña V.; von Schiller D.; García-Galán MJ.; Rodríguez-Mozaz S.; Corominas L.; Petrovic M.; Poch M.; Barceló D.; Sabater S. Occurrence and instream attenuation of wastewater-derived pharmaceuticals in Iberian rivers. Sci Total Environ. 2015, 503-504, 133-41. DOI: 10.1016/j.scitotenv.2014.05.067

86. Collado N.; Rodriguez-Mozaz S.; Gros M.; Rubirola A.; Barceló D.; Comas J.; Rodriguez-Roda I.; Buttiglieri G. Pharmaceuticals occurrence in a WWTP with significant industrial contribution and its input into the river system. Environ Pollut. 2014, 185, 202-12. DOI: 10.1016/j.envpol.2013.10.040

87. Fernández-Rubio J.; Rodríguez-Gil JL.; Postigo C.; Mastroianni N.; López de Alda M.; Barceló D.; Valcárcel Y. Psychoactive pharmaceuticals and illicit drugs in coastal waters of North-Western Spain: Environmental exposure and risk assessment. Chemosphere. 2019, 224, 379-89. DOI: 10.1016/j.chemosphere.2019.02.041

88. González Alonso S.; Catalá M.; Maroto RR.; Gil JLR.; de Miguel ÁG.; Valcárcel Y. Pollution by psychoactive pharmaceuticals in the Rivers of Madrid metropolitan area (Spain). Environ Int. 2010, 36, 195-201. DOI: 10.1016/j.envint.2009.11.004 
89. Valcárcel Y.; Alonso SG.; Rodríguez-Gil JL.; Castaño A.; Montero JC.; Criado-Alvarez JJ.; Mirón IJ.; Catalá M. Seasonal variation of pharmaceutically active compounds in surface (Tagus River) and tap water (Central Spain). Environ Sci Pollut Res. 2013, 20, 1396-412. DOI: $10.1007 / \mathrm{s} 11356-012-1099-2$

90. Golovko O.; Rehrl AL.; Köhler S.; Ahrens L. Organic micropollutants in water and sediment from Lake Mälaren, Sweden. Chemosphere. 2020, 258, 127293. DOI: 10.1016/j.chemosphere.2020.127293

91. Bradley PM.; Barber LB.; Clark JM.; Duris JW.; Foreman WT.; Furlong ET.; Givens CE.; Hubbard LE.; Hutchinson KJ.; Journey CA.; Keefe SH.; Kolpin DW. Pre/post-closure assessment of groundwater pharmaceutical fate in a wastewater-facility-impacted stream reach. Sci Total Environ. 2016, 568, 916-25. DOI: 10.1016/j.scitotenv.2016.06.104

92. Ferrer I.; Thurman EM. Analysis of 100 pharmaceuticals and their degradates in water samples by liquid chromatography/quadrupole time-of-flight mass spectrometry. J Chromatogr A. 2012, 1259, 148-57. DOI: 10.1016/j.chroma.2012.03.059

93. Schultz MM.; Furlong ET. Trace Analysis of Antidepressant Pharmaceuticals and Their Select Degradates in Environmental Matrices by LC/ESI/MS/MS. Anal Chem. 2008, 80, 1756-62. DOI: 10.1021/ac702154e

94. Schultz MM.; Furlong ET.; Kolpin DW.; Werner SL.; Schoenfuss HL.; Barber LB.; Blazer VS.; Norris DO.; Vajda AM. Antidepressant Pharmaceuticals in Two U.S. Effluent-Impacted Streams: Occurrence and Fate in Water and Sediment, and Selective Uptake in Fish Neural Tissue. Environ Sci Technol. 2010, 44, 1918-25. DOI: 10.1021/es9022706

95. de Souza RC.; Godoy AA.; Kummrow F.; dos Santos TL.; Brandão CJ.; Pinto E. Occurrence of caffeine, fluoxetine, bezafibrate and levothyroxine in surface freshwater of São Paulo State (Brazil) and risk assessment for aquatic life protection. Environ Sci Pollut Res. 2021,. DOI: 10.1007/s11356$020-11799-5$

96. Ma R.; Qu H.; Wang B.; Wang F.; Yu G. Widespread monitoring of chiral pharmaceuticals in urban rivers reveals stereospecific occurrence and transformation. Environ Int. 2020, 138, 105657. DOI: 10.1016/j.envint.2020.105657

97. Turcios AE.; Hielscher M.; Duarte B.; Fonseca VF.; Caçador I.; Papenbrock J. Screening of emerging pollutants (Eps) in estuarine water and phytoremediation capacity of tripolium pannonicum under controlled conditions. Int J Environ Res Public Health. 2021, 18, 943. DOI: 10.3390/ijerph18030943

98. Fernández C.; González-Doncel M.; Pro J.; Carbonell G.; Tarazona J V. Occurrence of pharmaceutically active compounds in surface waters of the henares-jarama-tajo river system (madrid, spain) and a potential risk characterization. Sci Total Environ. 2010, 408, 543-51. DOI: 10.1016/j.scitotenv.2009.10.009

99. Gros M.; Petrović M.; Ginebreda A.; Barceló D. Removal of pharmaceuticals during wastewater treatment and environmental risk assessment using hazard indexes. Environ Int. 2010, 36, 15-26. DOI: 10.1016/j.envint.2009.09.002 
100. Montesdeoca-Esponda S.; Palacios-Díaz M del P.; Estévez E.; Sosa-Ferrera Z.; Santana-Rodríguez JJ.; Cabrera M del C. Occurrence of Pharmaceutical Compounds in Groundwater from the Gran Canaria Island (Spain). Water. 2021, 13, 262. DOI: 10.3390/w13030262

101. Archer E.; Petrie B.; Kasprzyk-Hordern B.; Wolfaardt GM. The fate of pharmaceuticals and personal care products (PPCPs), endocrine disrupting contaminants (EDCs), metabolites and illicit drugs in a WWTW and environmental waters. Chemosphere. 2017, 174, 437-46. DOI: 10.1016/j.chemosphere.2017.01.101

102. Benotti MJ.; Brownawell BJ. Distributions of Pharmaceuticals in an Urban Estuary during both Dry- and Wet-Weather Conditions. Environ Sci Technol. 2007, 41, 5795-802. DOI: 10.1021/es0629965

103. Bringolf RB.; Heltsley RM.; Newton TJ.; Eads CB.; Fraley SJ.; Shea D.; Cope WG. Environmental occurrence and reproductive effects of the pharmaceutical fluoxetine in native freshwater mussels. Environ Toxicol Chem. 2010, 29, 1311-8. DOI: 10.1002/etc.157

104. Hedgespeth ML.; Sapozhnikova Y.; Pennington P.; Clum A.; Fairey A.; Wirth E. Pharmaceuticals and personal care products (PPCPs) in treated wastewater discharges into Charleston Harbor, South Carolina. Sci Total Environ. 2012, 437, 1-9. DOI: 10.1016/j.scitotenv.2012.07.076

105. Kolpin DW.; Furlong ET.; Meyer MT.; Thurman EM.; Zaugg SD.; Barber LB.; Buxton HT. Pharmceuticals, hormones, and other organic wastewater contaminants in US streams, 1999-2000: A National Reconnaissance. Environ Sci Technol. 2002, 36, 1202-11. DOI: 10.1021/es011055j

106. Gros M.; Petrović M.; Ginebreda A.; Barceló D. Removal of pharmaceuticals during wastewater treatment and environmental risk assessment using hazard indexes. Environ Int. 2010, 36, 15-26. DOI: 10.1016/j.envint.2009.09.002

107. Zhang S.; Wang Z.; Chen J. Physiologically based toxicokinetics (PBTK) models for pharmaceuticals and personal care products in wild common carp (Cyprinus carpio). Chemosphere. 2019, 220, 793-801. DOI: 10.1016/j.chemosphere.2018.12.172

108. Gornik T.; Kovacic A.; Heath E.; Hollender J.; Kosjek T. Biotransformation study of antidepressant sertraline and its removal during biological wastewater treatment. Water Res. 2020, 181, 115864. DOI: 10.1016/j.watres.2020.115864

109. Ghoshdastidar AJ.; Fox S.; Tong AZ. The presence of the top prescribed pharmaceuticals in treated sewage effluents and receiving waters in Southwest Nova Scotia, Canada. Environ Sci Pollut Res. 2015, 22, 689-700. DOI: 10.1007/s11356-014-3400-z

110. Rúa-Gómez PC.; Püttmann W. Degradation of lidocaine, tramadol, venlafaxine and the metabolites O-desmethyltramadol and Odesmethylvenlafaxine in surface waters. Chemosphere. 2013, 90, 1952-9. DOI: 10.1016/j.chemosphere.2012.10.039

111. Gracia-Lor E.; Sancho J V.; Hernández F. Simultaneous determination of acidic, neutral and basic pharmaceuticals in urban wastewater by ultra highpressure liquid chromatography-tandem mass spectrometry. J Chromatogr A. 2010, 1217, 622-32. DOI: 10.1016/j.chroma.2009.11.090

112. Gracia-Lor E.; Sancho J V.; Serrano R.; Hernández F. Occurrence and removal of pharmaceuticals in wastewater treatment plants at the Spanish Mediterranean area of Valencia. Chemosphere. 2012, 87, 453-62. DOI: 10.1016/j.chemosphere.2011.12.025 
113. Fonseca E.; Hernández F.; Ibáñez M.; Rico A.; Pitarch E.; Bijlsma L. Occurrence and ecological risks of pharmaceuticals in a Mediterranean river in Eastern Spain. Environ Int. 2020, 144, 106004. DOI: 10.1016/j.envint.2020.106004

114. David A.; Lange A.; Tyler CR.; Hill EM. Concentrating mixtures of neuroactive pharmaceuticals and altered neurotransmitter levels in the brain of fish exposed to a wastewater effluent. Sci Total Environ. 2018, 621, 782-90. DOI: 10.1016/j.scitotenv.2017.11.265

115. Deere JR.; Moore S.; Ferrey M.; Jankowski MD.; Primus A.; Convertino M.; Servadio JL.; Phelps NBD.; Hamilton MC.; Chenaux-Ibrahim Y.; Travis DA.; Wolf TM. Occurrence of contaminants of emerging concern in aquatic ecosystems utilized by Minnesota tribal communities. Sci Total Environ. 2020, 724, 138057. DOI: $10.1016 /$ j.scitotenv.2020.138057

116. Lajeunesse A.; Gagnon C.; Gagné F.; Louis S.; Čejka P.; Sauvé S. Distribution of antidepressants and their metabolites in brook trout exposed to municipal wastewaters before and after ozone treatment - Evidence of biological effects. Chemosphere. 2011, 83, 564-71. DOI: 10.1016/j.chemosphere.2010.12.026

117. Meador JP.; Yeh A.; Gallagher EP. Determining potential adverse effects in marine fish exposed to pharmaceuticals and personal care products with the fish plasma model and whole-body tissue concentrations. Environ Pollut. 2017, 230, 1018-29. DOI: 10.1016/j.envpol.2017.07.047

118. Meador JP.; Yeh A.; Gallagher EP. Adverse metabolic effects in fish exposed to contaminants of emerging concern in the field and laboratory. Environ Pollut. 2018, 236, 850-61. DOI: 10.1016/j.envpol.2018.02.007

119. Mijangos L.; Ziarrusta H.; Zabaleta I.; Usobiaga A.; Olivares M.; Zuloaga O.; Etxebarria N.; Prieto A. Multiresidue analytical method for the determination of 41 multiclass organic pollutants in mussel and fish tissues and biofluids by liquid chromatography coupled to tandem mass spectrometry. Anal Bioanal Chem. 2019, 411, 493-506. DOI: 10.1007/s00216-018-1474-z

120. Ziarrusta H.; Mijangos L.; Izagirre U.; Plassmann MM.; Benskin JP.; Anakabe E.; Olivares M.; Zuloaga O. Bioconcentration and biotransformation of amitriptyline in Gilt-head bream. Environ Sci Technol. 2017, 51, 2464-71. DOI: 10.1021/acs.est.6b05831

121. Álvarez-Muñoz D.; Rodríguez-Mozaz S.; Maulvault AL.; Tediosi A.; Fernández-Tejedor M.; Van den Heuvel F.; Kotterman M.; Marques A.; Barceló D. Occurrence of pharmaceuticals and endocrine disrupting compounds in macroalgaes, bivalves, and fish from coastal areas in Europe. Environ Res. 2015, 143, 56-64. DOI: 10.1016/j.envres.2015.09.018

122. Arnnok P.; Singh RR.; Burakham R.; Pérez-Fuentetaja A.; Aga DS. Selective Uptake and Bioaccumulation of Antidepressants in Fish from EffluentImpacted Niagara River. Environ Sci Technol. 2017, 51, 10652-62. DOI: 10.1021/acs.est.7b02912

123. Boulard L.; Parrhysius P.; Jacobs B.; Dierkes G.; Wick A.; Buchmeier G.; Koschorreck J.; Ternes TA. Development of an analytical method to quantify pharmaceuticals in fish tissues by liquid chromatography-tandem mass spectrometry detection and application to environmental samples. $J$ Chromatogr A. 2020, 1633, 461612. DOI: 10.1016/j.chroma.2020.461612

124. Gelsleichter J.; Szabo NJ. Uptake of human pharmaceuticals in bull sharks (Carcharhinus leucas) inhabiting a wastewater-impacted river. Sci Total 
Environ. 2013, 456-457, 196-201. DOI: 10.1016/j.scitotenv.2013.03.078

125. Grabicova K.; Lindberg RH.; Östman M.; Grabic R.; Randak T.; Joakim Larsson DG.; Fick J. Tissue-specific bioconcentration of antidepressants in fish exposed to effluent from a municipal sewage treatment plant. Sci Total Environ. 2014, 488-489, 46-50. DOI: 10.1016/j.scitotenv.2014.04.052

126. Grabicova K.; Grabic R.; Fedorova G.; Fick J.; Cerveny D.; Kolarova J.; Turek J.; Zlabek V.; Randak T. Bioaccumulation of psychoactive pharmaceuticals in fish in an effluent dominated stream. Water Res. 2017, 124, 654-62. DOI: 10.1016/j.watres.2017.08.018

127. Grabicova K.; Vojs Staňová A.; Koba Ucun O.; Borik A.; Randak T.; Grabic R. Development of a robust extraction procedure for the HPLC-ESIHRPS determination of multi-residual pharmaceuticals in biota samples. Anal Chim Acta. 2018, 1022, 53-60. DOI: 10.1016/j.aca.2018.04.011

128. Grabicová K.; Grabic R.; Fedorova G.; Vojs Staňová A.; Bláha M.; Randák T.; Brooks BW.; Žlábek V. Water reuse and aquaculture: Pharmaceutical bioaccumulation by fish during tertiary treatment in a wastewater stabilization pond. Environ Pollut. 2020, 267, 115593. DOI: 10.1016/j.envpol.2020.115593

129. Huerta B.; Jakimska A.; Gros M.; Rodríguez-Mozaz S.; Barceló D. Analysis of multi-class pharmaceuticals in fish tissues by ultra-high-performance liquid chromatography tandem mass spectrometry. J Chromatogr A. 2013, 1288, 63-72. DOI: 10.1016/j.chroma.2013.03.001

130. Huerta B.; Rodriguez-Mozaz S.; Lazorchak J.; Barcelo D.; Batt A.; Wathen J.; Stahl L. Presence of pharmaceuticals in fish collected from urban rivers in the U.S. EPA 2008-2009 National Rivers and Streams Assessment. Sci Total Environ. 2018, 634, 542-9. DOI: 10.1016/j.scitotenv.2018.03.387

131. Malev O.; Lovrić M.; Stipaničev D.; Repec S.; Martinović-Weigelt D.; Zanella D.; Ivanković T.; Sindičić Đuretec V.; Barišić J.; Li M.; Klobučar G. Toxicity prediction and effect characterization of 90 pharmaceuticals and illicit drugs measured in plasma of fish from a major European river (Sava, Croatia). Environ Pollut. 2020, 266,. DOI: 10.1016/j.envpol.2020.115162

132. McCallum ES.; Krutzelmann E.; Brodin T.; Fick J.; Sundelin A.; Balshine S. Exposure to wastewater effluent affects fish behaviour and tissuespecific uptake of pharmaceuticals. Sci Total Environ. 2017, 605-606, 578-88. DOI: 10.1016/j.scitotenv.2017.06.073

133. Pico Y.; Belenguer V.; Corcellas C.; Diaz-Cruz MS.; Eljarrat E.; Farré M.; Gago-Ferrero P.; Huerta B.; Navarro-Ortega A.; Petrovic M.; RodríguezMozaz S.; Sabater L.; Santín G.; Barcelo D. Contaminants of emerging concern in freshwater fish from four Spanish Rivers. Sci Total Environ. 2019, 659, 1186-98. DOI: 10.1016/j.scitotenv.2018.12.366

134. Yang H.; Lu G.; Yan Z.; Liu J.; Dong H.; Bao X.; Zhang X.; Sun Y. Residues, bioaccumulation, and trophic transfer of pharmaceuticals and personal care products in highly urbanized rivers affected by water diversion. J Hazard Mater. 2020, 391, 122245. DOI: 10.1016/j.jhazmat.2020.122245

135. Ziegler M.; Knoll S.; Köhler H-R.; Tisler S.; Huhn C.; Zwiener C.; Triebskorn R. Impact of the antidepressant citalopram on the behaviour of two different life stages of brown trout. PeerJ. 2020, 8 , e8765. DOI: $10.7717 /$ peerj. 8765

136. Cerveny D.; Grabic R.; Grabicová K.; Randák T.; Larsson DGJ.; Johnson AC.; Jürgens MD.; Tysklind M.; Lindberg RH.; Fick J. Neuroactive drugs and other pharmaceuticals found in blood plasma of wild European fish. Environ Int. 2021, 146, 106188. DOI: 10.1016/j.envint.2020.106188 
137. Bobrowska-korczak B.; Stawarska A.; Szterk A.; Ofiara K.; Czerwonka M.; Giebułtowicz J. Determination of Pharmaceuticals, Heavy Metals, and Oxysterols in Fish Muscle. Molecules. 2021, 26, 1229. DOI: 10.3390/molecules26051229

138. Boström ML.; Ugge G.; Jönsson JÅ.; Berglund O. Bioaccumulation and trophodynamics of the antidepressants sertraline and fluoxetine in laboratoryconstructed, 3-level aquatic food chains. Environ Toxicol Chem. 2017, 36, 1029-37. DOI: 10.1002/etc.3637

139. Brooks BW.; Chambliss CK.; Stanley JK.; Ramirez A.; Banks KE.; Johnson RD.; Lewis RJ. Determination of select antidepressants in fish from an effluent-dominated stream. Environ Toxicol Chem. 2005, 24, 464-9. DOI: 10.1897/04-081r.1

140. Chu S.; Metcalfe CD. Analysis of paroxetine, fluoxetine and norfluoxetine in fish tissues using pressurized liquid extraction, mixed mode solid phase extraction cleanup and liquid chromatography-tandem mass spectrometry. J Chromatogr A. 2007, 1163, 112-8. DOI: 10.1016/j.chroma.2007.06.014

141. Ding J.; Lu G.; Li Y. Interactive effects of selected pharmaceutical mixtures on bioaccumulation and biochemical status in crucian carp (Carassius auratus). Chemosphere. 2016, 148, 21-31. DOI: 10.1016/j.chemosphere.2016.01.017

142. Du B.; Perez-Hurtado P.; Brooks BW.; Chambliss CK. Evaluation of an isotope dilution liquid chromatography tandem mass spectrometry method for pharmaceuticals in fish. J Chromatogr A. 2012, 1253, 177-83. DOI: 10.1016/j.chroma.2012.07.026

143. Margiotta-Casaluci L.; Owen SF.; Cumming RI.; De Polo A.; Winter MJ.; Panter GH.; Rand-Weaver M.; Sumpter JP. Quantitative cross-species extrapolation between humans and fish: The case of the anti-depressant fluoxetine. PLoS One. 2014, 9, e1 10467. DOI: 10.1371/journal.pone.0110467

144. Martin JM.; Bertram MG.; Saaristo M.; Fursdon JB.; Hannington SL.; Brooks BW.; Burket SR.; Mole RA.; Deal NDS.; Wong BBM. Antidepressants in Surface Waters: Fluoxetine Influences Mosquitofish Anxiety-Related Behavior at Environmentally Relevant Levels. Environ Sci Technol. 2019, 53, 6035-43. DOI: $10.1021 /$ acs.est.9b00944

145. Nakamura Y.; Yamamoto H.; Sekizawa J.; Kondo T.; Hirai N.; Tatarazako N. The effects of pH on fluoxetine in Japanese medaka (Oryzias latipes): Acute toxicity in fish larvae and bioaccumulation in juvenile fish. Chemosphere. 2008, 70, 865-73. DOI: 10.1016/j.chemosphere.2007.06.089

146. Nowakowska K.; Giebu J.; Kamaszewski M.; Adamski A.; Szudrowicz H.; Ostaszewska T.; Solarska-dzi U.; Na G.; Wroczy P.; Drobniewska A. Acute exposure of zebrafish (Danio rerio) larvae to environmental concentrations of selected antidepressants: Bioaccumulation, physiological and histological changes. Comp Biochem Physiol Part C. 2020, 229, 108670. DOI: 10.1016/j.cbpc.2019.108670

147. Pan C.; Yang M.; Xu H.; Xu B.; Jiang L.; Wu M. Tissue bioconcentration and effects of fluoxetine in zebrafish (Danio rerio) and red crucian carp (Carassius auratus) after short-term and long-term exposure. Chemosphere. 2018, 205, 8-14. DOI: 10.1016/j.chemosphere.2018.04.082

148. Paterson G.; Metcalfe CD. Uptake and depuration of the anti-depressant fluoxetine by the Japanese medaka (Oryzias latipes). Chemosphere. 2008, 74 , 125-30. DOI: 10.1016/j.chemosphere.2008.08.022

149. Ramirez A.; Brain R.; Usenko S.; Mottaleb M.; O’Donnell J.; Stahl L.; Wathen J.; Snyder B.; Pitt J.; Perez-Hurtado P.; Dobbins L.; Brooks B.; Chambliss C. Occurence of pharmaceuticals and personal care products in fish: results of a national pilot study in the United States. Environ Toxicol 
Chem. 2009, 28, 2587-97. DOI: 10.1897/08-561.1

150. Schultz MM.; Painter MM.; Bartell SE.; Logue A.; Furlong ET.; Werner SL.; Schoenfuss HL. Selective uptake and biological consequences of environmentally relevant antidepressant pharmaceutical exposures on male fathead minnows. Aquat Toxicol. 2011, 104, 38-47. DOI:

10.1016/j.aquatox.2011.03.011

151. Sims JL.; Burket SR.; Franco ME.; Lovin LM.; Scarlett KR.; Steenbeek R.; Chambliss CK.; Ashcroft C.; Luers M.; Lavado R.; Brooks BW. Pharmaceutical uptake kinetics in rainbow trout: In situ bioaccumulation in an effluent-dominated river influenced by snowmelt. Sci Total Environ. 2020, 736, 139603. DOI: $10.1016 /$ j.scitotenv.2020.139603

152. Tisler S.; Zindler F.; Freeling F.; Nödler K.; Toelgyesi L.; Braunbeck T.; Zwiener C. Transformation products of fluoxetine formed by photodegradation in water and biodegradation in zebrafish embryos (Danio rerio). Environ Sci Technol. 2019, 53, 7400-9. DOI: 10.1021/acs.est.9b00789

153. Togunde OP.; Oakes KD.; Servos MR.; Pawliszyn J. Determination of pharmaceutical residues in fish bile by solid-phase microextraction couple with liquid chromatography-tandem mass spectrometry (LC/MS/MS). Environ Sci Technol. 2012, 46, 5302-9. DOI: 10.1021/es203758n

154. Yan Z.; Lu G.; Sun H.; Bao X.; Jiang R.; Liu J.; Ji Y. Comparison of the accumulation and metabolite of fluoxetine in zebrafish larva under different environmental conditions with or without carbon nanotubes. Ecotoxicol Environ Saf. 2019, 172, 240-5. DOI: 10.1016/j.ecoenv.2019.01.089

155. Yan Z.; Zhang X.; Bao X.; Ling X.; Yang H.; Liu J.; Lu G.; Ji Y. Influence of dissolved organic matter on the accumulation, metabolite production and multi-biological effects of environmentally relevant fluoxetine in crucian carp (Carassius auratus). Aquat Toxicol. 2020, 226, 105581. DOI: 10.1016/j.aquatox.2020.105581

156. Zindler F.; Tisler S.; Loerracher AK.; Zwiener C.; Braunbeck T. Norfluoxetine Is the only Metabolite of Fluoxetine in Zebrafish (Danio rerio) Embryos That Accumulates at Environmentally Relevant Exposure Scenarios. Environ Sci Technol. 2020, 54, 4200-9. DOI: 10.1021/acs.est.9b07618

157. Chen H.; Liang X.; Gu X.; Zeng Q.; Mao Z.; Martyniuk CJ. Environmentally relevant concentrations of sertraline disrupts behavior and the brain and liver transcriptome of juvenile yellow catfish (Tachysurus fulvidraco): Implications for the feeding and growth axis. J Hazard Mater. 2021, 409 , 124974. DOI: $10.1016 /$ j.jhazmat.2020.124974

158. Fick J.; Lindberg RH.; Parkkonen J.; Arvidsson B.; Tysklind M.; Joakim Larsson DG. Therapeutic levels of levonorgestrel detected in blood plasma of fish: results from screening rainbow trout exposed to treated sewage effluents. Environ Sci Technol. 2010, 44, 2661-6. DOI: 10.1021/es903440m

159. Tanoue R.; Nomiyama K.; Nakamura H.; Hayashi T.; Kim JW.; Isobe T.; Shinohara R.; Tanabe S. Simultaneous determination of polar pharmaceuticals and personal care products in biological organs and tissues. J Chromatogr A. 2014, 1355, 193-205. DOI: 10.1016/j.chroma.2014.06.016

160. Tanoue R.; Nomiyama K.; Nakamura H.; Kim JW.; Isobe T.; Shinohara R.; Kunisue T.; Tanabe S. Uptake and Tissue Distribution of Pharmaceuticals 
and Personal Care Products in Wild Fish from Treated-Wastewater-Impacted Streams. Environ Sci Technol. 2015, 49, 11649-58. DOI: $10.1021 /$ acs.est.5b02478

161. Tanoue R.; Nozaki K.; Nomiyama K.; Kunisue T.; Tanabe S. Rapid analysis of 65 pharmaceuticals and 7 personal care products in plasma and wholebody tissue samples of fish using acidic extraction, zirconia-coated silica cleanup, and liquid chromatography-tandem mass spectrometry. $J$ Chromatogr A. 2020, 1631, 461586. DOI: 10.1016/j.chroma.2020.461586

162. Xie Z.; Lu G.; Li S.; Nie Y.; Ma B.; Liu J. Behavioral and biochemical responses in freshwater fish Carassius auratus exposed to sertraline. Chemosphere. 2015, 135, 146-55. DOI: 10.1016/j.chemosphere.2015.04.031

163. Moreno-González R.; Rodríguez-Mozaz S.; Huerta B.; Barceló D.; León VM. Do pharmaceuticals bioaccumulate in marine molluscs and fish from a coastal lagoon? Environ Res. 2016, 146, 282-98. DOI: 10.1016/j.envres.2016.01.001

164. Qu H.; Ma R.; Wang B.; Yang J.; Duan L.; Yu G. Enantiospecific toxicity, distribution and bioaccumulation of chiral antidepressant venlafaxine and its metabolite in loach (Misgurnus anguillicaudatus) co-exposed to microplastic and the drugs. J Hazard Mater. 2019, 370, 203-11. DOI: 10.1016/j.jhazmat.2018.04.041

165. Rojo M.; Álvarez-Muñoz D.; Dománico A.; Foti R.; Rodriguez-Mozaz S.; Barceló D.; Carriquiriborde P. Human pharmaceuticals in three major fish species from the Uruguay River (South America) with different feeding habits. Environ Pollut. 2019, 252, 146-54. DOI: 10.1016/j.envpol.2019.05.099

166. Ali S.; Champagne DL.; Richardson MK. Behavioral profiling of zebrafish embryos exposed to a panel of 60 water-soluble compounds. Behav Brain Res. 2012, 228, 272-83. DOI: 10.1016/j.bbr.2011.11.020

167. Demin KA.; Kolesnikova TO.; Khatsko SL.; Meshalkina DA.; Efimova E V.; Morzherin YY.; Kalueff A V. Acute effects of amitriptyline on adult zebrafish: Potential relevance to antidepressant drug screening and modeling human toxidromes. Neurotoxicol Teratol. 2017, 62, 27-33. DOI: $10.1016 /$ j.ntt.2017.04.002

168. Demin KA.; Lakstygal AM.; Chernysh M V.; Krotova NA.; Taranov AS.; Ilyin NP.; Seredinskaya M V.; Tagawa N.; Savva AK.; Mor MS.; Vasyutina ML.; Efimova E V.; Kolesnikova TO.; Gainetdinov RR.; Strekalova T.; Amstislavskaya TG.; Abreu MS De.; Kalueff A V. The zebrafish tail immobilization (ZTI) test as a new tool to assess stress- related behavior and a potential screen for drugs affecting despair-like states. $J$ Neurosci Methods. 2020, 337, 108637. DOI: 10.1016/j.jneumeth.2020.108637

169. Meshalkina DA.; Kysil E V.; Antonova KA.; Demin KA.; Kolesnikova TO.; Khatsko SL.; Gainetdinov RR.; Alekseeva PA.; Kalueff A V. The effects of chronic amitriptyline on zebrafish behavior and monoamine neurochemistry. Neurochem Res. 2018, 43, 1191-9. DOI: 10.1007/s11064-018-2536-5

170. Schmieg H.; Burmester JKY.; Krais S.; Ruhl AS.; Tisler S.; Zwiener C.; Köhler HR.; Triebskorn R. Interacting effects of polystyrene microplastics and the antidepressant amitriptyline on early life stages of brown trout (Salmo trutta f. fario). Water. 2020, 12, 2361. DOI: 10.3390/W12092361 
171. Sehonova P.; Plhalova L.; Blahova J.; Doubkova V.; Marsalek P.; Prokes M.; Tichy F.; Skladana M.; Fiorino E.; Mikula P.; Vecerek V.; Faggio C.; Svobodova Z. Effects of selected tricyclic antidepressants on early-life stages of common carp (Cyprinus carpio). Chemosphere. 2017, 185, 1072-80. DOI: $10.1016 /$ j.chemosphere.2017.07.092

172. Sehonova P.; Hodkovicova N.; Urbanova M.; Örn S.; Blahova J.; Svobodova Z.; Faldyna M.; Chloupek P.; Briedikova K.; Carlsson G. Effects of antidepressants with different modes of action on early life stages of fish and amphibians. Environ Pollut. 2019, 254, 112999. DOI: 10.1016/j.envpol.2019.112999

173. Sehonova P.; Zikova A.; Blahova J.; Svobodova Z.; Chloupek P.; Kloas W. mRNA expression of antioxidant and biotransformation enzymes in zebrafish (Danio rerio) embryos after exposure to the tricyclic antidepressant amitriptyline. Chemosphere. 2019, 217, 516-21. DOI: 10.1016/j.chemosphere.2018.10.208

174. Wu M.; Liu S.; Hu L.; Qu H.; Pan C.; Lei P. Global transcriptomic analysis of zebrafish in response to embryonic exposure to three antidepressants, amitriptyline, fluoxetine and mianserin. Aquat Toxicol. 2017, 192, 274-83. DOI: 10.1016/j.aquatox.2017.09.027

175. Yang M.; Qiu W.; Chen J.; Zhan J.; Pan C.; Lei X.; Wu M. Growth inhibition and coordinated physiological regulation of zebrafish (Danio rerio) embryos upon sublethal exposure to antidepressant amitriptyline. Aquat Toxicol. 2014, 151, 68-76. DOI: 10.1016/j.aquatox.2013.12.029

176. Ziarrusta H.; Ribbenstedt A.; Mijangos L.; Picart-Armada S.; Perera-Lluna A.; Prieto A.; Izagirre U.; Benskin JP.; Olivares M.; Zuloaga O.; Etxebarria N. Amitriptyline at an Environmentally Relevant Concentration Alters the Profile of Metabolites Beyond Monoamines in Gilt-Head Bream. Environ Toxicol Chem. 2019, 38, 965-77. DOI: 10.1002/etc.4381

177. Bachour RL.; Golovko O.; Kellner M.; Pohl J. Behavioral effects of citalopram, tramadol, and binary mixture in zebrafish (Danio rerio) larvae. Chemosphere. 2020, 238, 124587. DOI: 10.1016/j.chemosphere.2019.124587

178. Chiffre A.; Clerandeau C.; Dwoinikoff C.; Le Bihanic F.; Budzinski H.; Geret F.; Cachot J. Psychotropic drugs in mixture alter swimming behaviour of Japanese medaka (Oryzias latipes) larvae above environmental concentrations. Environ Sci Pollut Res. 2016, 23, 4964-77. DOI: 10.1007/s11356$014-3477-4$

179. Clément RJG.; Macrì S.; Porfiri M. Design and development of a robotic predator as a stimulus in conditioned place aversion for the study of the effect of ethanol and citalopram in zebrafish. Behav Brain Res. 2020, 378, 112256. DOI: 10.1016/j.bbr.2019.112256

180. Fraher D.; Hodge JM.; Collier FM.; McMillan JS.; Kennedy RL.; Ellis M.; Nicholson GC.; Walder K.; Dodd S.; Berk M.; Pasco JA.; Williams LJ.; Gibert Y. Citalopram and sertraline exposure compromises embryonic bone development. Mol Psychiatry. 2016, 21, 656-64. DOI: $10.1038 / \mathrm{mp} .2015 .135$

181. Höglund E.; Øverli Ø.; Åtland Å. Assaying waterborne psychoactive drugs by the response to naturalistic predator cues in the stickleback (Gasterosteus aculeatus). Sci Total Environ. 2020, 737, 140257. DOI: 10.1016/j.scitotenv.2020.140257 
182. Kellner M.; Porseryd T.; Porsch-Hällström I.; Hansen SH.; Olsén KH. Environmentally relevant concentrations of citalopram partially inhibit feeding in the three-spine stickleback (Gasterosteus aculeatus). Aquat Toxicol. 2015, 158, 165-70. DOI: 10.1016/j.aquatox.2014.11.003

183. Kellner M.; Porseryd T.; Hallgren S.; Porsch-H??llstr??m I.; Hansen SH.; Ols??n KH. Waterborne citalopram has anxiolytic effects and increases locomotor activity in the three-spine stickleback (Gasterosteus aculeatus). Aquat Toxicol. 2016, 173, 19-28. DOI: 10.1016/j.aquatox.2015.12.026

184. Kellner M.; Porseryd T.; Porsch-Hällström I.; Borg B.; Roufidou C.; Olsén KH. Developmental exposure to the SSRI citalopram causes long-lasting behavioural effects in the three-spined stickleback (Gasterosteus aculeatus). Ecotoxicology. 2018, 27, 12-22. DOI: 10.1007/s10646-017-1866-4

185. Kellner M.; Olsén KH. Divergent Response to the SSRI Citalopram in Male and Female Three-Spine Sticklebacks (Gasterosteus aculeatus). Arch Environ Contam Toxicol. 2020, 79, 478-87. DOI: 10.1007/s00244-020-00776-1

186. Olsén KH.; Ask K.; Olsén H.; Porsch-Hällström I.; Hallgren S. Effects of the SSRI citalopram on behaviours connected to stress and reproduction in Endler guppy, Poecilia wingei. Aquat Toxicol. 2014, 151, 97-104. DOI: 10.1016/j.aquatox.2014.02.011

187. Porseryd T.; Kellner M.; Reyhanian N.; Volkova K.; Elabbas L.; Ullah S.; Olsén H.; Dinnétz P.; Porsch I. Combinatory effects of low concentrations of $17 \alpha$-etinylestradiol and citalopram on non-reproductive behavior in adult zebrafish (Danio rerio). Aquat Toxicol. 2017, 193, 9-17. DOI: 10.1016/j.aquatox.2017.10.001

188. Prasad P.; Ogawa S.; Parhar IS. Serotonin Reuptake Inhibitor Citalopram Inhibits GnRH Synthesis and Spermatogenesis in the Male Zebrafish. Biol Reprod. 2015, 93, 1-10. DOI: 10.1095/biolreprod.115.129965

189. Sackerman J.; Donegan JJ.; Cunningham CS.; Nhung Nyuyen N.; Lawless K.; Long A.; Benno RH.; Gould GG. Zebrafish behaviour in novel environments: effects of acute exposure to anxiolytic compounds and chhoice of Danio rerio line. Int J Comp Psychol. 2010, 23, 43-61. DOI: 10.1016/j.jdiacomp.2008.01.002.Postural

190. Steele WB.; Kristofco LA.; Corrales J.; Saari GN.; Haddad SP.; Gallagher EP.; Kavanagh TJ.; Kostal J.; Zimmerman JB.; Voutchkova-Kostal A.; Anastas P.; Brooks BW. Comparative behavioral toxicology with two common larval fish models: Exploring relationships among modes of action and locomotor responses. Sci Total Environ. 2018, 640-641, 1587-600. DOI: 10.1016/j.scitotenv.2018.05.402

191. Ziegler M.; Eckstein H.; Ottmann S.; Reinelt L.; Stepinski S.; Köhler HR.; Triebskorn R. Biochemical and cellular biomarkers in brown trout (Salmo trutta f. fario) in response to the antidepressants citalopram and venlafaxine. Environ Sci Eur. 2020, 32, 158. DOI: 10.1186/s12302-020-00437-z

192. Zindler F.; Beedgen F.; Brandt D.; Steiner M.; Stengel D.; Baumann L.; Braunbeck T. Analysis of tail coiling activity of zebrafish (Danio rerio) embryos allows for the differentiation of neurotoxicants with different modes of action. Ecotoxicol Environ Saf. 2019, 186, 109754. DOI: 10.1016/j.ecoenv.2019.109754

193. Zindler F.; Stoll S.; Baumann L.; Knoll S.; Huhn C.; Braunbeck T. Do environmentally relevant concentrations of fluoxetine and citalopram impair stress-related behavior in zebrafish (Danio rerio) embryos? Chemosphere. 2020, 261, 127753. DOI: 10.1016/j.chemosphere.2020.127753 
194. Zhu J-J.; Xu Y-Q.; He J-H.; Yu H-P.; Huang C-J.; Gao J-M.; Dong Q-X.; Xuan Y-X.; Li C-Q. Human cardiotoxic drugs delivered by soaking and microinjection induce cardiovascular toxicity in zebrafish. $J$ Appl Toxicol. 2014, 34, 139-48. DOI: 10.1002/jat.2843

195. Richendrfer H.; Creton R. Cluster analysis profiling of behaviors in zebrafish larvae treated with antidepressants and pesticides. Neurotoxicol Teratol. 2018, 69, 54-62. DOI: $10.1016 /$ j.ntt.2017.10.009

196. Nielsen S V.; Kellner M.; Henriksen PG.; Olsén H.; Hansen SH.; Baatrup E. The psychoactive drug Escitalopram affects swimming behaviour and increases boldness in zebrafish (Danio rerio). Ecotoxicology. 2018, 27, 485-97. DOI: 10.1007/s10646-018-1920-x

197. De Abreu MS.; Koakoski G.; Ferreira D.; Acosta Oliveira T.; Santos Da Rosa JG.; Gusso D.; Varrone Giacomini AC.; Piato AL.; Barcellos LJG. Diazepam and fluoxetine decrease the stress response in zebrafish. PLoS One. 2014, 9, e103232. DOI: 10.1371/journal.pone.0103232

198. Abreu MS.; Giacomini AC V.; Koakoski G.; Oliveira TA.; Gusso D.; Baldisserotto B.; Barcellos LJG. Effects of waterborne fluoxetine on stress response and osmoregulation in zebrafish. Environ Toxicol Pharmacol. 2015, 40, 704-7. DOI: 10.1016/j.etap.2015.09.001

199. Abreu MS.; Giacomini ACVV.; Koakoski G.; Piato ALS.; Barcellos LJG. Divergent effect of fluoxetine on the response to physical or chemical stressors in zebrafish. PeerJ. 2017, 5, e3330. DOI: 10.7717/peerj.3330

200. Airhart MJ.; Lee DH.; Wilson TD.; Miller BE.; Miller MN.; Skalko RG. Movement disorders and neurochemical changes in zebrafish larvae after bath exposure to fluoxetine (PROZAC). Neurotoxicol Teratol. 2007, 29, 652-64. DOI: 10.1016/j.ntt.2007.07.005

201. Aliko V.; Mehmeti E.; Qirjo M.; Faggio C. Drink and sleep like a fish: Goldfish as a behavior model to study pharmaceutical effects in freshwater ecosystems. J Biol Res. 2019, 92, 7939. DOI: 10.4081/jbr.2019.7939

202. Amador MHB.; Schauer KL.; McDonald MD. Does fluoxetine exposure affect hypoxia tolerance in the Gulf toadfish, Opsanus beta? Aquat Toxicol. 2018, 199, 55-64. DOI: 10.1016/j.aquatox.2018.03.023

203. Bain PA.; Basheer VS.; Gregg A.; Jena JK.; Kumar A. In vitro nuclear receptor activity and in vivo gene expression analysis in Murray-Darling rainbowfish (Melanotaenia fluviatilis) after short-term exposure to fluoxetine. Comp Biochem Physiol Part C. 2016, 188, 1-8. DOI: 10.1016/j.cbpc.2016.05.007

204. Barry MJ. Effects of fluoxetine on the swimming and behavioural responses of the Arabian killifish. Ecotoxicology. 2013, 22, 425-32. DOI: $10.1007 / \mathrm{s} 10646-012-1036-7$

205. Bertram MG.; Ecker TE.; Wong BBM.; O’Bryan MK.; Baumgartner JB.; Martin JM.; Saaristo M. The antidepressant fluoxetine alters mechanisms of pre- and post-copulatory sexual selection in the eastern mosquitofish (Gambusia holbrooki). Environ Pollut. 2018, 238, 238-47. DOI: 10.1016/j.envpol.2018.03.006

206. Chai T.; Cui F.; Di S.; Wu S.; Zhang Y.; Wang X. New insights into cardiotoxicity induced by chiral fluoxetine at environmental-level: Enantioselective arrhythmia in developmental zebrafish (Danio rerio). Environ Pollut. 2021, 270, 116182. DOI: 10.1016/j.envpol.2020.116182 
207. Chen H.; Zeng X.; Mu L.; Hou L.; Yang B.; Zhao J.; Schlenk D.; Dong W.; Xie L.; Zhang Q. Effects of acute and chronic exposures of fluoxetine on the Chinese fish, topmouth gudgeon Pseudorasbora parva. Ecotoxicol Environ Saf. 2018, 160, 104-13. DOI: 10.1016/j.ecoenv.2018.04.061

208. Cunha V.; Rodrigues P.; Santos MM.; Moradas-Ferreira P.; Ferreira M. Danio rerio embryos on Prozac - Effects on the detoxification mechanism and embryo development. Aquat Toxicol. 2016, 178, 182-9. DOI: 10.1016/j.aquatox.2016.08.003

209. Cunha V.; Rodrigues P.; Santos MM.; Moradas-Ferreira P.; Ferreira M. Fluoxetine modulates the transcription of genes involved in serotonin, dopamine and adrenergic signalling in zebrafish embryos. Chemosphere. 2018, 191, 954-61. DOI: 10.1016/j.chemosphere.2017.10.100

210. Demin KA.; Lakstygal AM.; Krotova NA.; Masharsky A.; Tagawa N.; Chernysh M V.; Ilyin NP.; Taranov AS.; Galstyan DS.; Derzhavina KA.; Levchenko NA.; Kolesnikova TO.; Mor MS.; Vasyutina ML.; Efimova E V.; Katolikova N.; Prjibelski AD.; Gainetdinov RR.; de Abreu MS.; Amstislavskaya TG.; Strekalova T.; Kalueff, AV. Understanding complex dynamics of behavioral, neurochemical and transcriptomic changes induced by prolonged chronic unpredictable stress in zebrafish. Sci Rep. 2020, 10, 19981. DOI: 10.1038/s41598-020-75855-3

211. Duarte IA.; Pais MP.; Reis-Santos P.; Cabral HN.; Fonseca VF. Biomarker and behavioural responses of an estuarine fish following acute exposure to fluoxetine. Mar Environ Res. 2019, 147, 24-31. DOI: 10.1016/j.marenvres.2019.04.002

212. Duarte IA.; Reis-Santos P.; Novais SC.; Rato LD.; Lemos MFL.; Freitas A.; Pouca ASV.; Barbosa J.; Cabral HN.; Fonseca VF. Depressed, hypertense and sore: Long-term effects of fluoxetine, propranolol and diclofenac exposure in a top predator fish. Sci Total Environ. 2020, 712, 136564. DOI: 10.1016/j.scitotenv.2020.136564

213. Dzieweczynski TL.; Kane JL.; Campbell BA.; Lavin LE. Fluoxetine exposure impacts boldness in female Siamese fighting fish, Betta splendens. Ecotoxicology. 2016, 25, 69-79. DOI: 10.1007/s10646-015-1568-8

214. Dzieweczynski TL.; Hebert OL. Fluoxetine alters behavioral consistency of aggression and courtship in male Siamese fighting fish, Betta splendens. Physiol Behav. 2012, 107, 92-7. DOI: 10.1016/j.physbeh.2012.06.007

215. Egan RJ.; Bergner CL.; Hart PC.; Cachat JM.; Canavello PR.; Elegante MF.; Elkhayat SI.; Bartels BK.; Tien AK.; Tien DH.; Mohnot S.; Beeson E.; Glasgow E.; Amri H.; Zukowska Z.; Kalueff A V. Understanding behavioral and physiological phenotypes of stress and anxiety in zebrafish. Behav Brain Res. 2009, 205, 38-44. DOI: 10.1016/j.bbr.2009.06.022

216. Eisenreich BR.; Szalda-petree A. Behavioral effects of fluoxetine on aggression and associative learning in Siamese fighting fish (Betta splendens). Behav Processes. 2015, 121, 37-42. DOI: 10.1016/j.beproc.2015.10.008

217. de Farias NO.; Oliveira R.; Sousa-Moura D.; de Oliveira RCS.; Rodrigues MAC.; Andrade TS.; Domingues I.; Camargo NS.; Muehlmann LA.; Grisolia CK. Exposure to low concentration of fluoxetine affects development, behaviour and acetylcholinesterase activity of zebrafish embryos. Comp Biochem Physiol Part C. 2019, 215, 1-8. DOI: 10.1016/j.cbpc.2018.08.009

218. Fursdon JB.; Martin JM.; Bertram MG.; Lehtonen TK.; Wong BBM. The pharmaceutical pollutant fluoxetine alters reproductive behaviour in a fish 
independent of predation risk. Sci Total Environ. 2019, 650, 642-52. DOI: 10.1016/j.scitotenv.2018.09.046

219. Gaworecki KM.; Klaine SJ. Behavioral and biochemical responses of hybrid striped bass during and after fluoxetine exposure. Aquat Toxicol. 2008, 88, 207-13. DOI: 10.1016/j.aquatox.2008.04.011

220. Giacomini ACVV.; Piassetta AS.; Genario R.; Bonan CD.; Piato A.; Barcellos LJG.; de Abreu MS. Tryptophan alleviates neuroendocrine and behavioral responses to stress in zebrafish. Behav Brain Res. 2020, 378, 112264. DOI: 10.1016/j.bbr.2019.112264

221. Greaney NE.; Mannion KL.; Dzieweczynski TL. Signaling on Prozac: altered audience effects on male-male interactions after fluoxetine exposure in Siamese fighting fish. Behav Ecol Sociobiol. 2015, 69, 1925-32. DOI: 10.1007/s00265-015-2005-y

222. Henry TB.; Black MC. Acute and Chronic Toxicity of Fluoxetine (Selective Serotonin Reuptake Inhibitor) in Western Mosquitofish. Arch Environ Contam Toxicol. 2008, 54, 325-30. DOI: 10.1007/s00244-007-9018-0

223. Huang IJ.; Dheilly NM.; Sirotkin HI.; McElroy AE. Comparative transcriptomics implicate mitochondrial and neurodevelopmental impairments in larval zebrafish (Danio rerio) exposed to two selective serotonin reuptake inhibitors (SSRIs). Ecotoxicol Environ Saf. 2020, 203, 110934. DOI: 10.1016/j.ecoenv.2020.110934

224. Kalichak F.; Idalencio R.; Rosa JGS.; Oliveira TA d.; Koakoski G.; Gusso D.; Abreu MS d.; Giacomini AC V.; Barcellos HHA.; Fagundes M.; Piato AL.; Barcellos LJG. Waterborne psychoactive drugs impair the initial development of Zebrafish. Environ Toxicol Pharmacol. 2016, 41, 89-94. DOI: 10.1016/j.etap.2015.11.014

225. Lister A.; Regan C.; Van Zwol J.; Van Der Kraak G. Inhibition of egg production in zebrafish by fluoxetine and municipal effluents: A mechanistic evaluation. Aquat Toxicol. 2009, 95, 320-9. DOI: 10.1016/j.aquatox.2009.04.011

226. Magno LDP.; Fontes A.; Gonçalves BMN.; Gouveia A. Pharmacological study of the light/dark preference test in zebrafish (Danio rerio): Waterborne administration. Pharmacol Biochem Behav. 2015, 135, 169-76. DOI: 10.1016/j.pbb.2015.05.014

227. Marcon M.; Herrmann AP.; Mocelin R.; Rambo CL.; Koakoski G.; Abreu MS.; Conterato GMM.; Kist LW.; Bogo MR.; Zanatta L.; Barcellos LJG.; Piato AL. Prevention of unpredictable chronic stress-related phenomena in zebrafish exposed to bromazepam, fluoxetine and nortriptyline. Psychopharmacology (Berl). 2016, 233, 3815-24. DOI: 10.1007/s00213-016-4408-5

228. Martin JM.; Saaristo M.; Bertram MG.; Lewis PJ.; Coggan TL.; Clarke BO.; Wong BBM. The psychoactive pollutant fluoxetine compromises antipredator behaviour in fish. Environ Pollut. 2017, 222, 592-9. DOI: 10.1016/j.envpol.2016.10.010

229. Martin JM.; Bertram MG.; Saaristo M.; Ecker TE.; Hannington SL.; Tanner JL.; Michelangeli M.; O’Bryan MK.; Wong BBM. Impact of the widespread pharmaceutical pollutant fluoxetine on behaviour and sperm traits in a freshwater fish. Sci Total Environ. 2019, 650, 1771-8. DOI: 10.1016/j.scitotenv.2018.09.294

230. Martin JM.; Saaristo M.; Tan H.; Bertram MG.; Nagarajan-Radha V.; Dowling DK.; Wong BBM. Field-realistic antidepressant exposure disrupts 
group foraging dynamics in mosquitofish. Biol Lett. 2019, 15, 20190615. DOI: 10.1098/rsbl.2019.0615

231. Martin JM.; Nagarajan-Radha V.; Tan H.; Bertram MG.; Brand JA.; Saaristo M.; Dowling DK.; Wong BBM. Antidepressant exposure causes a nonmonotonic reduction in anxiety-related behaviour in female mosquitofish. J Hazard Mater Lett. 2020, 1, 100004. DOI: 10.1016/j.hazl.2020.100004

232. Martinez R.; Vera-Chang MN.; Haddad M.; Zon J.; Navarro-Martin L.; Trudeau VL.; Mennigen JA. Developmental fluoxetine exposure in zebrafish reduces offspring basal cortisol concentration via life stage-dependent maternal transmission. PLoS One. 2019, 14, e0212577. DOI: 10.1371/journal.pone.0212577

233. McCallum ES.; Bose APH.; Warriner TR.; Balshine S. An evaluation of behavioural endpoints: The pharmaceutical pollutant fluoxetine decreases aggression across multiple contexts in round goby (Neogobius melanostomus). Chemosphere. 2017, 175, 401-10. DOI: 10.1016/j.chemosphere.2017.02.059

234. Meijide FJ.; Da Cuña RH.; Prieto JP.; Dorelle LS.; Babay PA.; Lo Nostro FL. Effects of waterborne exposure to the antidepressant fluoxetine on swimming, shoaling and anxiety behaviours of the mosquitofish Gambusia holbrooki. Ecotoxicol Environ Saf. 2018, 163, 646-55. DOI: 10.1016/j.ecoenv.2018.07.085

235. Mennigen JA.; Lado WE.; Zamoraa JM.; Duarte-Guterman P.; Langlois VS.; Metcalfe CD.; Chang JP.; Moon TW.; Trudeau VL. Waterborne fluoxetine disrupts the reproductive axis in sexually mature male goldfish, Carassius auratus. Aquat Toxicol. 2010, 100, 354-64. DOI: 10.1016/j.aquatox.2010.08.016

236. Mennigen JA.; Sassine J.; Trudeau VL.; Moon TW. Waterborne fluoxetine disrupts feeding and energy metabolism in the goldfish Carassius auratus. Aquat Toxicol. 2010, 100, 128-37. DOI: 10.1016/j.aquatox.2010.07.022

237. Mennigen JA.; Zamora JM.; Chang JP.; Trudeau VL. Endocrine disrupting effects of waterborne fluoxetine exposure on the reproductive axis of female goldfish, Carassius auratus. Comp Biochem Physiol Part C Toxicol Pharmacol. 2017, 202, 70-8. DOI: 10.1016/j.cbpc.2017.08.003

238. Mishra P.; Gong Z.; Kelly BC. Assessing biological effects of fluoxetine in developing zebrafish embryos using gas chromatography-mass spectrometry based metabolomics. Chemosphere. 2017, 188, 157-67. DOI: 10.1016/j.chemosphere.2017.08.149

239. Mishra P.; Gong Z.; Kelly BC. Assessing pH-dependent toxicity of fluoxetine in embryonic zebrafish using mass spectrometry-based metabolomics. Sci Total Environ. 2019, 650, 2731-41. DOI: 10.1016/j.scitotenv.2018.09.364

240. Painter MM.; Buerkley MA.; Julius ML.; Vajda AM.; Norris DO.; Barber LB.; Furlong ET.; Schultz MM.; Schoenfuss HL. Antidepressants at environmentally relevant concentrations affect predator avoidance behavior of larval fathead minnows (Pimephales promelas). Environ Toxicol Chem. 2009, 28, 2677-84. DOI: $10.1897 / 08-556.1$

241. Park J-W.; Heah TP.; Gouffon JS.; Henry TB.; Sayler GS. Global gene expression in larval zebrafish (Danio rerio) exposed to selective serotonin reuptake inhibitors (fluoxetine and sertraline) reveals unique expression profiles and potential biomarkers of exposure. Environ Pollut. 2012, 167, 
163-70. DOI: $10.1016 / j$.envpol.2012.03.039

242. Parolini M.; Ghilardi A.; De Felice B.; Del Giacco L. Environmental concentration of fluoxetine disturbs larvae behavior and increases the defense response at molecular level in zebrafish (Danio rerio). Environ Sci Pollut Res. 2019, 26, 34943-52. DOI: 10.1007/s11356-019-06619-4

243. Pei S.; Liu L.; Zhong Z.; Wang H.; Lin S.; Shang J. Risk of prenatal depression and stress treatment: alteration on serotonin system of offspring through exposure to Fluoxetine. Sci Rep. 2016, 6, 33822. DOI: 10.1038/srep33822

244. Pelli M.; Connaughton VP. Chronic exposure to environmentally-relevant concentrations of fluoxetine (Prozac) decreases survival, increases abnormal behaviors, and delays predator escape responses in guppies. Chemosphere. 2015, 139, 202-9. DOI: 10.1016/j.chemosphere.2015.06.033

245. Saaristo M.; McLennan A.; Johnstone CP.; Clarke BO.; Wong BBM. Impacts of the antidepressant fluoxetine on the anti-predator behaviours of wild guppies (Poecilia reticulata). Aquat Toxicol. 2017, 183, 38-45. DOI: 10.1016/j.aquatox.2016.12.007

246. Shen Q.; Truong L.; Simonich MT.; Huang C.; Tanguay RL.; Dong Q. Rapid well-plate assays for motor and social behaviors in larval zebrafish. Behav Brain Res. 2020, 391, 112625. DOI: 10.1016/j.bbr.2020.112625

247. Al Shuraiqi A.; Al-Habsi A.; Barry MJ. Time-, dose- and transgenerational effects of fluoxetine on the behavioural responses of zebrafish to a conspecific alarm substance. Environ Pollut. 2021, 270, 116164. DOI: 10.1016/j.envpol.2020.116164

248. Singer ML.; Oreschak K.; Rhinehart Z.; Robison BD. Anxiolytic effects of fluoxetine and nicotine exposure on exploratory behavior in zebrafish. PeerJ. 2016, 4, e2352. DOI: $10.7717 /$ peerj.2352

249. Sinyakova NA.; Kulikova EA.; Englevskii NA.; Kulikov A V. Effects of Fluoxetine and Potential Antidepressant 8-Trifluoromethyl 1,2,3,4,5Benzopentathiepin-6-Amine Hydrochloride (TC-2153) on Behavior of Danio rerio Fish in the Novel Tank Test and Brain Content of Biogenic Amines and Their Metabolites. Bull Exp Biol Med. 2018, 164, 620-3. DOI: 10.1007/s10517-018-4045-6

250. Stanley JK.; Ramirez AJ.; Chambliss CK.; Brooks BW. Enantiospecific sublethal effects of the antidepressant fluoxetine to a model aquatic vertebrate and invertebrate. Chemosphere. 2007, 69, 9-16. DOI: 10.1016/j.chemosphere.2007.04.080

251. Tan H.; Polverino G.; Martin JM.; Bertram MG.; Wiles SC.; Palacios MM.; Bywater CL.; White CR.; Wong BBM. Chronic exposure to a pervasive pharmaceutical pollutant erodes among-individual phenotypic variation in a fish. Environ Pollut. 2020, 263, 114450. DOI: 10.1016/j.envpol.2020.114450

252. Theodoridi A.; Tsalafouta A.; Pavlidis M. Acute exposure to fluoxetine alters aggressive behavior of zebrafish and expression of genes involved in serotonergic system regulation. Front Neurosci. 2017, 11, 223. DOI: 10.3389/fnins.2017.00223

253. Thomas MA.; Joshi PP.; Klaper RD. Gene-class analysis of expression patterns induced by psychoactive pharmaceutical exposure in fathead minnow (Pimephales promelas) indicates induction of neuronal systems. Comp Biochem Physiol Part C. 2012, 155, 109-20. DOI: 10.1016/j.cbpc.2011.05.014 
254. Thoré ESJ.; Philippe C.; Brendonck L.; Pinceel T. Antidepressant exposure reduces body size, increases fecundity and alters social behavior in the short-lived killifish Nothobranchius furzeri. Environ Pollut. 2020, 265, 115068. DOI: 10.1016/j.envpol.2020.115068

255. Thoré ESJ.; Van Hooreweghe F.; Philippe C.; Brendonck L.; Pinceel T. Generation-specific and interactive effects of pesticide and antidepressant exposure in a fish model call for multi-stressor and multigenerational testing. Aquat Toxicol. 2021, 232,. DOI: 10.1016/j.aquatox.2021.105743

256. Vázquez GR.; Hernán R.; Cuña D.; Dorelle LS.; Laura F.; Nostro L. Immunohistological Biomarkers of Toxicity by a Pharmaceutical Antidepressant in the Freshwater Cichlid Fish Cichlasoma dimerus. Bull Environ Contam Toxicol. 2020, 104, 180-4. DOI: 10.1007/s00128-019-02770-3

257. Vera-Chang MN.; St-Jacques AD.; Gagné R.; Martyniuk CJ.; Yauk CL.; Moon TW.; Trudeau VL. Transgenerational hypocortisolism and behavioral disruption are induced by the antidepressant fluoxetine in male zebrafish Danio rerio. PNAS. 2018, 115, E12435-42. DOI: 10.1073/pnas.1811695115

258. Vera-Chang MN.; Moon TW.; Trudeau VL. Cortisol disruption and transgenerational alteration in the expression of stress-related genes in zebrafish larvae following fluoxetine exposure. Toxicol Appl Pharmacol. 2019, 382, 114742. DOI: 10.1016/j.taap.2019.114742

259. Weinberger J.; Klaper R. Environmental concentrations of the selective serotonin reuptake inhibitor fluoxetine impact specific behaviors involved in reproduction, feeding and predator avoidance in the fish Pimephales promelas (fathead minnow). Aquat Toxicol. 2014, 151, 77-83. DOI: 10.1016/j.aquatox.2013.10.012

260. Wiles SC.; Bertram MG.; Martin JM.; Tan H.; Lehtonen TK.; Wong BBM. Long-Term Pharmaceutical Contamination and Temperature Stress Disrupt Fish Behavior. Environ Sci Technol. 2020, 54, 8072-82. DOI: 10.1021/acs.est.0c01625

261. Winder VL.; Pennington PL.; Hurd MW.; Wirth EF. Fluoxetine effects on sheepshead minnow (Cyprinodon variegatus) locomotor activity. J Environ Sci Heal Part B. 2012, 47, 51-8. DOI: 10.1080/03601234.2012.607767

262. Wong RY.; Oxendine SE.; Godwin J. Behavioral and neurogenomic transcriptome changes in wild-derived zebrafish with fluoxetine treatment. BMC Genomics. 2013, 14, 1-13. DOI: 10.1186/1471-2164-14-348

263. Oliveira AC.; Fascineli ML.; Andrade TS.; Sousa-Moura D.; Domingues I.; Camargo NS.; Oliveira R.; Grisolia CK.; Villacis RAR. Exposure to tricyclic antidepressant nortriptyline affects early-life stages of zebrafish (Danio rerio). Ecotoxicol Environ Saf. 2021, 210, 111868. DOI: 10.1016/j.ecoenv.2020.111868

264. Carty DR.; Hala D.; Huggett DB. The Effects of Sertraline on Fathead Minnow (Pimephales promelas) Growth and Steroidogenesis. Bull Environ Contam Toxicol. 2017, 98, 753-7. DOI: 10.1007/s00128-017-2079-5

265. Hedgespeth ML.; Nilsson PA.; Berglund O. Ecological implications of altered fish foraging after exposure to an antidepressant pharmaceutical. Aquat Toxicol. 2014, 151, 84-7. DOI: 10.1016/j.aquatox.2013.12.011

266. Kania BF.; Wrońska D. The Selective Serotonin Reuptake Inhibitor-Sertraline Diminishes Conspecific Aggression in Male Fighting Betta splendens Fish. J Behav Brain Sci. 2015, 5, 578-85. DOI: 10.4236/jbbs.2015.513055 
267. Ribeiro S.; Torres T.; Martins R.; Santos MM. Toxicity screening of diclofenac, propranolol, sertraline and simvastatin using danio rerio and paracentrotus lividus embryo bioassays. Ecotoxicol Environ Saf. 2015, 114, 67-74. DOI: 10.1016/j.ecoenv.2015.01.008

268. Stoczynski L.; van den Hurk P. Effects of selective serotonin reuptake inhibitor sertraline on hybrid striped bass predatory behavior and brain chemistry. Aquat Toxicol. 2020, 226, 105564. DOI: 10.1016/j.aquatox.2020.105564

269. Valenti TW.; Perez-Hurtado P.; Chambliss CK.; Brooks BW. Aquatic toxicity of sertraline to Pimephales promelas at environmentally relevant surface water pH. Environ Toxicol Chem. 2009, 28, 2685-94. DOI: 10.1897/08-546.1

270. Valenti TW.; Gould GG.; Berninger JP.; Connors KA.; Keele NB.; Prosser KN.; Brooks BW. Human therapeutic plasma levels of the selective serotonin reuptake inhibitor (SSRI) sertraline decrease serotonin reuptake transporter binding and shelter-seeking behavior in adult male fathead minnows. Environ Sci Technol. 2012, 46, 2427-35. DOI: 10.1021/es204164b

271. Best C.; Melnyk-lamont N.; Gesto M.; Vijayan MM. Environmental levels of the antidepressant venlafaxine impact the metabolic capacity of rainbow trout. Aquat Toxicol. 2014, 155, 190-8. DOI: 10.1016/j.aquatox.2014.06.014

272. Bisesi JH.; Bridges W.; Klaine SJ. Effects of the antidepressant venlafaxine on fish brain serotonin and predation behavior. Aquat Toxicol. 2014, 151, 88-96. DOI: 10.1016/j.aquatox.2014.02.015

273. Galus M.; Kirischian N.; Higgins S.; Purdy J.; Chow J.; Rangaranjan S.; Li H.; Metcalfe C.; Wilson JY. Chronic, low concentration exposure to pharmaceuticals impacts multiple organ systems in zebrafish. Aquat Toxicol. 2013, 132-133, 200-11. DOI: 10.1016/j.aquatox.2012.12.021

274. Hodkovicova N.; Sehonova P.; Blahova J.; Faldyna M.; Marsalek P.; Mikula P.; Chloupek P.; Dobsikova R.; Vecerek V.; Vicenova M.; Vosmerova P.; Svobodova Z. The effect of the antidepressant venlafaxine on gene expression of biotransformation enzymes in zebrafish (Danio rerio) embryos. Environ Sci Pollut Res. 2020, 1686-96. DOI: 10.1007/s11356-019-06726-2

275. Ikert H.; Craig PM. Chronic exposure to venlafaxine and increased water temperature reversibly alters microRNA in zebrafish gonads (Danio rerio). Comp Biochem Physiol - Part D. 2020, 33, 100634. DOI: 10.1016/j.cbd.2019.100634

276. Ings JS.; George N.; Peter MCS.; Servos MR.; Vijayan MM. Venlafaxine and atenolol disrupt epinephrine-stimulated glucose production in rainbow trout hepatocytes. Aquat Toxicol. 2012, 106-107, 48-55. DOI: 10.1016/j.aquatox.2011.10.006

277. Maulvault AL.; Santos LHMLM.; Paula JR.; Camacho C.; Pissarra V.; Fogaça F.; Barbosa V.; Alves R.; Ferreira PP.; Barceló D.; Rodriguez-Mozaz S.; Marques A.; Diniz M.; Rosa R. Differential behavioural responses to venlafaxine exposure route, warming and acidification in juvenile fish (Argyrosomus regius). Sci Total Environ. 2018, 634, 1136-47. DOI: 10.1016/j.scitotenv.2018.04.015

278. Melnyk-Lamont N.; Best C.; Gesto M.; Vijayan MM. The antidepressant venlafaxine disrupts brain monoamine levels and neuroendocrine responses to stress in rainbow trout. Environ Sci Technol. 2014, 48, 13434-42. DOI: 10.1021/es504331n

279. Melvin SD. Effect of antidepressants on circadian rhythms in fish : Insights and implications regarding the design of behavioural toxicity tests. Aquat 
Toxicol. 2017, 182, 20-30. DOI: 10.1016/j.aquatox.2016.11.007

280. Parrott JL.; Metcalfe CD. Assessing the effects of the antidepressant venlafaxine to fathead minnows exposed to environmentally relevant concentrations over a full life cycle. Environ Pollut. 2017, 229, 403-11. DOI: 10.1016/j.envpol.2017.06.009

281. Parrott JL.; Metcalfe CD. Nest-defense behaviors in fathead minnows after lifecycle exposure to the antidepressant venlafaxine. Environ Pollut. 2018, 234, 223-30. DOI: 10.1016/j.envpol.2017.11.049

282. Rodrigues A.; Borges FO.; Pissarra V.; Luísa Maulvault A.; Paula JR.; Bispo R.; Rosa R. First indication of deleterious impacts in white-seabream larvae (Diplodus sargus) survival and behaviour following acute venlafaxine exposure. Ecotoxicology. 2019, 28, 612-8. DOI: 10.1007/s10646-01902057-7

283. Rodrigues P.; Cunha V.; Oliva-Teles L.; Ferreira M.; Guimarães L. Norfluoxetine and venlafaxine in zebrafish larvae: Single and combined toxicity of two pharmaceutical products relevant for risk assessment. J Hazard Mater. 2020, 400, 123171. DOI: 10.1016/j.jhazmat.2020.123171

284. Tang Y.; Mi P.; Li M.; Zhang S.; Li J.; Feng X. Environmental level of the antidepressant venlafaxine induces behavioral disorders through cortisol in zebrafish larvae (Danio rerio). Neurotoxicol Teratol. 2021, 83, 106942. DOI: 10.1016/j.ntt.2020.106942

285. Ziegler M.; Banet M.; Bauer R.; Köhler HR.; Stepinski S.; Tisler S.; Huhn C.; Zwiener C.; Triebskorn R. Behavioral and Developmental Changes in Brown Trout After Exposure to the Antidepressant Venlafaxine. Front Environ Sci. 2021, 8, 586584. DOI: 10.3389/fenvs.2020.586584

286. Wu C.; Witter JD.; Spongberg AL.; Czajkowski KP. Occurrence of selected pharmaceuticals in an agricultural landscape, western Lake Erie basin. Water Res. 2009, 43, 3407-16. DOI: 10.1016/j.watres.2009.05.014

287. Vera-Chang MN.; Moon TW.; Trudeau VL. Ancestral fluoxetine exposure sensitizes zebrafish to venlafaxine-induced reductions in cortisol and spawning. Endocrinology. 2019, 160, 2137-42. DOI: 10.1210/en.2019-00281 